\title{
Cesar Isaac
}

\section{Estudo in vitro da ação de pentoxifilina em fibroblastos oriundos de cicatrizes hipertróficas pós-queimadura e de pele não-cicatricial}

\author{
Tese apresentada à Faculdade de Medicina da \\ Universidade de São Paulo para obtenção do título \\ de Doutor em Ciências
}

Área de concentração: Cirurgia Plástica Orientadora: Dra. Monica Beatriz Mathor

São Paulo

2007 
Dados Internacionais de Catalogação na Publicação (CIP)

Preparada pela Biblioteca da

Faculdade de Medicina da Universidade de São Paulo

Creprodução autorizada pelo autor

\section{Isaac, Cesar}

Estudo in vitro da ação de pentoxifilina em fibroblastos oriundos de cicatrizes hipertróficas pós-queimadura e de pele não-cicatricial / Cesar Isaac. -- São Paulo, 2007.

Tese(doutorado)--Faculdade de Medicina da Universidade de São Paulo. Departamento de Cirurgia.

Área de concentração: Cirurgia Plástica.

Orientadora: Mônica Beatriz Mathor.

Descritores: 1.Técnicas de cultura de células 2.Fibroblastos 3.Pentoxifilina 4. Pentoxifilina/uso terapêutico 5.Colágeno 6.Cicatriz hipertrófica 7.Proliferação celular

USP/FM/SBD-421/07 
DEO-IN.HONOREM

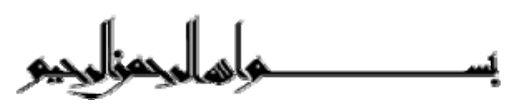

הללו אח אדוני ישו הוא האלוים 


\section{Eu agradeço...}

Ao meu pai, Youssef, que sempre me disse uma frase árabe, cuja tradução livre seria: "que Deus tenha orgulho de você!"

- Pai, eu sei que Ele tem... E o maior motivo de orgulho que eu posso dar a Deus é ser seu filho!

À minha mãe, Nadia, a quem devo a vida, que sempre me disse: "Você consegue, basta querer!"

— Mãe, uma vez mais você está certa!

À minha família: Maria José, Roberta, Filipe, vó Delia, Totó e Zozô.

— Sem vocês eu não seria ninguém!

À minha querida irmã Profa. Dra. Lourdes Isaac, presente em minha vida desde o primeiro teatrinho, o primeiro cinema, o primeiro livro, cuja participação foi fundamental na conclusão de mais esta etapa.

Aos meus irmãos Ivone e Gilberto, pelo carinho de todos os dias.

In memoriam, às minhas "mães postiças" Rosa Namour e Georgette Gaui Namour que, de onde estiverem, certamente, ainda zelam por mim. 
À Dra. Monica Beatriz Mathor, querida amiga e orientadora, com a mais profunda gratidão por ter acreditado em mim.

À Dra. Marisa Roma Herson, preciosa amiga que, dentre infinitos gestos de carinho, um dia me disse: "Seja bem-vindo!"

Ao Prof. Dr. Marcus Castro Ferreira, pela confiança em mim depositada.

Ao colega e grande amigo André Oliveira Paggiaro, que está sempre presente, atento e pronto para ajudar.

À minha querida companheira de folguedos e desventuras Dra. Viviane Fernandes de Carvalho: - Pois é, Vi... fim de mais uma etapa em nossas vidas. Oxalá continuemos sempre juntos, rumo a novos desafios.

Aos colegas Giovanni Bariani e Fabio Kamamoto, pela amizade, carinho e colaboração no desenvolvimento desta tese.

À Dra. Walcy Rosolia Teodoro, a Solange Carrasco, Ana Paula Pereira Velosa, Cristiane Carla Oliveira e Rodnei Francisco Moutinho - LIM 17 FMUSP, pela preciosa colaboração na realização deste projeto.

Ao Dr. David de Souza Gomez cuja minuciosa, atenta e carinhosa avaliação desta tese tornou-a uma "obra de arte". 
Aos "amigos do laboratório": Edna Maria Rodrigues dos Santos, Maria Aparecida de Oliveira, Roqueline Alves Lago, Ronaldo dos Santos e Victor Scripnic dos Santos, por vocês tornarem meus dias mais alegres.

Aos meus professores: Silvana Cereijido Altran - LIM 04 FMUSP; Alexandre Queiroz Silva e Gina Camilo Rocha Silvestre - LIM 02 FMUSP e Marlene Pereira Carvalho Florido - Dpto. Imunologia - ICB 4, que sempre responderam, com um sorriso no rosto, a cada vez que eu disse "Não sei, me ensina?".

Às "meninas da biblioteca": Valéria de Vilhena Lombardi, Suely Campos Cardoso e Fernanda Fernandes Vitorino, cujo carinho tornou este percurso mais ameno.

À querida amiga Gorette Aparecida Stecca Duarte, sempre carinhosa, atenta e zelosa no cuidado comigo.

Às minhas "fiéis escudeiras": Fabiana Guerreiro dos Santos e Luciana de Oliveira Borges de Moraes que, com enorme afinco, transformam o caos dos meus dias.

Aos amigos que não foram aqui nomeados, mas que, também, enriquecem minha vida, e aos inimigos que sempre serviram de estímulo para que eu me superasse. 


\section{Sumário}

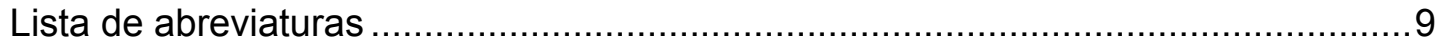

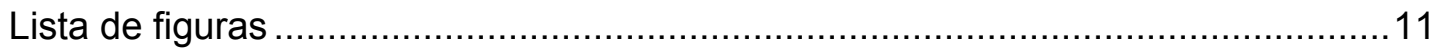

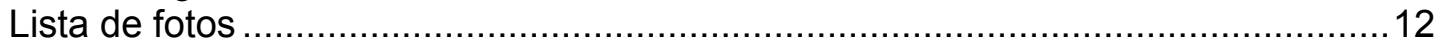

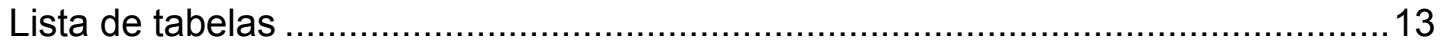

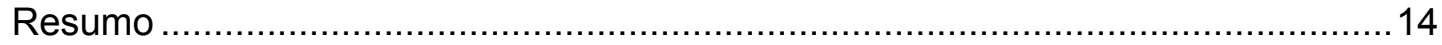

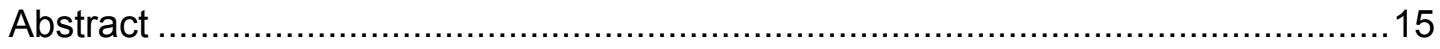

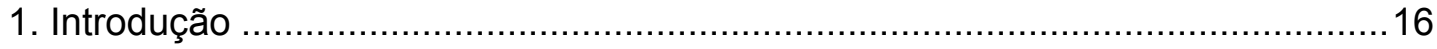

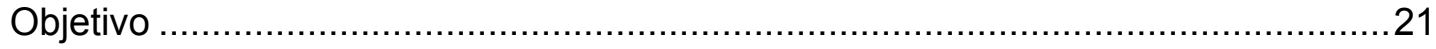

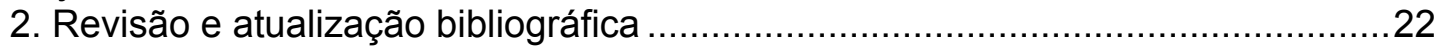

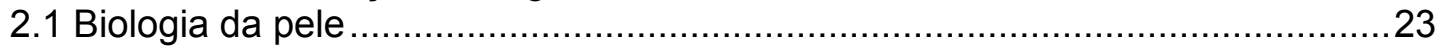

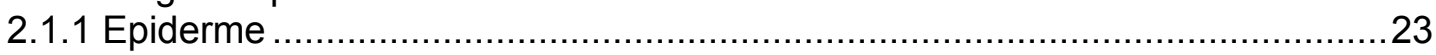

2.1.2 Derme

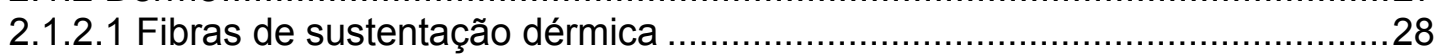

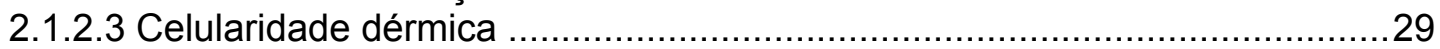

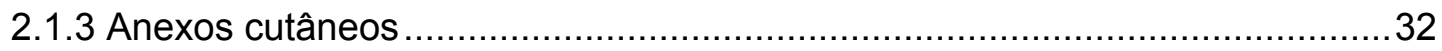

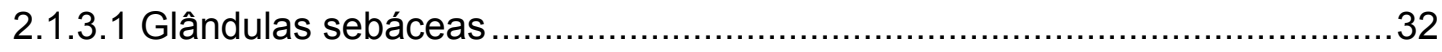

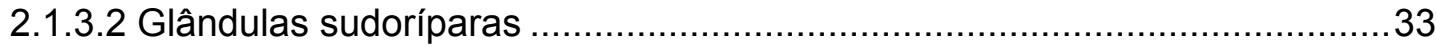

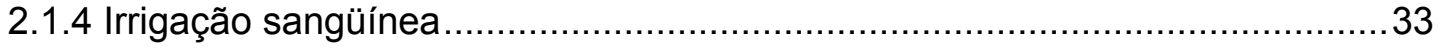

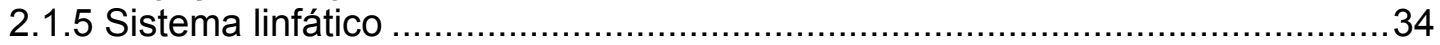

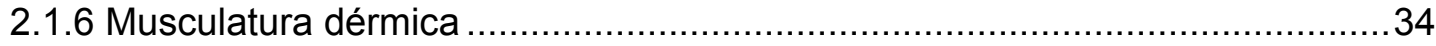

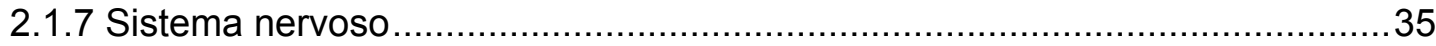

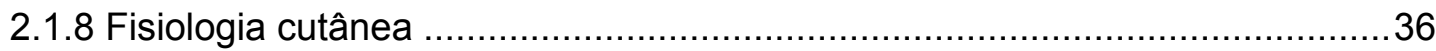

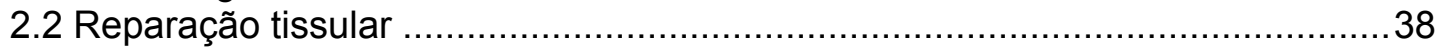

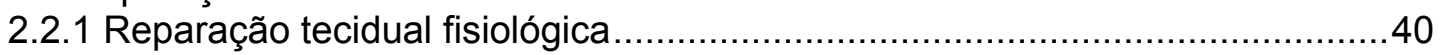

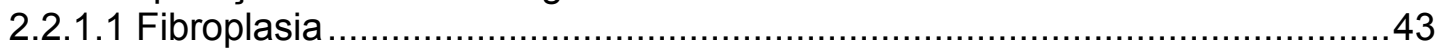

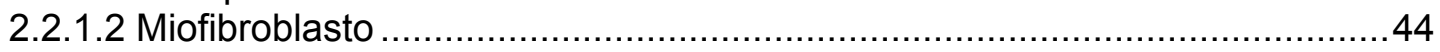

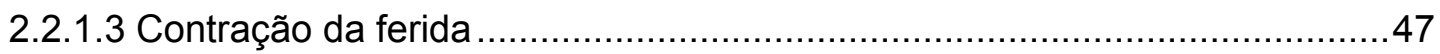

2.2.1.4 Formação de matriz e remodelagem da cicatriz .................................... 47

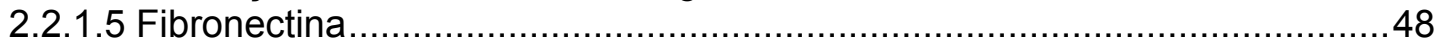

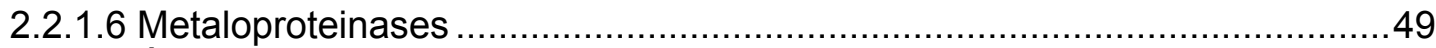

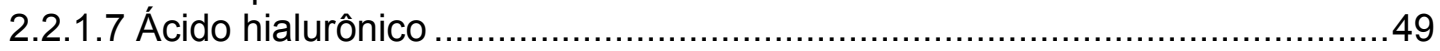

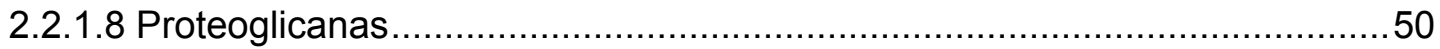

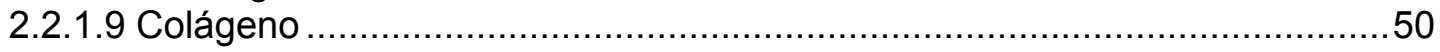

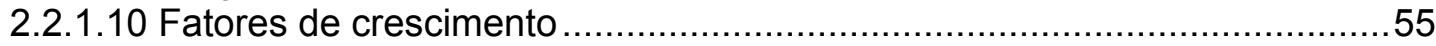

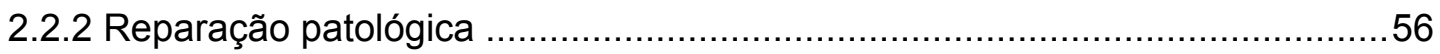

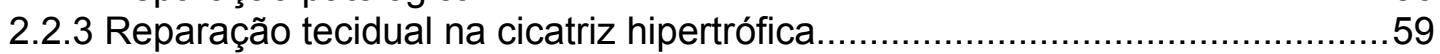

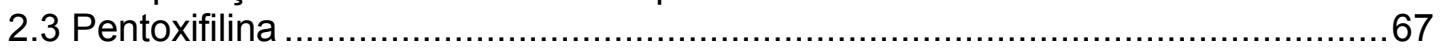

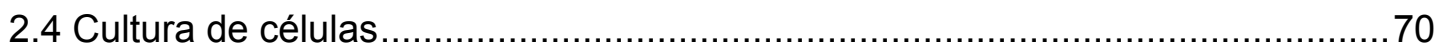

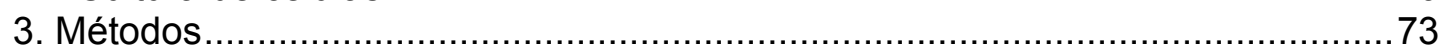

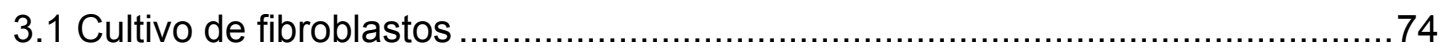

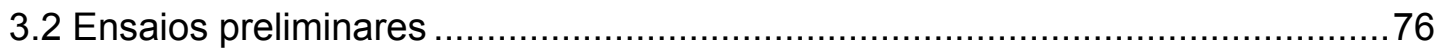

3.2.1 Determinação do número de amostras de pele …..................................... 77

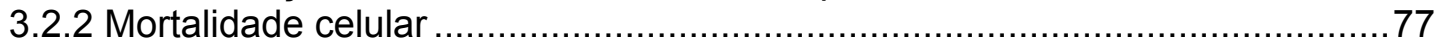

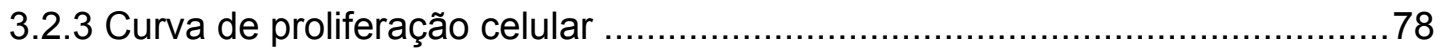

3.3 Experimentos em cultura de célula em monocamada....................................79

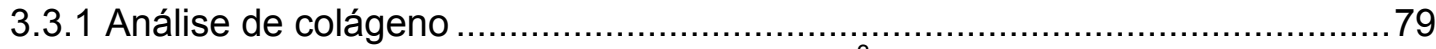

3.3.1.1 Avaliação quantitativa da incorporação de ${ }^{3} \mathrm{H}$-prolina ....................................79

3.3.1.2 Avaliação semiquantitativa de colágeno I e colágeno III extracelular ...........81

3.3.1.3 Proliferação de HSHF e NHF ............................................................... 82 
3.4 Modelo tridimensional de contração 83

3.4.1 Modelo de contração de matriz extracelular povoada por fibroblastos ...........83

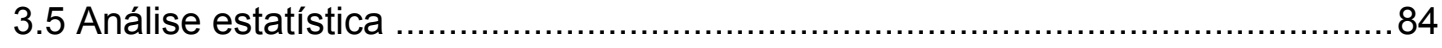

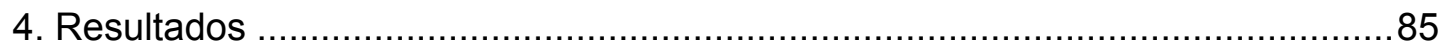

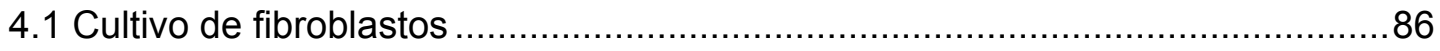

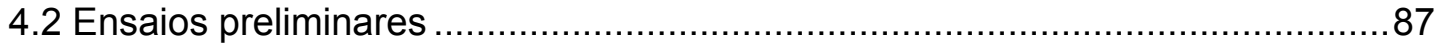

4.2.1 Determinação do número de amostras de pele ....................................... 87

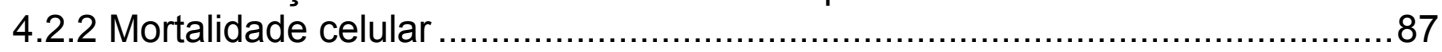

4.2.3 Curva de proliferação celular ............................................................. 88

4.3 Experimentos em cultura de célula em monocamada.....................................90

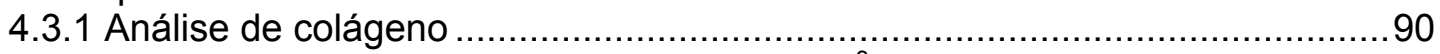

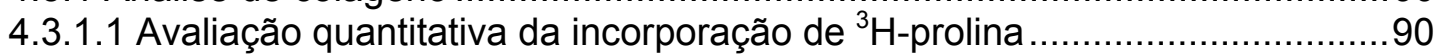

4.3.1.2 Avaliação semiquantitativa de colágeno I e colágeno III extracelular ..........92

4.3.2 Proliferação de HSHF e NHF .................................................................97

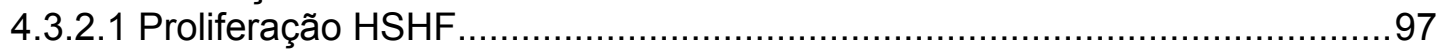

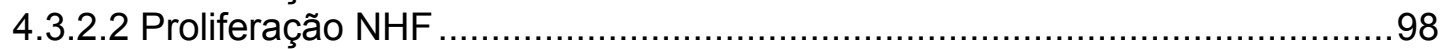

4.4 Modelo tridimensional de contração ........................................................... 100

4.4.1 Modelo de contração de matriz extracelular de colágeno povoada por

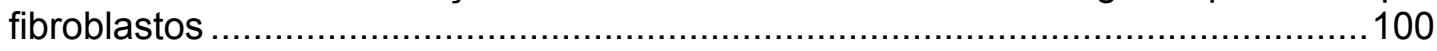

4.4.1.1 Contração de matriz povoada por HSHF ........................................... 100

4.4.1.2 Contração de matriz povoada por NHF ................................................. 102

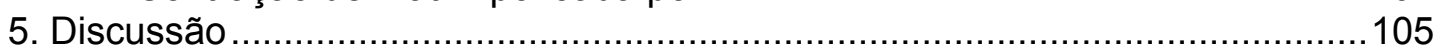

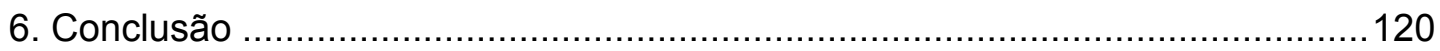

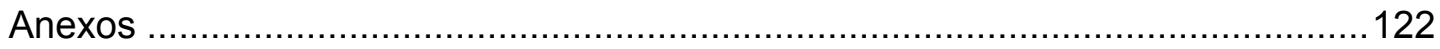

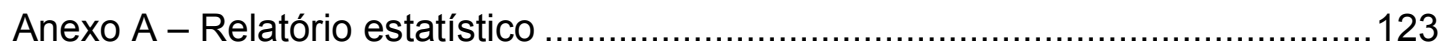

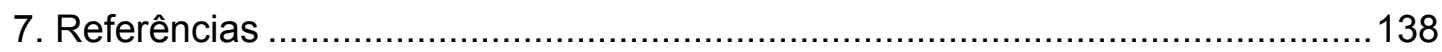

Apêndices 


\section{Lista de abreviaturas}

$\%-$ por cento

$\alpha$ actina - [alfa] actina (de musculatura lisa)

anti-lgG - anticorpo antiimunoglobulina $G$

bFGF - basic fibroblast growth factor (fator de crescimento de fibroblastos básico)

$\mathrm{Ci}-$ Curie

$\mathrm{CO}_{2}$ - dióxido de carbono

$D_{10}-$ meio de cultura para fibroblastos

DMEM - Dulbeco Modified Eagle's Medium (meio de Eagle modificado por Dulbeco)

EDTA - ácido etilenodiaminotetracético

EEG - equações de estimação generalizada

FGF - fibroblast growth factor (fator de crescimento de fibroblastos)

GAG - glicosaminoglicana(s)

$\mathrm{HCl}$ - ácido clorídrico

HOP - hidroxiprolina

HSHF - hypertrophic scar human fibroblast (fibroblasto humano de cicatriz hipertrófica)

$\mathrm{LiOH}$ - hidróxido de lítio

M - molar

ME - microscopia eletrônica

MO - microscopia óptica

$\mathrm{NaOH}$ - hidróxido de sódio

NHF - normal human fibroblast (fibroblasto humano normal)

nm - nanômetro

$p$ - probabilidade estatística de rejeitar a hipótese nula quando ela é verdadeira 
PBS - phosphate buffered solution (solução tampão fosfatada)

PDGF - platelet derived growth factor (fator de crescimento derivado de plaquetas)

PTF - pentoxifilina

$\mathrm{RE}$ - retículo endoplasmático

rpm - rotações por minuto

SBF - soro bovino fetal

TGF $\beta$ - transforming growth factor [beta] (fator transformador de crescimento [beta])

TNF $\alpha$ - tumor necrosis factor [alpha] (fator de necrose de tumor)

VEGF - vascular endothelium growth factor (fator de crescimento de endotélio vascular)

(v/v) - volume a volume

$\mu \mathrm{Ci}$ - micro Curie

$\mu g-$ micrograma

$\mu \mathrm{L}-$ microlitro 


\section{Lista de figuras}

Figura 1 - Fases da cicatrização de feridas

Figura 2 - Produção de colágeno por fibroblastos humanos na presença de pentoxifilina e outras xantinas 68

Figura 3 - Fluxograma dos experimentos realizados no estudo. .79

Figura 4 - Cultivo de fibroblastos .86

Figura 5 - Comparação da média de células mortas na presença e ausência de PTF nos momentos $12 \mathrm{~h}, 24 \mathrm{~h}, 48 \mathrm{~h}, 72 \mathrm{~h}$ e $96 \mathrm{~h}$.

Figura 6 - Curva de proliferação de NHF nos momentos 12 h, 24 h, 48 h, 72 h e $96 \mathrm{~h}$, na presença e ausência de PTF.

Figura 7 - Fluxograma dos resultados obtidos no estudo, destacando que os resultados correspondentes aos Itens 3.3 e 3.4 encontram-se nos Itens 4.3.1.1; 4.3.1.2; 4.3.2.1; 4.3.2.2; 4.4.1.1; 4.4.1.2. .90

Figura 8 - Box plots (utilizando medianas, máximos e mínimos) comparativos de incorporação de ${ }^{3} \mathrm{H}$-prolina por HSHF e NHF, na presença (verde) e ausência (azul) de PTF

Figura 9 - Escore de imunomarcação de colágeno extracelular tipo I e tipo III em HSHF, na presença e ausência de PTF (média $\pm D P$ ).

Figura.10 - Escore de imunomarcação de colágeno extracelular tipo I e tipo III em NHF, na presença e ausência de PTF (média \pm DP) .............................................94

Figura 11 - Proliferação de HSHF na presença e ausência de PTF........................98

Figura 12 - Proliferação de NHF na presença e ausência de PTF...........................99

Figura 13 - Contração de matriz de colágeno povoada por HSHF na presença e ausência de PTF.... 101

Figura 14 - Contração de matriz de colágeno povoada por NHF na presença e ausência de PTF. 103 


\section{Lista de fotos}

Foto 1 - Cultivo de tecidos por Carrel e Burrows..............................................

Foto 2 - Escore de imunofluorescência para colágeno tipo I. A. escore 1; B. escore 2; C. escore 3... .95

Foto 3 - Escore de imunofluorescência para colágeno tipo III. A. escore 1;B. escore 2; C. escore 3 


\section{Lista de tabelas}

Tabela 1 - Receptores nervosos presentes na derme e suas funções. .35

Tabela 2 - Funções dos principais componentes e sistemas da pele

Tabela 3 - Classificação das fibras colágenas

Tabela 4 - Quantidade de colágeno tipo III dividido pela quantidade de colágeno tipo I 65

Tabela 5 - Contrastes para EEG de incorporação de ${ }^{3} \mathrm{H}$-prolina. .92

Tabela 6 - Escore de fibras colágenas tipo I e III intensamente marcadas, expresso em média e desvios padrões, na presença e ausência de PTF em culturas de HSHF e NHF

Tabela 7 - Número de HSHF após 96 horas de exposição (ou não) à PTF. .97

Tabela 8 - Número de NHF após 96 horas .98

Tabela 9 - Contrastes para a EEG da interação entre uso de PTF e grupo celular (NHF e HSHF)...... .99

Tabela 10 - Contração de matriz de colágeno povoada por HSHF 101

Tabela 11 - Contração de matriz de colágeno povoada por NHF. 102

Tabela 12 - Comparações (ou contrastes) entre grupo celular (NHF e HSHF), exposição ou não à pentoxifilina e tempo de exposição. 104 


\section{Resumo}

Isaac C. Estudo in vitro da ação de pentoxifilina em fibroblastos oriundos de cicatrizes hipertróficas pós-queimadura e de pele não-cicatricial [tese]. São Paulo: Faculdade de Medicina, Universidade de São Paulo; 2007 $157 p$.

Pentoxifilina (PTF), um derivado da metilxantina, tem ação terapêutica como agente antifibrótico. In vitro, a PTF causa inibição na produção de colágeno, glicosaminoglicanos e fibronectina, bem como promove acentuada redução na proliferação dos próprios fibroblastos de quelóides. A PTF na concentração de $1.000 \mu \mathrm{g} / \mathrm{mL}$ foi seletiva no controle da inibição da síntese protéica pelos fibroblastos. $O$ objetivo deste estudo foi verificar 0 comportamento in vitro de fibroblastos oriundos de cicatrizes hipertróficas (HSHF) e de pele não-cicatricial (NHF) na presença e ausência de PTF $(1.000 \mu \mathrm{g} / \mathrm{mL})$, quanto à: proliferação celular, produção de colágeno e capacidade dos fibroblastos gerarem contração em modelo experimental de matriz de colágeno. Para tanto, foram utilizados fibroblastos cultivados a partir de amostras de cicatrizes hipertróficas e pele não-cicatricial doadas, com finalidade de pesquisa, pelo banco de Tecidos do Instituto Central do Hospital das Clínicas da FMUSP. Culturas celulares expostas a PTF apresentaram diminuição na proliferação celular em HSHF $(46,35 \%)$ e em $\operatorname{NHF}(37,73 \%)(p<0,0001)$. Na presença de PTF, foi observada seletividade de inibição na síntese de colágenos, havendo inibição mais expressiva de colágeno tipo III em HSHF e de colágeno tipo I em NHF $(p<0,0001)$. O modelo experimental de matriz de colágeno povoada por fibroblastos de cicatriz hipertrófica apresentou contração menor (12\%) na presença de PTF $(p<0,0001)$, em relação à sua ausência.

Palavras-chave: cultura celular; fibroblastos; pentoxifilina; matriz de colágeno; cicatriz hipertrófica. 


\section{Abstract}

Isaac C. In vitro effects of pentoxifylline on human fibroblasts derived from post-burn hypertrophic scars and from normal skin [thesis]. São Paulo: "Faculdade de Medicina, Universidade de São Paulo"; 2007 157p

Fibroblasts are thought to be partially responsible for the persisting contractile forces that result in burn contractures. Using a monolayer and fibroblast populated collagen lattice (FPCL) three-dimensional (3D) model we subjected hypertrophic scar and non-cicatricial fibroblasts to the antifibrogenic agent pentoxifylline (PTF) $1000 \mu \mathrm{g} / \mathrm{mL}$ attempting to reduce proliferation, collagen type I and III synthesis and contraction in this 3D model. Fibroblasts were isolated from post burn hypertrophic scars (HSHF) and non-scarred skin (NHF). Cells were grown in monolayer or incorporated into FPCL's and exposed to PTF. In monolayer, cell number proliferation was reduced $(46.35 \%$ in HSHF group and $37.73 \%$ in NHF group) $p<0,0001$. The PTF also demonstrated to be selective on collagen type I and III synthesis inhibition suggesting higher inhibition of collagen type III on HSHF group and more evident inhibition of type I on NHF group. FPCL's containing PTF had surface areas reduced in about $12 \% p<0,0001$. PTF showed inhibition effects on cell proliferation and reduced contraction in both HSHF and NHF.

Key words: cell culture; fibroblasts; fibroblast populated collagen lattice (FPCL); pentoxifylline; hypertrophic scars. 


\section{Introdução}




\section{Introdução*}

O organismo humano pode sofrer diversos tipos de traumatismos decorrentes da exposição a agentes químicos e físicos. O trauma tecidual e a inflamação aguda causam a morte celular e destroem a matriz intersticial. O processo de reparação tissular freqüentemente evolui de forma fisiológica, resultando em cicatriz plana, não endurecida, de limites precisos e não retraída. Quando a resposta cicatricial é exagerada, ocorre formação de cicatriz com característica hipertrófica ou hiperplásica (quelóide). ${ }^{1}$

Clinicamente, a cicatriz hipertrófica caracteriza-se como lesão cicatricial retraída, elevada, porém restrita aos seus limites iniciais, de coloração avermelhada, com presença de prurido e passível de regressão ao longo do tempo. ${ }^{2}$ Estudos histológicos mostram presença de pequenos vasos, fibroblastos expressando $\alpha$-actina de músculo liso (miofibroblastos) e feixes delicados de colágeno, dispostos de forma aleatória, que geralmente formam nódulos. ${ }^{3} \mathrm{O}$ colágeno tipo III, tipicamente secretado nas fases iniciais do processo de reparo, ${ }^{4}$ pode ser observado tardiamente nesses nódulos, sugerindo que as células ali presentes permanecem ativas. ${ }^{5}$

No processo de reparo tissular, a expressão de proteínas contráteis e a disposição dos miofibroblastos no tecido de granulação sugerem que estas células sejam responsáveis pela produção da força que causa a contração

\footnotetext{
* NOTA: Esta tese foi revisada de acordo com os padrões ortográficos e gramaticais estabelecidos, respectivamente, pelo Dicionário eletrônico Houaiss da língua portuguesa e pela Nova gramática do português contemporâneo, de Celso Cunha e Lindley Cintra, edição de 2001.
} 
da lesão. ${ }^{6}$ Além disso, os miofibroblastos são responsáveis pela síntese de componentes da matriz extracelular. ${ }^{7}{ }^{8}$ Acredita-se que esse processo seja regulado pela interação entre fibroblastos e os diversos componentes extracelulares.

A pentoxifilina (PTF) (1-hexil-3,7-dimetilxantina), um derivado trimetilado das xantinas, indicada na prática clínica no tratamento de pacientes com deficiência circulatória regional graças ao seu efeito hemorreológico, também interfere na síntese de colágeno e na proliferação de fibroblastos. ${ }^{9}$

O provável mecanismo de ação da PTF nos fibroblastos gera ao menos três efeitos intracelulares diferentes: (1) inibição da atuação dos prócolágenos I e III, precursores das fibrilas de colágeno, graças à diminuição da expressão do fator nuclear 1 , um regulador positivo da transcrição dos genes de pró-colágenos, que é estimulado pelo TGF- $\beta_{1}$ (transforming growth factor[beta]1); ${ }^{11}$ (2) aumento da degradação de pró-colágenos previamente à sua secreção e deposição extracelular; ${ }^{12}$ (3) inibição dos fatores de crescimento derivados de plaquetas. ${ }^{13}$

Estudos in vitro demonstraram ainda que a PTF reduz a proliferação desses fibroblastos, estimula a atividade intersticial da colagenase e suprime a produção, a secreção e a deposição de colágenos tipos I e III, proteoglicanas e fibronectina. ${ }^{14}$

Berman e Duncan descreveram os efeitos da pentoxifilina em fibroblastos dérmicos não cicatriciais e originados de quelóide e escleroderma, sugerindo que: (1) o efeito antiproliferativo da PTF sobre 
fibroblastos oriundos de derme não-cicatricial e quelóide não decorre de citotoxicidade, uma vez que culturas de fibroblastos tratadas ou não com PTF apresentaram igual viabilidade, quando testadas com o corante transmembrana Azul de Tripan; (2) PTF na dose de $1.000 \mu \mathrm{g} / \mathrm{mL}$ não interfere na produção de citocinas, interleucinas ou moléculas de adesão; (3) a presença de PTF mostrou-se efetiva na redução do número de fibras colágenas, fibronectina e glicosaminoglicanas. ${ }^{15}$

Dans e Isseroff, ${ }^{16}$ em 1994, realizaram estudo da contração de matriz extracelular povoada por fibroblastos dérmicos provenientes de prepúcio de recém-nascidos na presença de PTF, concluindo que: (1) a contração da matriz extracelular depende da concentração de células existentes; (2) a inibição da contração de matriz pela presença de PTF é dose dependente, afirmando que na concentração de $1.000 \mu \mathrm{g} / \mathrm{mL}$ a contração da matriz é quase completamente bloqueada.

Rawlins et al., ${ }^{17}$ em 2006, demonstraram os efeitos inibitórios de PTF sobre a proliferação celular e a contração de modelo experimental de matriz extracelular povoada por fibroblastos oriundos de seqüelas cicatriciais pósqueimadura. Esse estudo, único até o presente momento, descreveu somente a diminuição no número de fibroblastos e a contração do gel de colágeno quando expostos a PTF. Os autores não avaliaram as modificações na expressão de colágenos produzidos nessa condição.

Com o intuito de melhor compreender os fenômenos desencadeados pela presença de pentoxifilina em cicatrizes hipertróficas e vislumbrando a possibilidade de aplicação clínica desse fármaco no tratamento das seqüelas 
de queimadura, realizamos o presente estudo, ratificando achados descritos na literatura e contribuindo com a descoberta dos efeitos de PTF sobre colágenos envolvidos nas reparações tissulares. Estudos subseqüentes, detalhando o mecanismo de ação da PTF, ainda serão necessários antes da utilização clínica desse fármaco. 


\section{Objetivos}

O objetivo deste estudo foi verificar os efeitos da PTF em fibroblastos cultivados a partir de amostra de cicatrizes hipertróficas pós-queimadura e pele não-cicatricial, quanto à:

produção de colágeno;

proliferação celular; e

capacidade de fibroblastos gerarem contração em modelo experimental de matriz de colágeno. 
Revisão e atualização bibliográfica 


\section{Revisão e atualização bibliográfica}

Cicatrizes são respostas às soluções de continuidade cutânea que ultrapassem a camada basal da epiderme.

Para melhor compreensão do processo de reparo de feridas e suas possíveis alterações, faremos um breve resumo da biologia da pele humana.

\subsection{Biologia da pele}

A pele ${ }^{18}$ é o maior órgão do corpo humano. Quando íntegra, suas principais funções são evitar agressões do meio externo e impedir a perda de líquidos internos.

Esse órgão é composto por duas camadas originadas em folhetos embriológicos distintos: epiderme e derme.

\subsubsection{Epiderme}

Derivada do ectoderma, a epiderme é a camada mais superficial da pele. Por estar em contato direto com o meio externo, essa camada torna-se responsável pela barreira contra agentes externos e pela preservação de líquidos internos.

A população celular da epiderme é composta principalmente por queratinócitos e melanócitos, estando também presentes células aurófilas apresentadoras de antígenos (células de Langerhans) ${ }^{19}$ e células 
neuroendócrinas responsáveis pela síntese de catecolaminas (células de Merkel). ${ }^{20}$

A epiderme não possui vasos sangüíneos, mas apresenta espaços intercelulares, preenchidos por substância intersticial, que permitem trocas entre as células.

Seu epitélio é estratificado, pavimentoso e queratinizado. A estratificação é mantida graças à presença de tonofilamentos e desmossomas que unem os citoplasmas dessas células.

A espessura da epiderme varia de acordo com o número de camadas de células e o local revestido por ela, sendo mais espessa nas regiões palmares e plantares $(1,0$ a $1,5 \mathrm{~mm})$ e mais fina nas pálpebras $(0,4$ a 0,8 $\mathrm{mm}){ }^{21}$

A epiderme apresenta cinco camadas distintas: camada basal (cilíndrica) ou de Malpighi; camada espinhosa; camada granulosa, contendo fibrilas de querato-hialina; camada lúcida, encontrada exclusivamente nas regiões plantares e palmares e camada córnea.

A camada basal ou camada germinativa repousa sobre a membrana basal, estrutura que separa epiderme e derme.

Queratinócitos presentes na camada basal sofrem mitose. Das duas células resultantes dessa multiplicação, uma permanece ligada à membrana basal, enquanto a outra forma a camada imediatamente superior. Graças a esse fenômeno, queratinócitos maduros tendem à superfície da epiderme, enquanto uma nova camada se forma na membrana basal. Durante esse 
processo, queratinócitos adultos sofrem transformações estruturais, o que permite distinguir, à microscopia, a estratificação da epiderme.

O intervalo entre mitoses nos queratinócitos basais é de seis dias e o ciclo biológico completo destas células (do nascimento à descamação) é de aproximadamente vinte e oito dias. Nem todos os queratinócitos presentes na camada basal proliferam ao mesmo tempo.

Melanócitos também estão presentes na camada basal da epiderme. Essas células, responsáveis pela produção de melanina, mantêm íntima relação com queratinócitos de vizinhança, transferindo para estes a melanina produzida, que confere à pele proteção contra os efeitos nocivos da radiação ultravioleta. ${ }^{22}$

No estrato espinhoso, queratinócitos apresentam formato poligonal ou ligeiramente achatado. Nessa camada, tem início a produção de pequenos prolongamentos de citoqueratina chamados tonofibrilas, que reforçam a adesão intercelular, aumentando a resistência da pele ao atrito. Além das tonofibrilas, os desmossomos, estruturas discóides dispostas na face citoplasmática de uma membrana celular e que exercem atração eletrostática entre si, reforçam essa adesão. Quanto mais intensa for a fricção e/ou a pressão exercida sobre o epitélio, tanto maior será a espessura da camada espinhosa.

$\mathrm{Na}$ camada granulosa, queratinócitos apresentam forma poligonal. No citoplasma dessas células estão presentes grânulos grosseiros de queratohialina, proteína constitucional do material interfilamentoso presente na camada córnea. Além destes, são produzidos outros grânulos envoltos por 
membranas de fosfolipídios associados a glicosaminoglicanas que, ao serem eliminados, aglutinam-se formando uma camada impermeável de substância intercelular, vedando inclusive a passagem de água.

A camada lúcida é constituída por uma fileira de células achatadas, cujos núcleos e organelas desapareceram. Ainda existem alguns desmossomos entre essas células. Essa camada é mais evidente nas regiões plantares e palmares.

A camada córnea apresenta espessura muito variável. Formada por células achatadas, sem núcleo, cujo citoplasma está abarrotado de queratina, uma escleroproteína rica em pontes dissulfeto (S-S).

A junção entre epiderme e derme é caracterizada pela presença de papilas dérmicas (vilosidades imbricadas de modo a conferir forte adesão entre essas duas camadas), cuja principal função é aumentar a superfície de contato entre epiderme e derme, favorecendo assim trocas de líquidos e substâncias da rede vascular, de localização dérmica, para a epiderme e vice-versa. 


\subsubsection{Derme}

É o tecido conjuntivo sobre o qual se apóia a epiderme, conferindo resistência mecânica à pele. A derme apresenta espessura variável de acordo com a região analisada, atingindo até três milímetros na região plantar.

Graças a diferenças na disposição de colágeno e elastina, podem-se visualizar, na derme, duas camadas distintas: camada papilar (superficial) e camada reticular (profunda). Na camada papilar, estão presentes fibrilas de colágeno que se prendem firmemente à membrana basal, com a função de reforçar a adesão da derme e epiderme. A camada reticular é mais espessa, apresenta mais fibras colágenas e menor número de células.

Ambas as camadas possuem igual quantidade de fibras elásticas e fibras de reticulina (elementos pré-colágeno), que são parcialmente responsáveis pela elasticidade da pele. A rede de fibras elásticas acompanha a estrutura do colágeno. Quando a pele é submetida à distensão, as fibras elásticas parecem estar aderidas ao colágeno.

A matriz extracelular (também conhecida como substância intersticial, substância intercelular, substância fundamental amorfa ou substância homogênea da derme) é composta por: mucopolissacáridos ácidos, glicosaminoglicanas (GAG) e proteínas, que podem se associar formando proteoglicanas. Essas proteínas podem tanto ser estruturais (colágeno e elastina), quanto adesivas 
(integrinas, lamininas e fibronectinas). Proteínas adesivas exercem importante função nos fenômenos de migração e interação celular.

\subsubsection{Fibras de sustentação dérmica}

\section{Fibras colágenas}

As fibras colágenas são compostas de glicina, prolina e hidroxiprolina. A microscopia eletrônica mostra que essas fibras estão dispostas em bandas ou estrias transversais, a intervalos de aproximadamente 700 angstrons em arranjo de tríplice fita helicoidal.

O colágeno tipo I, cuja principal característica é formar fibrilas, pode associar-se a outros colágenos como: tipo $V$, na formação de pele, ossos, tendões, ligamentos etc.; colágeno tipo II, formando cartilagem hialina e cartilagem elástica e colágeno tipo III (que forma as fibras reticulares). Os colágenos associados a fibrilas são os tipos IX e XII, que promovem ligações entre fibrilas e entre outros componentes da matriz. Existem ainda os colágenos formadores de rede, como o tipo IV, que forma a lâmina basal, ou colágeno tipo VII.

A síntese de colágeno começa nos ribossomos aderidos à membrana citoplasmática que, a partir daí, crescem entrando no retículo endoplasmático (RE). Formam-se três cadeias polipeptídicas pró-alfa, contendo aminoácidos terminais (pró-peptídeos). No RE, prolina e lisina sofrem hidroxilação, algumas lisinas são glicosiladas. Com isso, há formação do pró-colágeno, auxiliado pelos peptídeos de 
registro, ao deixar a célula, o pró-colageno transforma-se em colágeno.

\section{Fibras reticulares}

Formadas por colágeno tipo III e açúcares (6-12\%), as fibras reticulares são mais finas que as fibras colágenas (tipo I) e se localizam em órgãos relacionados ao sangue.

\section{Sistema elástico: fibras elásticas}

Formadas por glicoproteínas (microfibrilas) e elastina (mais resistente que o colágeno), essas fibras organizam-se em trama irregular. Estão presentes na parede de vasos e formam as membranas elásticas fenestradas.

\subsubsection{Celularidade dérmica}

As principais células dérmicas são fibroblastos e fibrócitos, porém basófilos, histiócitos e plasmócitos também estão ali presentes. As células do tecido conjuntivo localizam-se em meio à matriz extracelular, mantendo estreito contato com as estruturas fibrilares. 


\section{Fibroblastos}

Originam-se de células mesenquimatosas indiferenciadas. À microscopia óptica (MO), os fibroblastos apresentam prolongamentos citoplasmáticos, núcleo eucromático e nucléolo evidente. À microscopia eletrônica (ME), nota-se grande quantidade de retículo endoplasmático rugoso (RER) e a presença do complexo de Golgi, devido à grande produção protéica destinada à formação de matriz extracelular. O fibroblasto inativo recebe a denominação de fibrócito, cuja morfologia difere do fibroblasto, por ser menor, apresentar citoplasma mais acidófilo, possuir menor número de prolongamentos citoplasmáticos, menos RER e menos complexos de Golgi.

Fibroblastos que participam ativamente no processo de fechamento de feridas, possuindo altos teores de actina e miosina e expressando $\alpha$-actina de musculatura lisa, são chamados de miofibroblastos.

\section{Macrófagos}

Os macrófagos originam-se de monócitos (células sangüíneas provenientes de tecido hematopoiético) e apresentam morfologia variável. Seu núcleo é geralmente reniforme. Seu citoplasma apresenta vários prolongamentos, lisossomos e citoesqueleto exuberante. São células de defesa que fagocitam corpos estranhos e 
restos celulares. Células apresentadoras de antígenos são tipos especiais de macrófagos que possuem maior número de prolongamentos para melhor desempenho de funções. Por estímulo específico, macrófagos tornam-se ativados, adquirindo maior capacidade de fagocitose (metabolismo aumentado para maior produção de substâncias de defesa)

\section{Mastócitos}

Mastócitos originam-se na medula óssea. São células grandes, com inúmeros grânulos basófilos apicais, que produzem e armazenam mediadores químicos pró-inflamatórios. Também são responsáveis pelo reconhecimento das imunoglobulinas $E(\lg E)$, produzidas por plasmócitos.

\section{Plasmócitos}

Plasmócitos são células ovóides, compostas de cromatina compacta, que confere aspecto de "roda de carroça" à ME, e citoplasma basófilo (rico em RER). O complexo de Golgi encontra-se ao lado do núcleo. Essas células sintetizam e secretam imunoglobulinas (anticorpos) de alta especificidade. 


\subsubsection{Anexos cutâneos}

\subsubsection{Glândulas sebáceas}

Glândulas sebáceas apresentam densidade estimada superior a 900 glândulas por $\mathrm{cm}^{2}$ de pele. As regiões mais ricas em glândulas sebáceas são: fronte, mento, dorso e tórax anterior. Essas glândulas não estão presentes nas regiões palmares e plantares.

Geralmente, mantêm relação anatômica com folículos pilosos pelo ducto sebáceo. As glândulas sebáceas que desembocam livremente na superfície da pele, ou seja, sem manter relação com folículos, são encontradas em mamilos, região anal, glande peniana (glândulas de Tyson), pequenos lábios e pálpebras (glândulas de Mibom), assim como na porção vermelha dos lábios e na mucosa geniana.

A secreção sebácea é uma mistura complexa de lipídeos que contém triglicérides, ácidos graxos livres, colesterol e seus ésteres. A produção diária de gordura é de, aproximadamente, dois gramas (incluindo suor e restos celulares queratinizados). Classicamente, considera-se o suor como principal emoliente responsável pela distribuição de gordura. 


\subsubsection{Glândulas sudoríparas}

As glândulas sudoríparas, cujo número estimado é da ordem de três milhões em toda superfície corporal, são estruturas em forma de "novelo de lã" com ducto de saída para a superfície cutânea, localizadas entre 1 e 2 milímetros abaixo da epiderme. Aparecem em maior densidade nas palmas das mãos e plantas dos pés, estando ausentes na porção vermelha dos lábios, na glande, clitóris e pequenos lábios.

Essas estruturas são ricas em glicogênio. Suas células apresentam forma cúbica ou cilíndrica, com núcleos ovais. O epitélio glandular é cercado por membrana basal sobre a qual se dispõe um epitélio composto por células mioepiteliais, responsáveis pela eliminação do suor (constituído por água, sódio, potássio, cloretos, uréia, cálcio, lipídeos e ferro).

\subsubsection{Irrigação sangüínea}

A epiderme é desprovida de vasos. Já a arquitetura dos vasos sangüíneos da derme é bastante complexa. Originadas das grandes artérias, surgem artérias perfurantes entre as aponeuroses que se ramificam de forma horizontal na derme superficial.

O retorno venoso dá-se, a partir dos capilares, por três redes venosas consecutivas: plexo venoso superficial ou plexo venoso subpapilar, rede venosa da derme e, finalmente, pela rede venosa 
que se localiza na camada limítrofe entre a derme e o tecido celular subcutâneo.

Existem anastomoses arteriovenosas no sistema vascular da pele, sobretudo nas extremidades dos membros. Essas anastomoses ou shunts permitem as variações rápidas de irrigação e drenagem do fluxo sangüíneo cutâneo.

\subsubsection{Sistema linfático}

Os vasos linfáticos da pele são revestidos por uma única camada de células endoteliais. Esse sistema encontra-se na porção superior da derme. Os vasos linfáticos começam em "fundo de saco", formando depois a rede linfática subpapilar que se dirige ao tecido subcutâneo.

Os vasos linfáticos da pele somente se tornam visíveis em casos patológicos (infecções cutâneas, disseminação linfática de neoplasias ou doenças do colágeno).

\subsubsection{Musculatura dérmica}

A musculatura lisa da pele (túnica de dartos do escroto, músculo da aréola mamilar e do aparelho pilo-sebáceo) não apresenta estrias transversais. Seu núcleo celular localiza-se no centro das fibras musculares. 


\subsubsection{Sistema nervoso}

$\mathrm{Na}$ derme existem terminações nervosas provenientes das fibras sensitivas do sistema nervoso cérebro-espinhal e do sistema nervoso autônomo. Essas terminações nervosas podem ser livres ou conjugadas a receptores em forma de corpúsculos. Na Tabela 1, a seguir, estão relacionados receptores e suas funções.

Tabela 1 - Receptores nervosos presentes na derme e suas funções \begin{tabular}{l|l} 
Receptor & Função
\end{tabular}

Corpúsculo de Vater-Pacini Sensíveis à pressão

Corpúsculo de Meissner Detecção de pressões de freqüência diferente

Corpúsculo de Krause Sensíveis ao frio (pele glabra)

Órgão de Ruffini Sensíveis ao calor

Célula de Merckel Sensíveis a tacto e pressão

Folículo piloso Terminações nervosas associadas

Terminação nervosa livre Dendritos livres sensíveis à dor e temperatura 


\subsubsection{Fisiologia cutânea}

A pele é um órgão de revestimento complexo e heterogêneo sob o ponto de vista histológico (tecido epitelial, conjuntivo, muscular, vascular e nervoso). Sua função primordial é formar a barreira de proteção (impedindo a perda de líquidos, exercendo ação antimicrobiana, química, física, elétrica, térmica etc.) às agressões externas.

Apesar de sua localização periférica, a pele está intimamente relacionada aos diferentes órgãos e sistemas do corpo, graças à rica circulação sangüínea e linfática e à presença de terminações nervosas sensitivas e reguladoras.

A função de revestimento, diretamente relacionada às propriedades mecânicas da pele (elasticidade e plasticidade), envolve vários tipos de tecidos e líquidos, pois mantém a forma do corpo, permitindo movimentos sem que ocorra ruptura dos tecidos.

A camada córnea desempenha papel fundamental na proteção cutânea, pois é mais resistente que a derme. Acredita-se que a flexibilidade da camada córnea dependa, principalmente, do correto equilíbrio de lipídeos, de substâncias hidrossolúveis, da água e da presença de queratinas.

Além das funções de revestimento e proteção, a pele apresenta outras funções como: regulação térmica, metabolismo de vitamina $D$, 
sensibilidade e absorção tópica. Na Tabela 2 estão resumidas as estruturas cutâneas e suas principais funções. ${ }^{23}$

Tabela 2 - Funções dos principais componentes e sistemas da pele Componente Funções

\begin{tabular}{|c|c|}
\hline Queratinócitos & $\begin{array}{l}\text { Barreira mecânica, produção de } \\
\text { citocinas e sinalização celular }\end{array}$ \\
\hline Melanócitos & $\begin{array}{l}\text { Síntese de pigmentos, proteção contra } \\
\text { ações nocivas dos raios ultravioletas }\end{array}$ \\
\hline Células de Langerhans & Apresentação de antígenos \\
\hline Células de Merkel & Síntese de catecolaminas \\
\hline Fibroblastos & $\begin{array}{l}\text { Síntese e degradação de matriz } \\
\text { extracelular, produção e organização de } \\
\text { colágenos, produção de citocinas e } \\
\text { sinalizadores celulares }\end{array}$ \\
\hline Colágenos / Elastina & Sustentação dermo-epidérmica \\
\hline $\begin{array}{l}\text { Inibidores tissulares de } \\
\text { metaloproteinases de matriz }\end{array}$ & $\begin{array}{l}\text { Proteção do sistema colágeno/elastina } \\
\text { contra digestão endógena }\end{array}$ \\
\hline Plexo vascular dérmico & Regulação térmica, nutrição celular \\
\hline Tecido celular subcutâneo & $\begin{array}{l}\text { Regulação térmica e armazenamento de } \\
\text { energia }\end{array}$ \\
\hline Sistema endócrino - vitamina D & $\begin{array}{l}\text { Proteção ultravioleta e homeostase de } \\
\text { cálcio }\end{array}$ \\
\hline $\begin{array}{l}\text { Sistema endócrino - estrógeno } \\
\text { cutâneo }\end{array}$ & $\begin{array}{l}\text { Melhora a performance dos colágenos, a } \\
\text { vascularização e aumenta a espessura } \\
\text { da derme }\end{array}$ \\
\hline Glândula sudorípara & $\begin{array}{l}\text { Regulação térmica, equilíbrio } \\
\text { hidroeletrolítico e hidratação epidérmica }\end{array}$ \\
\hline Glândula sebácea & $\begin{array}{l}\text { Excreção de metábolitos / óleo e } \\
\text { hidratação epidérmica }\end{array}$ \\
\hline
\end{tabular}




\subsection{Reparação tissular}

O corpo humano pode sofrer diversos tipos de traumatismos decorrentes da exposição a agentes químicos, físicos ou biológicos. O processo de reparação tissular, freqüentemente estudado na pele, ${ }^{24} 25262728$ busca substituir, por um novo tecido, as células mortas e a matriz extracelular destruídas durante o trauma.

O resultado dessa reparação depende da profundidade do trauma. Em queimaduras, a pele é restaurada (pós-queimadura de $2^{\circ}$ grau e/ou pós-doação de enxertos de espessura parcial), chegando a constituir cerca de $80 \%$ do tegumento resultante do processo de cura. A despeito de sua freqüência, a pele restaurada não é identificada como tegumento individualizado por autores que lidam com queimaduras, sendo freqüentemente descrita de maneira incorreta. ${ }^{29}$

O termo "cicatriz" foi usado, em nosso meio, por Russo, ${ }^{30} \mathrm{em}$ 1959, em referência à cura das queimaduras de $1^{\circ}$ e $2^{\circ}$ graus. Além da denominação "cicatriz", encontra-se, na literatura, os termos "pele regenerada" para descrever a pele restaurada, evidenciando dessa forma grande desconhecimento sobre esse tegumento, que tem propiciado rotulações absolutamente antagônicas.

A sistematização de terminologia e a conceituação de pele restaurada vêm sendo difundidas pela disciplina de Cirurgia Plástica da Faculdade de Medicina da Universidade de São Paulo 
desde 1972, culminando na publicação de um estudo que diferencia os vários tipos de tegumento resultantes da cura de queimaduras. ${ }^{31}$

Após lesão cutânea com perda de substância, podem ocorrer três tipos distintos de reparação tecidual apresentando aspectos histológicos, estéticos e funcionais diferentes, a saber: (1) a regeneração da epiderme após queimadura de $1^{\circ}$ grau resulta em estrutura histológica idêntica à pele sã, que apropriadamente podemos denominar "pele regenerada"; (2) a restauração pósqueimadura de $2^{\circ}$ grau origina um tegumento peculiar, formado por tecido conjuntivo jovem, diferente do tecido de granulação, sem formação de cicatriz, preservando as estruturas dermo-epidérmicas e mantendo as funções de pele em graus variados, a essa estrutura dá-se o nome de "pele restaurada" que é semelhante à pele sã, e como tal, não deve ser rotulada de cicatriz; e (3) a cicatrização espontânea de lesão após queimadura de $3^{\circ}$ grau que resulta em cicatriz, nada semelhante à pele sã.

A cicatrização espontânea freqüentemente evolui sem intercorrência, resultando em cicatriz plana, não endurecida, de limites precisos e não retraída. A este processo dá-se o nome de reparação tecidual fisiológica. 


\subsubsection{Reparação tecidual fisiológica}

Didaticamente, o processo de reparação pode ser dividido em três fases que se sobrepõem: inflamação, formação do tecido de granulação e remodelagem da cicatriz (Figura 1).

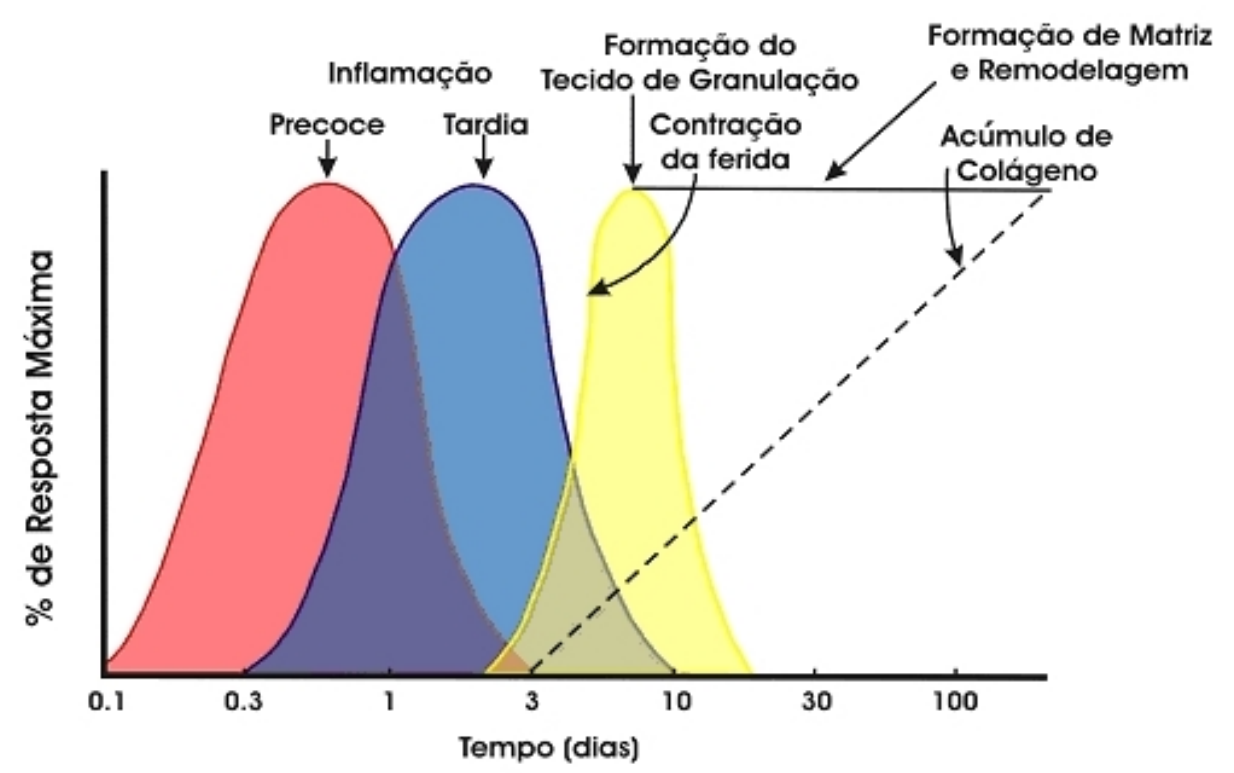

Figura 1 - Fases da cicatrização de feridas

A cicatrização de feridas é arbitrariamente dividida em três fases: inflamação (inicial e tardia), granulação tissular e remodelagem cicatricial. Esses acontecimentos são simultâneos e demonstrados ao longo das abscissas como uma função logarítmica de tempo.

Na fase inflamatória, a ruptura do vaso provoca extravasamento do sangue, agregação plaquetária (coagulação sangüínea) e formação de bradicininas e anafilatoxinas complementodependentes. A agregação plaquetária oclui a lesão vascular, além de ativar a migração e o crescimento celular na área lesada. Uma série de atividades intrínsecas ao endotélio vascular limita a agregação plaquetária e a coagulação sangüínea na área ferida. 
Os primeiros leucócitos a infiltrarem a área de inflamação da ferida são os neutrófilos, porém os monócitos migram simultaneamente. Ambas as células são atraídas para a área lesada por fatores quimiotácticos. A principal função dos neutrófilos na fase inflamatória inicial é livrar a área ferida da contaminação de bactérias. Verifica-se que o afluxo de monócitos e sua conversão em macrófagos parece ser crítica para o início da reparação tecidual. À medida que o infiltrado de neutrófilos se resolve e o acúmulo de macrófagos continua, pode-se dividir arbitrariamente essa fase em reação inflamatória precoce e tardia.

Macrófagos, a exemplo dos neutrófilos, não só fagocitam e digerem organismos patogênicos, como também promovem limpeza de material desvitalizado. Macrófagos liberam substâncias biologicamente ativas que facilitam a atração de células inflamatórias adicionais, que participam da descontaminação e do desbridamento de tecidos.

Fatores de crescimento e outras substâncias são necessários para o início da próxima fase da cicatrização, ou seja, a granulação dos tecidos, que consiste de uma densa população de macrófagos, fibroblastos e neovascularização envolvida por matriz de colágeno, fibronectina e ácido hialurônico. Assim, os macrófagos representam um papel essencial na transição da fase inflamatória para a fase de granulação de tecidos. 
À medida que fibroblastos proliferam na ferida, sofrem modificação do fenótipo, ganhando motilidade, o que facilita a reconstrução da matriz extracelular perdida. Além disso, essas células alinham-se com sua matriz recém-construída ao longo do eixo radial da ferida formando ligações "célula-célula" e "célula-matriz" (fibronexus); esta construção de arcabouço gera tensão na superfície e contração da ferida. O crescimento vascular (angiogênese) na ferida ocorre simultaneamente à fibroplasia.

Estudos científicos mostram que fibroblastos, macrófagos e vasos sangüíneos movem-se em bloco em direção à área lesada. ${ }^{32} \mathrm{~A}$ rede de fibrina é estimulada por fatores quimiotáticos e de crescimento, liberados por macrófagos.

Fibroblastos respondem a esses estímulos com proliferação, migração e deposição sobre a matriz. Esta matriz de tecido conjuntivo promove a formação de substrato, para o qual macrófagos, neovascularização e os próprios fibroblastos possam migrar. Sem a neovascularização, o crescimento de macrófagos e fibroblastos diminui, pois haverá falta de oxigenação e nutrientes nessa área.

A reepitelização da ferida inicia-se algumas horas após a agressão pelo movimento das células epiteliais da borda livre em direção à área lesada. ${ }^{33}$ Alterações específicas no fenótipo das células epidérmicas acontecem concomitantemente à migração. Essa metamorfose celular inclui retração dos tonofilamentos intracelulares, 
dissolução da maioria dos desmossomas e formação de filamentos actinícos no citoplasma periférico. ${ }^{34}$

Durante a reepitelização da ferida, se a camada basal for destruída, a membrana basal se formará somente após a parada da migração de células epidérmicas. Portanto, as células epidérmicas irão atravessar uma rede de fibronectina, fibrina e colágeno tipo $V,{ }^{35}$ que são provenientes principalmente do plasma sangüíneo circulante. Se existirem objetos estranhos ou tecidos desvitalizados na região, a reepitelização não se processará sobre essas estruturas. ${ }^{36}$ Uma vez terminado esse processo, as células retornam ao seu fenótipo normal e ligam-se firmemente à membrana basal na junção dermoepidérmica. ${ }^{34}$

\subsubsection{Fibroplasia}

Conforme os fibroblastos proliferam e migram em direção à ferida, sofrem alterações de fenótipo tais como: retração do retículo endoplasmático, deslocamento perinuclear dos complexos de Golgi e formação de grandes feixes de actina, localizados na periferia citoplasmática, orientados paralelamente ao maior eixo dessas células. ${ }^{37}$ Após estas modificações fenotípicas, o fibroblasto passa a ser chamado de miofibroblasto, ganhando motilidade e contratilidade, sem perder a habilidade de sintetizar e secretar macromoléculas. ${ }^{38}$ 


\subsubsection{Miofibroblasto}

Apesar de ter sido observado pela primeira vez no tecido de granulação, ${ }^{39}$ onde é o principal constituinte celular, o miofibroblasto pode ser observado em outras situações, tanto normais como patológicas. No tecido normal, os miofibroblastos estão presentes, por exemplo: na mucosa do palato $^{40}$ e no septo alveolar. ${ }^{41} \mathrm{Em}$ condições patológicas, o miofibroblasto pode ser observado na reação estromal aos tumores, ${ }^{42}{ }^{43}$ em fibromatoses superficiais (Doença de Dupuytren), ${ }^{44}$ na cicatriz hipertrófica, ${ }^{45}$ entre outras. ${ }^{38}$

A definição do termo miofibroblasto baseia-se em sua ultraestrutura. Essa é uma célula bem diferenciada com organelas especializadas, apresentando características comuns às células musculares lisas e aos fibroblastos. Ou seja, feixes de microfilamentos com corpos densos paralelos ao eixo maior da célula, retículo endoplasmático granular e aparelho de Golgi bem desenvolvidos. $^{46}$

Embora, como descrito acima, a definição do miofibroblasto se baseie em características ultra-estruturais, a caracterização imunoistoquímica dos constituintes do citoesqueleto é importante na identificação dos diferentes fenótipos dos miofibroblastos.

O principal componente do citoesqueleto é a actina, proteína presente nos microfilamentos. Existem seis isoformas diferentes de actinas: duas citoplasmáticas $(\beta$ e $\gamma$ ), presentes em todos os tipos 
celulares, e quatro musculares: duas presentes em músculos estriados ( $\alpha$-esquelética e $\alpha$-cardíaca) e duas presentes em músculos lisos $(\alpha$ e $\gamma){ }^{47}$

A origem celular dos miofibroblastos ainda é um fato controverso. Teoricamente, os miofibroblastos podem ser originários de três tipos celulares: fibroblastos, pericitos e células musculares lisas. Estudos realizados in vitro e in vivo, considerando a expressão de proteínas do citoesqueleto, reforçam a hipótese de que todos esses tipos celulares podem dar origem a miofibroblastos, ${ }^{48}$ o que suporta a hipótese de que fibroblastos, células musculares lisas, pericitos e miofibroblastos têm um ancestral comum. ${ }^{49}$ Os miofibroblastos do tecido de granulação são derivados das células do tecido conjuntivo local. Entre as células do tecido conjuntivo que podem se transformar em miofibroblastos estão todas as células mesenquimais presentes na derme e no tecido subcutâneo. Na maior parte dos casos, miofibroblastos se originam de fibroblastos locais. ${ }^{49}$

\section{Miofibroblasto no reparo tissular}

Durante o reparo tissular, os fibroblastos participam da formação do tecido de granulação e se diferenciam em miofibroblastos. ${ }^{39}$ Nos estágios iniciais da formação do tecido de granulação, os miofibroblastos são pouco diferenciados, atingindo a maior concentração durante a retração. ${ }^{50} \mathrm{Na}$ fase de retração, os 
miofibroblastos estão bem organizados formando camadas paralelas à superfície tissular, enquanto os vasos estão dispostos perpendicularmente. Ao fim do processo de reparo tissular, os miofibroblastos e os vasos desaparecem por apoptose. ${ }^{51}$

Durante o reparo tissular normal, a expressão de proteínas contráteis e a disposição dos miofibroblastos no tecido de granulação sugerem que essas células sejam responsáveis pela produção da força que causa a contração da lesão. ${ }^{6}$ Além disso, essas células realizam a síntese de componentes da matriz extracelular. ${ }^{78}$

Uma vez que ocorre uma importante interação entre matriz extracelular e miofibroblastos no fibronexus, pode-se sugerir que essa matriz extracelular influencia a diferenciação dos miofibroblastos. $^{52}$

Na década de 1990 demonstrou-se a relação entre a expressão de $\alpha$-actina de músculo liso pelos miofibroblastos e a remodelagem do colágeno, ${ }^{53}$ pois os resultados mostraram que a contração do gel de colágeno é dependente da expressão de $\alpha$-actina de músculo liso, e que a $\alpha$-actina de músculo liso é um marcador funcional para um subtipo de fibroblastos envolvidos na remodelagem da matriz extracelular.

Acredita-se que a diferenciação miofibroblástica representa uma resposta adaptativa às modificações do meio extracelular, e que a matriz extracelular pode funcionar como um reservatório de citocinas e fatores de crescimento inativos. ${ }^{4}$ 


\subsubsection{Contração da ferida}

A capacidade de contração da ferida está relacionada aos miofibroblastos presentes no tecido de granulação e à alta concentração de actina intercelular presente nos microfilamentos.

Fibras de fibronectina são encontradas ao redor dos miofibroblastos formando uma rede que confere um distanciamento entre eles, alongando a matriz extracelular do tecido de granulação. Singer et al. $^{52}$ acreditam que $\mathrm{o}$ fibronexus funciona como um complexo coesivo que transmite de maneira coletiva as forças geradas pela contração dos microfilamentos de actina por todos os miofibroblastos do tecido de granulação, promovendo, assim, a contração da ferida.

\subsubsection{Formação de matriz e remodelagem da cicatriz}

A terceira e última fase da cicatrização de feridas é a formação de matriz e remodelagem cicatricial, cujo início é concomitante à formação do tecido de granulação. Nos meses seguintes à dissolução da granulação, a matriz é constantemente alterada, com eliminação rápida da maior parte de fibronectina e acúmulo gradual de feixes de colágeno tipo I, que aumentam a força tensiva da cicatriz. 
A composição e a estrutura da matriz extracelular mudam constantemente desde sua primeira deposição. A matriz extracelular deposita-se primeiramente nas margens da ferida sobre o tecido de granulação, a deposição na região central dá-se após algum tempo, portanto, essas matrizes terão características diferentes entre si nessas duas regiões. Assim, a composição e a estrutura da matriz extracelular do tecido de granulação dependem de dois fatores: tempo decorrente desde a agressão e distância da margem da ferida.

\subsubsection{Fibronectina}

O depósito inicial de matriz extracelular é rico em fibronectina, a qual atua como substrato para deposição de colágeno. Observa-se que os fibroblastos tendem a se orientar no eixo das fibras de fibronectina e o colágeno terá a mesma orientação. ${ }^{35}$ Estudos realizados em culturas de células da matriz mostram íntima associação entre fibronectina, colágeno e glicosaminoglicanas. ${ }^{54}$ Nessa matriz, a colagenase quebra somente as moléculas de colágeno preservando as de fibronectina, assim, a deposição de fibronectina fibrilar extracelular é essencial na organização dos colágenos tipo I e III. $^{55}$ Fibroblastos cultivados na ausência de ascorbato não produzem colágeno, mas, sim, uma densa matriz de fibronectina. ${ }^{56}$ 


\subsubsection{Metaloproteinases}

Metaloproteinases são proteases que degradam ao menos um componente da matriz extracelular. Essas proteínas contêm íon zinco e são inibidas por agentes quelantes; sendo secretadas na forma latente, necessitam ativação para exercer sua função proteolítica; são ainda inibidas por inibidores tissulares e têm seqüência comum de aminoácidos. $^{57}$ São exemplos de metaloproteinases: colagenases, estromelisinas, gelatinases e matrilisinas.

\subsubsection{7 Ácido hialurônico}

O ácido hialurônico é um polímero de cadeia linear que repete o dissacarídeo N-acetylglicosamina-ácido glicurônico. Essa molécula também faz parte do tecido de granulação. Recentes estudos mostram que o ácido hialurônico tem participação importante na proliferação de fibroblastos, produção e maturação das fibras colágenas. ${ }^{58}$ Com a maturação do tecido de granulação, o ácido hialurônico será degradado por ação da hialuronidase tissular, sendo substituído por uma glicosaminoglicana sulfatada, associada a uma proteína chamada proteoglicana. 


\subsubsection{Proteoglicanas}

São as estruturas mais complexas da família das glicosaminoglicanas. Por definição, as proteoglicanas contêm uma proteína core unida por ligação co-valente à cadeia da glicosaminoglicana. Geralmente, essas proteoglicanas formam com o ácido hialurônico ligações não-co-valentes. A grande versatilidade desse sacarídeo confere às proteoglicanas diversas funções organizacionais nos tecidos.

No tecido de granulação maduro, somente o ácido hialurônico se apresenta como polissacarídeo de cadeia linear. Condroitin-4sulfato e dermatan-sulfato aparecem somente dentro das proteoglicanas. O condroitin-4-sulfato acelera a polimerização dos monômeros de colágeno, deposição do colágeno durante a fase de formação da matriz e na fase de remodelagem cicatricial.

\subsubsection{Colágeno}

O colágeno é a proteína mais abundante do corpo humano, representando $30 \%$ do total das proteínas existentes. As fibras colágenas são as mais freqüentes no tecido conjuntivo, aproximadamente $75 \%$ tem cor branca, conferindo essa cor aos tecidos nos quais são predominantes, por exemplo, em tendões. ${ }^{59}$ 
Por serem fibras longas e de trajeto sinuoso, sua morfologia não é fácil de ser estudada nos cortes histológicos. Nesses cortes, por distensão, as fibras colágenas aparecem como estruturas cilíndricas alongadas e flexíveis, cujas extremidades se perdem entre os outros elementos do tecido. Essas fibras têm diâmetro variando entre 1 e 20 micrometros. Graças às fibrilas que as constituem, as fibras colágenas apresentam estriações longitudinais.

São fibras constituídas por uma escleroproteína denominada colágeno cuja composição de aminoácidos é bem característica. $\mathrm{O}$ aminoácido glicina aparece no colágeno à proporção de 33,5\%, enquanto prolina e hidroxiprolina estão presentes à proporção de $12 \%$ e $10 \%$, respectivamente. O restante é formado por outros aminoácidos, e aminoácidos sulfurados e tirosina são pouco freqüentes.

Colágeno e elastina são as únicas proteínas que contêm hidroxiprolina em concentrações diferentes, portanto, podemos determinar seu teor num tecido pela dosagem de hidroxiprolina. ${ }^{60}$

Existem numerosos tipos de colágeno, divididos em quatro classes (Tabela 3): ${ }^{61}$ 
Tabela 3 - Classificação das fibras colágenas

\begin{tabular}{|c|c|c|c|}
\hline Classe & Característica & Tipo & Localização \\
\hline 1 & Fibrilar intersticial & I, II e III & $\begin{array}{l}\text { Estrutura extracelular dos principais } \\
\text { tecidos conectivos } \\
\text { mais abundante nos mamíferos }\end{array}$ \\
\hline 2 & Membrana basal & IV & $\begin{array}{l}\text { Disposição reticular } \\
\text { integridade membrana basal } \\
\text { fibras de ancoragem - membrana basal }\end{array}$ \\
\hline 3 & Pericelular & V e VI & $\begin{array}{l}\text { Tipo V envolve os fibroblastos, as } \\
\text { células do músculo liso e outras células } \\
\text { mesenquimais } \\
\text { Tipo VI é encontrado em muitos tecidos } \\
\text { conectivos }\end{array}$ \\
\hline 4 & $\begin{array}{c}\text { Recém- } \\
\text { descobertos }\end{array}$ & $\begin{array}{l}\text { VII, VIII, } \\
\text { IX, X e XI }\end{array}$ & $\begin{array}{l}\text { Tipo VII tem como principal função } \\
\text { estabilizar a junção dermo-epidérmica e } \\
\text { a derme subjacente } \\
\text { Tipo X participa da ossificação } \\
\text { endocondral } \\
\text { Tipo XI é um produto específico dos } \\
\text { tecidos cartilaginosos }\end{array}$ \\
\hline
\end{tabular}

O colágeno mais abundante no organismo é o tipo I, no qual, das três cadeias peptídicas, duas são idênticas entre si (alfa-1) e uma é diferente (alfa-2). ${ }^{62}$ A diferença entre as cadeias alfa um e alfa dois está na seqüência de aminoácidos. O tropocolágeno é uma molécula assimétrica, isto é, cada extremidade tem propriedades químicas diferentes. ${ }^{63}$ As moléculas de tropocolágeno são os blocos com os quais as fibrilas são construídas. No colágeno do tipo III, cada molécula de tropocolágeno é formada por três cadeias alfa-1. Esse tipo de colágeno é encontrado nas fibras reticulares presentes, por exemplo, nos vasos sangüíneos, útero e nervos. ${ }^{64} \mathrm{Na}$ formação dos 
tecidos cicatriciais, é freqüente o aparecimento inicial do colágeno tipo III, que depois é substituído pelo colágeno tipo I. ${ }^{65}$

Do tecido conjuntivo que está em fase ativa de fibrinogênese (cicatrização, por exemplo), é possível extrair várias frações do colágeno, cujas solubilidades são diferentes. A primeira dessas frações é extraída por soluções neutras e parece incluir as moléculas de tropocolágeno ainda não polimerizadas e as polimerizadas até o estado de fibrilas muito finas. Trata-se do colágeno recémsintetizado. A segunda fração é o colágeno solúvel em soluções ácidas e a última fração contém o colágeno que restou após as duas primeiras extrações e chama-se colágeno insolúvel.

O colágeno é sintetizado por diversos tipos celulares, como fibroblasto, osteoblasto, odontoblasto, condrócito e célula muscular lisa. Uma vez que esse estudo enfoca somente a pele, os relatos a seguir dizem respeito ao fibroblasto desse tecido.

Os polipeptídeos precursores do colágeno, também chamados de pré-cadeias alfa, são sintetizados nos ribossomos dos fibroblastos. Esse produto inicial contém seqüência terminal amina, sendo constituído de diversas proteínas secretadas e rico em aminoácidos hidrófobos, que, provavelmente, servem de sinal para acoplamento dos ribossomos na membrana do endotélio endoplasmático rugoso. Esses polipeptídios ficam nas cisternas do retículo endoplasmático. 
Diversas modificações são feitas nos peptídeos pré-cadeia alfa até a molécula de colágeno estar completa e depositada no espaço extracelular. A maioria dessas modificações é catalisada por enzimas específicas, o que inclui síntese de hidroxiprolina por hidroxilação de resíduos selecionados da prolina; síntese de hidroxilisina por hidroxilação de resíduos selecionados da lisina; adesão de carboidratos, galactose ou glicosilactose em certos resíduos de hidroxila; formação da tríplice hélice; conversão do pró-colágeno em colágeno e formação de fibras por proteólise e ligações cruzadas.

Cada cadeia alfa é sintetizada com dois peptídeos de registro, um em cada extremidade. Esses peptídeos determinam o alinhamento das cadeias protéicas em grupos de três, facilitando a combinação dessas cadeias para formar uma molécula de prócolágeno, que é precursora, porém maior que o tropocolágeno. Outra função desses peptídeos é impedir a formação de fibrilas colágenas no interior das células.

Sabe-se que após traumas, ou pelo envelhecimento fisiológico, as fibras colágenas vão se modificando e assumindo arquitetura anárquica. O caráter rígido e quebradiço do tecido conjuntivo nas pessoas idosas é o resultado do acúmulo de ligações co-valentes cruzadas no colágeno. 


\subsubsection{Fatores de crescimento}

O desempenho da matriz extracelular é fortemente influenciado por fatores de crescimento, a saber: TGFß (transforming growth factor-[beta]) ativa a produção de matriz extracelular; PDGF (plateletderived growth factor) estimula a proliferação e a migração celular; bFGF (basic fibroblast growth factor) induz a formação de novos vasos sanguíneos; TNF $\alpha$ (tumor necrosis factor-[alpha]) e interleucina-1 promovem inflamação, migração celular e proliferação celular. $^{66}$

TGFß, um dos fatores de crescimento melhor estudado na literatura mundial, tem papel fundamental no processo de reparação tecidual. O passo inicial no desenvolvimento da resposta fibrótica do tecido cicatricial envolve a expressão de TGFß1 por células endoteliais neoformadas. Essas células endoteliais estimulam fibroblastos adjacentes para aumentar a produção de TGFß1, colágeno tipo I e colágeno tipo $\mathrm{VI}^{67}$ Linfócitos-T e macrófagos estimulam fibroblastos a produzir colágeno tipo I, colágeno tipo III, ácido hialurônico, condroitin-4-sulfato e dermatan-sulfato. ${ }^{68}$ Interleucina-4 produzida por linfócitos-T e por mastócitos apresenta os mesmos efeitos. ${ }^{69}$ 


\subsubsection{Reparação patológica}

Como já descrito, o reparo tissular é um processo complexo, no qual diversos componentes interagem para que o resultado final seja satisfatório.

Em alguns casos, os mecanismos fisiológicos de reparação não ocorrem de forma harmoniosa devido a perturbações no decorrer do processo, assim o reparo passa a ser considerado patológico. Basicamente, as perturbações no processo de reparo envolvem retardo, ausência de processo, ou processo exacerbado. Os exemplos típicos de situações em que o reparo não ocorre são: úlceras venosas, arteriais ou linfáticas, e escaras por pressão. Numa visão mais ampla, os tumores, em particular a sua porção estromal, também podem ser considerados lesões que nunca cicatrizam. ${ }^{70}$ Quando ocorre um processo exacerbado de reparo, a cicatriz resultante é excessiva e, na maior parte dos casos, prejudica o correto desenvolvimento das funções fisiológicas da região atingida. Como exemplos de reparo excessivo podemos citar: cicatriz hipertrófica, quelóide, aderências e fibrose em diversos órgãos.

Os primeiros relatos de cicatrizes excessivas ou "exuberantes" foram encontrados em papiros egípcios datados de 1770 a.C. ${ }^{71}$

Segundo Berman e Bieley, ${ }^{72}$ Alibert em 1806, descreveu essa cicatriz exuberante como um tumor, referindo-se a ela como cancróide, que mais tarde originou o termo quelóide (do grego chele, que significa pata de caranguejo). 
Mancini, ${ }^{73}$ em 1962, e Peacock, ${ }^{74}$ em 1970, observaram diferenças clínicas entre as cicatrizes excessivas, chamando de hipertróficas aquelas que crescem acima da superfície da pele, porém sem ultrapassar as bordas da lesão original; e quelóide quando, além de crescer acima da superfície cutânea, ultrapassam as bordas da lesão original.

Ao contrário do quelóide, cicatrizes hipertróficas podem apresentar regressão espontânea, parcial ou total, com o passar do tempo. Essa hipertrofia cicatricial, geralmente, está associada à tensão cutânea durante o processo de reparo. ${ }^{75} \mathrm{~A}$ cicatriz hipertrófica pode apresentar coloração avermelhada, prurido e retração. ${ }^{2}$ Outra característica que pode diferenciar os dois tipos de cicatriz é a recidiva após correção cirúrgica, freqüentemente presente no quelóide e mais rara na cicatriz hipertrófica. ${ }^{76}$

Muir et al., ${ }^{77}$ em 1990, propuseram um terceiro tipo de cicatriz excessiva, com as mesmas características das anteriores. Nesse grupo, as cicatrizes permanecem limitadas às bordas da lesão original como cicatrizes hipertróficas, porém comportam-se como quelóides: apresentam alto índice de recidiva após correção cirúrgica e não demonstram tendência à regressão espontânea.

Por serem entidades de comportamento e aspectos clínicos tão diversos, é fundamental a diferenciação entre ambas as cicatrizes excessivas. ${ }^{3} 7879$ 
Cicatrizes hipertróficas e quelóides não apresentam prevalência por gênero, sendo sua maior incidência na segunda década de vida. Segundo a literatura médica indexada, 33\% a $91 \%$ das cicatrizes hipertróficas existentes, decorrem de queimaduras. ${ }^{80}$

Cicatrizes hipertróficas geralmente aparecem duas a quatro semanas após o trauma, enquanto quelóides desenvolvem-se ao redor do terceiro mês pós-trauma. Sintomas como dor e prurido são mais comumente associados ao quelóide, mas podem estar presentes também nas cicatrizes hipertróficas. ${ }^{81}$

Quelóides podem ser observados em pessoas de qualquer etnia, porém apresentam freqüência até quinze vezes maior em indivíduos de pele escura, quando comparados àqueles de pele clara. Não se observa quelóide em albinos. ${ }^{82} 83$

Regiões como tórax anterior, ombros, lóbulo de orelha, braço e terço médio de face apresentam maior predisposição à formação de quelóides que outras áreas anatômicas, enquanto pálpebras, genitais, palma das mãos, planta dos pés, córneas, mucosas e cordão umbilical estão menos sujeitos à formação desse tipo de cicatriz. $^{84}$

Acredita-se que o surgimento de cicatrizes hipertróficas esteja relacionado à tensão sofrida pela pele durante o processo de cicatrização, pois retrações cicatriciais aparecem na face flexora das articulações e nunca na face extensora. ${ }^{85}$ Feridas orientadas sobre as linhas de força da pele tendem à cicatrização fisiológica. ${ }^{86}$ 
No presente estudo, trataremos somente de um tipo de reparo excessivo: as cicatrizes hipertróficas.

\subsubsection{Reparação tecidual na cicatriz hipertrófica}

Na fase inflamatória inicial, plaquetas participam da formação de matriz, pois são responsáveis pela produção de fibronectina que facilita a migração celular e a formação de tecido de granulação. Distúrbios na função das plaquetas podem, teoricamente, exacerbar o processo de reparação gerando cicatrizes excessivas. ${ }^{87}$

A fase inflamatória pode estar prolongada em lesões extensas como queimaduras ou feridas contaminadas, o que acarreta aumento de citocinas pró-fibróticas como PDGF e TGFß, predispondo-as, assim, à formação de cicatrizes hipertróficas. ${ }^{88}$ Hipertrofias cicatriciais são mais freqüentes em feridas que permanecem mais de três semanas abertas. ${ }^{89}$

Cicatrizes hipertróficas ativas têm grandes quantidades de TGFß e PDGF ${ }^{90}$ e pouca quantidade de interleucinas- $1 \alpha$ e $1 \beta^{91}$ Os dois primeiros fatores são importantes, tanto na migração e adesão celular, quanto na formação da matriz, enquanto as interleucinas- $1 \alpha$ e $1 ß$, em ação sinérgica com interferon $\gamma$ e TNF $\alpha$ produzidos por células inflamatórias, estimulam a liberação de metaloproteinases presentes na matriz, aumentando a atividade das colagenases. 
Assim, a diminuição nos níveis de interleucinas-1 gera excessivo depósito de matriz. ${ }^{92}$

Queratinócitos produzem fatores de crescimento como: TGFß, PDGF, bFGF, interleucinas-1 e TNF $\alpha$, que têm participação fundamental na formação de tecido de granulação e remodelagem de matriz. Estudos in vitro demonstram que queratinócitos oriundos de cicatrizes hipertróficas apresentam aumento na proliferação e diferenciação celular, assim como de PDGF, e diminuição na expressão de interleucina- $1 \alpha^{93}$

Como já foi descrita, a transformação do coágulo sangüíneo em tecido de granulação depende do equilíbrio preciso entre síntese e degradação da matriz extracelular. A degradação de matriz decorre da ação de metaloproteinases sintetizadas por mastócitos, macrófagos, células endoteliais e fibroblastos. Já a formação dessa matriz depende de síntese, pelos fibroblastos, de fibras colágenas, de fibronectina e de proteoglicanas. Degradação deficitária, síntese excessiva de matriz ou ambos podem formar uma cicatriz hipertrófica. $^{88}$

Cicatrizes hipertróficas são caracterizadas, à microscopia, pela presença de pequenos vasos circundados por fibronectina, miofibroblastos, que expressam $\alpha$-actina de musculatura lisa, e feixes delicados de colágeno, dispostos em arranjo aleatório. Estas estruturas geralmente apresentam disposição nodular. ${ }^{3}$ Colágeno tipo III, predominantemente secretado nas fases iniciais do processo de 
reparo, ainda pode ser observado nesses nódulos, sugerindo que as células ali presentes estão continuamente ativadas. ${ }^{5}$

O fibroblasto exerce papel fundamental na formação de tecido de granulação e remodelagem de matriz extracelular. O estudo detalhado das modificações no comportamento dessa célula permite não só a melhor compreensão do processo de reparo tissular, como também a utilização de terapias mais efetivas.

Estudos in vitro demonstram que fibroblastos derivados de cicatrizes hipertróficas apresentam parâmetros normais de crescimento (i.e., tempo médio de duplicação populacional, volume celular e cariótipo), porém evidenciam produção de matriz extracelular aumentada. ${ }^{94} \mathrm{O}$ aumento na produção de colágeno é moderado, mas sua resposta a fatores de crescimento é similar à resposta de fibroblastos normais. ${ }^{95}$

A produção de fibronectina in vitro está aumentada, se comparada à produção por fibroblastos derivados de pele normal e cicatrizes fisiológicas. ${ }^{87}$ Esses achados explicam a alta concentração de fibronectina ao redor dos vasos e nos nódulos de colágeno. Nas cicatrizes fisiológicas, a fibronectina desaparece poucos dias após o fechamento da ferida, já nas cicatrizes hipertróficas essa atividade permanece intensa por meses ou anos. ${ }^{96}$

Concomitantemente à formação de tecido de granulação, a ferida reduz seu diâmetro (fase de contração da ferida) graças à atuação dos fibroblastos que sofrem alteração em seu fenótipo, 
modificando sua interação com a matriz extracelular. Inicialmente, esses fibroblastos assumem fenótipo de células migratórias para, posteriormente, apresentarem fenótipo pró-fibrótico (produzindo grandes quantidades de colágeno I e III, além de outros componentes de matriz). Cerca de nove dias após o início da reparação da ferida, os fibroblastos gradativamente modificam seus citoesqueletos para a forma definitiva, o miofibroblasto, passando a expressar $\alpha$-actina de musculatura lisa. ${ }^{50}$

Tanto fibroblastos derivados de cicatrizes hipertróficas quanto fibroblastos derivados de quelóide expressam quantidades semelhantes de $\alpha$-actina de musculatura lisa, sugerindo que fatores locais podem modificar o comportamento dessas células. ${ }^{3}$ Nos experimentos in vitro, TGFß1 tem capacidade de aumentar a expressão de $\alpha$-actina, além de promover a contração do modelo experimental de matriz de colágeno povoada por fibroblastos. ${ }^{97}$

Fibroblastos oriundos de cicatrizes hipertróficas apresentam aumento da expressão do receptor CD44 (molécula de adesão para hialuronas). ${ }^{98}$ Nessas cicatrizes, o ácido hialurônico aparece como uma fina camada na derme papilar. Na derme normal, o ácido hialurônico forma um "revestimento pericelular", i.e., a matriz extracelular, responsável pela manutenção do TGFß1 nesse microambiente. Essa interação com TGFß1 forma uma molécula resistente à degradação enzimática preservando, assim, a atividade desse TGF (estimular síntese de colágeno). Caso, nessa matriz, 
também ocorra aumento de inibidores das metaloproteinases, a síntese de colágeno sofrerá aumento, enquanto a degradação do colágeno existente estará diminuída, resultando, com isso, em tecido cicatricial excessivo. ${ }^{99}$

Durante o processo fisiológico de remodelagem da matriz, o ácido hialurônico é substituído por proteoglicanas sulfatadas como decorina, biglican e versican, presentes nas cadeias de dermatansulfato e condroitin-4-sulfato (galactosaminoglicana). ${ }^{100}$ Estas proteoglicanas sulfatadas que conferem elasticidade aos tecidos são habitualmente produzidas por fibroblastos de cicatrizes maduras. ${ }^{101}$ Condroitin-4-sulfato está presente nas fases iniciais do processo de reparo da ferida. À medida que a cicatriz amadurece, diminuem os níveis de condroitin-4-sulfato e surge dermatan-sulfato. No entanto, nas cicatrizes hipertróficas os níveis de condroitin-4-sulfato permanecem altos. A concentração de dermatan-sulfato também aumenta, porém nunca alcança níveis de cicatriz madura. ${ }^{102}$ Esse aumento de condroitin-4-sulfato é verificado principalmente nos nódulos de colágeno. ${ }^{103} \mathrm{~A}$ concentração de biglican permanece elevada durante 0 processo de maturação das cicatrizes hipertróficas, já a expressão de decorina diminui quando comparada à derme normal ou cicatrizes fisiológicas maduras.

Nos experimentos in vitro, decorina induz a expressão de metaloproteinases na presença de vitronectina, porém não modifica 
essas enzimas na presença de fibronectina íntegra ou colágeno tipo I. ${ }^{104}$

Organização e degradação de fibras colágenas estão também relacionadas à concentração de proteoglicanas contendo decorina e biglican, pois tanto o ácido hialurônico quanto proteoglicanas podem ligar-se às fibras de colágeno, influenciando seu arranjo tridimensional. ${ }^{105}$ Ambas, decorina e biglican, interagem com colágeno tipo I influenciando a síntese de suas fibrilas. ${ }^{106}$ Observouse ainda que essas moléculas podem inibir a adesão de fibroblastos a componentes da matriz e que, ao ligarem-se ao TGFß, modulam sua atuação. ${ }^{107}$

Acredita-se que a diminuição, ou mesmo a ausência, de decorina nas cicatrizes hipertróficas contribua para a organização nodular das fibras colágenas. ${ }^{108}$

As fibras colágenas são responsáveis pela manutenção da força tensiva tanto na pele cicatricial quanto na pele normal. Nas feridas recentes, essa força tensiva depende da interação entre fibrina, fibronectina, colágeno, glicosaminoglicanas e fibroblastos ali presentes. ${ }^{109}$ À medida que o processo de reparação acontece, a força tensiva das feridas passa a depender de: deposição de colágeno neoformado, remodelagem desse colágeno com formação de novas bandas largas e ricas em ligações intermoleculares (crosslinks). ${ }^{110}$ 
Durante o processo de reparo da ferida, colágeno tipo III começa a surgir entre o segundo e o terceiro dia, seguido de colágeno tipo I, que aparece entre o sexto e o sétimo dia. A concentração de colágeno tipo $\mathrm{V}$ aumenta concomitantemente ao desenvolvimento da vascularização. ${ }^{111}$

A quantidade total de colágenos tipo I e III nas cicatrizes fisiológicas aumenta com o passar do tempo, porém a proporção entre eles não é constante. Essa proporção varia de $60 \%$ de colágeno tipo III na primeira semana após o trauma para $28 \%$ em cicatrizes maduras. ${ }^{112}$ Essa variação nas concentrações de colágenos tipo I e III tende a diminuir gradativamente até atingir a proporção normal em, aproximadamente, dois anos. ${ }^{113}$

Nas cicatrizes excessivas, a quantidade de colágeno tipo III permanece aumentada, se comparada à pele normal ou à cicatriz fisiológica. ${ }^{114}$ A relação de proporcionalidade entre colágeno tipo III e tipo I na pele em diferentes situações está demonstrada na Tabela 4. ${ }^{115}$

Tabela 4 - Quantidade de colágeno tipo III dividido pela quantidade de colágeno tipo I

\begin{tabular}{|c|c|}
\hline Tecido & Relação colágeno III / colágeno I \\
\hline Pele normal & 0,17 \\
\hline $\begin{array}{c}\text { Tecido de granulação } \\
\text { (pós-queimadura) }\end{array}$ & $0,37-0,72$ \\
\hline Quelóides & 0,61 \\
\hline
\end{tabular}


Como descrito anteriormente, nas cicatrizes excessivas há aumento de síntese e metabolismo de colágeno. Nas cicatrizes hipertróficas, as fibrilas de colágeno são menores, apresentam maior distância interfibrilar e aspecto mais regular que as fibrilas presentes em quelóides. ${ }^{116}$ As fibras de colágeno existentes nas cicatrizes hipertróficas ainda apresentam maior solubilidade ácida, diminuição no número de ligações cruzadas dependentes de lisil-oxidase e deficiência de amadurecimento, quando comparadas ao colágeno normal. $^{117}$

Existem várias teorias sobre a patogênese das cicatrizes excessivas. Como já foi citado, esse tipo de cicatrização pode ocorrer devido a: alterações nos fatores de crescimento celular; alterações da matriz extracelular; alterações do metabolismo de colágeno ou tensão cutânea excessiva sobre cicatrizes.

Alguns autores crêem que alterações imunológicas sejam responsáveis pela formação excessiva de tecido cicatricial. ${ }^{118}$ Diminuição de interferon- $\alpha$, interferon- $\gamma$ e TNF- $\alpha$ em quelóides sugere que linfócitos-T tenham capacidade de induzir fibroblastos a sintetizar mais colágeno. ${ }^{119}$ Deficiência de interferon- $\alpha$ (inibidor de síntese de colágeno) e de interferon- $\gamma$, responsável pela diminuição na atividade das colagenases, formam cicatrizes hipertroficas. ${ }^{120}$

Embora a cicatriz hipertrófica possa regredir com o tempo, a longa duração desse processo (muitos anos) e o comprometimento 
funcional e estético fazem com que haja uma busca ativa de tratamentos que acelerem sua regressão.

Diversas terapias têm sido propostas para o tratamento ou prevenção das cicatrizes hipertróficas. ${ }^{121} 122123124125$.

Ward e Clissold $^{126}$ descreveram a ação antifibrótica das metilxantinas, especialmente da pentoxifilina, possibilitando, assim, sua utilização no tratamento de cicatrizes excessivas.

\subsection{Pentoxifilina}

As primeiras descrições da utilização de pentoxifilina (1-hexil3,7-dimetilxantina - PTF) datam da década de 1970, na Alemanha, onde se demonstrou sua ação em doenças vasculares oclusivas alterando os níveis séricos de cálcio e magnésio. ${ }^{127} 128$

A PTF é um derivado da metilxantina de toxicidade sistêmica mínima, aprovada pelo Food and Drug Administration, dos Estados Unidos, para utilização no tratamento da insuficiência vascular. Essa substância diminui a viscosidade do sangue promovendo aumento do fluxo sangüíneo. ${ }^{129} \mathrm{O}$ mecanismo de ação é, provavelmente, mediado pela inibição do nucleotídeo da fosfodiesterase resultando em aumento de flexibilidade dos eritrócitos, além de produção plaquetária e endotelial de prostaglandinas melhorando, assim, o fluxo sangüíneo local e promovendo trombólise. ${ }^{130}$

Estudos científicos demonstraram que a PTF apresenta ação antifibrótica hepática, atuando sobre as células miofibroblasto-like 
(tipo miofibroblasto) responsáveis pela produção excessiva de matriz extracelular, característica desses quadros de fibrose, ${ }^{131} 132$ além de melhorar a perfusão sangüínea hepática. ${ }^{133} 134$ Desmouliere et al. ${ }^{135}$ demonstraram a capacidade da PTF de reduzir a fibroproliferação e a diferenciação de fibroblastos em modelo animal de oclusão do ducto biliar.

Berman e Duncan ${ }^{15} 130$ demonstram que a PTF tem ação terapêutica como agente antifibrótico. In vitro, PTF causa inibição na produção de colágeno, GAG e fibronectina, assim como promove acentuada redução na proliferação dos próprios fibroblastos originados de quelóides e de peles portadoras de escleroderma e morféia.

Dentre todas as xantinas com capacidade de diminuir a atividade do fibroblasto, a PTF é a mais potente ${ }^{136}$ (Figura 2).

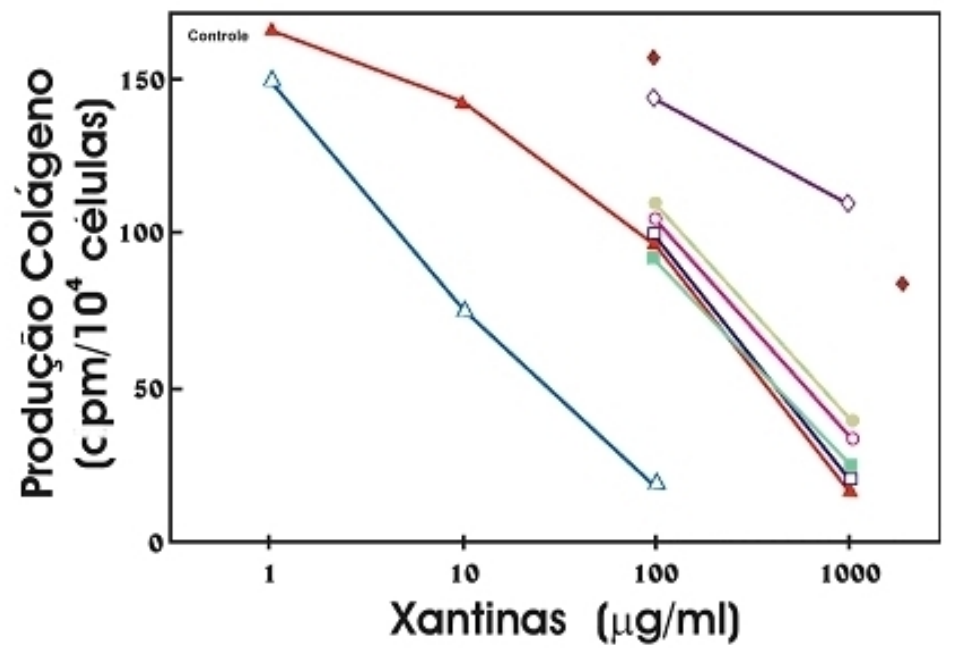

Figura 2 - Produção de colágeno por fibroblastos humanos na presença de pentoxifilina e outras xantinas

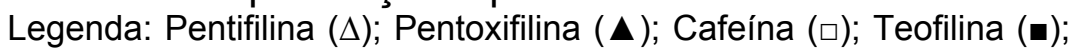
Teobromina (o); Isobutilmetilxantina $(\bullet)$; Hipoxantina $(\diamond)$. 
Esse efeito inibidor não parece ser decorrente de toxicidade celular, pois tanto culturas de fibroblastos tratadas com PTF quanto culturas de fibroblastos de controle apresentam baixo número de células não-viáveis, o que ratifica o efeito inibitório, não-tóxico, dessa substância.

A inibição do colágeno causada pela presença da PTF em culturas de fibroblastos deu-se independentemente da presença ou ausência do soro bovino fetal (um enriquecedor de meio de cultura que propicia melhor desenvolvimento dos fibroblastos).

O mecanismo de inibição do colágeno ocorre pela diminuição nas sínteses dos pró-colágenos tipo I e III graças à ação inibitória da PTF sobre o RNA mensageiro na transcrição protéica. Acredita-se que a PTF impeça o gene promotor de pró-colágeno chamado fator nuclear (NF)-1. ${ }^{130}$

Além de atuar sobre os fibroblastos, a PTF tem a capacidade de inibir a produção de fibronectina gerando menor contração da rede de colágeno (fibronexus). ${ }^{137}$ Outro fator que contribui para a menor contração do fibronexus é a diminuição na produção de GAG, principalmente do ácido hialurônico, que facilita a contração da rede de colágeno. ${ }^{138}$

A PTF é seletiva no controle da inibição da síntese protéica pelos fibroblastos. Em concentração de $1.000 \mu \mathrm{g} / \mathrm{mL}$, a PTF não interfere em outros processos bioquímicos de síntese do colágeno. 
O efeito antifibrótico da PTF pode ser útil no tratamento de doenças que apresentam fibrose dérmica. Essas observações foram também confirmadas por outros autores em patologias diversas do tecido conjuntivo envolvendo deposição excessiva de matriz extracelular. ${ }^{9} 139$

\subsection{Cultura de células}

Em condições apropriadas, a maior parte das células pode viver, multiplicar-se ou mesmo expressar propriedades diferenciadas em laboratório. Este processo recebe o nome de cultura celular.

As células em cultura podem ser observadas ao microscópio ou analisadas bioquimicamente, com o objetivo de avaliar os efeitos da adição ou remoção de moléculas específicas, tais como hormônios ou fatores de crescimento. Além disso, em cultura mista, as interações entre os vários tipos de células podem ser estudadas.

Experimentos com células oriundas de cultura são, às vezes, referidos como in vitro para contrastá-los daqueles experimentos com organismos intactos, os quais são denominados in vivo.

A primeira tentativa bem-sucedida na manutenção de tecidos em "cultura", ou seja, viáveis in vitro, foi divulgada por Ljunggren em 1898. Este pesquisador manteve fragmentos de pele humana submersos por vários dias em líquido ascítico e, em seguida, transplantou-os novamente ao doador original. Uma vez que ocorreu a integração desses enxertos, o autor concluiu que os fragmentos 
haviam se mantido viáveis durante sua conservação no líquido ascítico. $^{140}$

Foi a partir de 1907 que a cultura de células e tecidos despertou maior interesse nos pesquisadores da área biológica. Nessa ocasião, Harrison demonstrou que prolongamentos de neurônios poderiam ser formados in vitro. Ainda em 1907, Burrows, estudando meios de cultura, descobriu que o plasma de galinha era o ideal para tecidos humanos.

Carrel e Burrows, ${ }^{141}$ em 1911, publicaram seu primeiro artigo sobre o cultivo de tecidos, descrevendo a proliferação centrípeta de células a partir da periferia de fragmentos de pele total, estabelecendo a técnica de cultura por explantes (Foto 1).

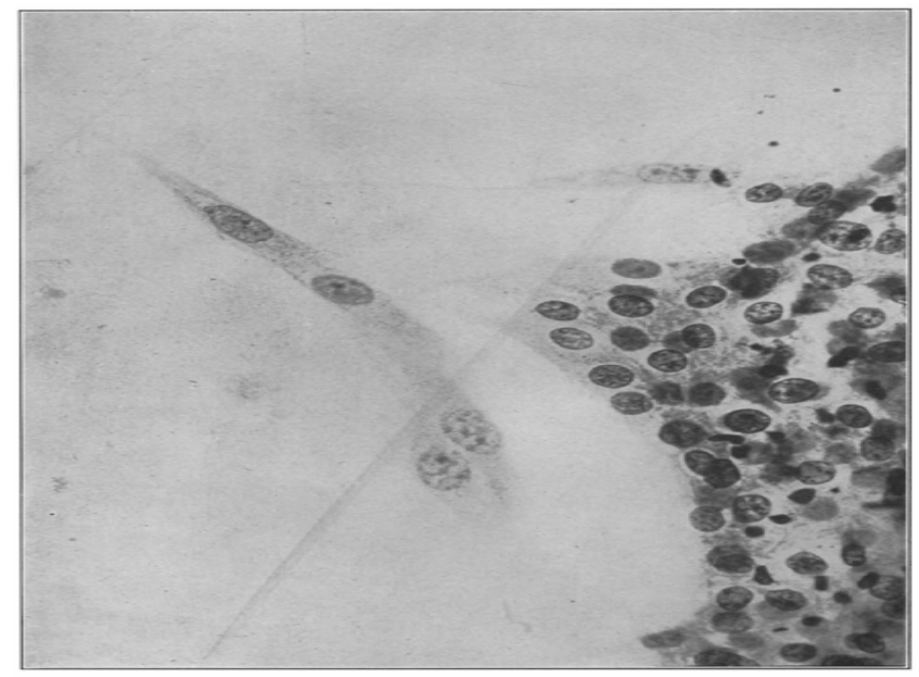

Foto 1 - Cultivo de tecidos por Carrel e Burrows Fonte: J. Exp. Med. 1911;13 (3): 387.

A partir de 1942, a técnica de cultura de tecidos integrou a rotina de vários laboratórios brasileiros na realização de estudos biológicos. 
Eagle, em 1955, pesquisou, pela primeira vez, as necessidades nutricionais para que uma célula em cultura se multiplicasse.

Hayflick e Moorhead, em 1961 demonstraram que fibroblastos humanos morrem após um número finito de multiplicações in vitro.

Desde então, um número cada vez maior de pesquisadores vêm elucidando etapas desse processo ou utilizando-o como ferramenta para outras investigações.

Culturas preparadas diretamente de tecidos de um organismo, com ou sem fracionamento inicial das células, são chamadas culturas primárias. Na maioria dos casos, células em culturas primárias podem ser retiradas da placa de cultura e usadas para formar um número razoável de culturas secundárias, assim, elas podem ser cultivadas novamente, por semanas ou meses.

Células mantidas em cultura, freqüentemente, apresentam características semelhantes à sua origem, p.ex.: células epiteliais formam extensas lâminas com muitas das propriedades de um epitélio intacto e fibroblastos continuam a secretar colágeno, como se essas células estivessem numa ferida.

Graças a essa propriedade podemos estudar, in vitro, o processo de reparação tissular. 
Métodos 


\section{Métodos}

Este estudo, realizado no Laboratório de Investigação Médica (LIM) 04 da Faculdade de Medicina da Universidade de São Paulo, foi aprovado pela Comissão de Ética para Análise de Projetos de Pesquisa - CAPPesq da diretoria Clínica do Hospital das Clínicas e da Faculdade de Medicina da Universidade de São Paulo, em 26 de agosto de 2004 , sob o $n^{\circ} 455 / 04$.

Os experimentos de incorporação citoplasmática de ${ }^{3} \mathrm{H}$-prolina e imunofluorescência, para avaliação de colágenos I e III, foram realizados no LIM 17 da FMUSP.

Este estudo foi realizado totalmente sem conflitos de interesses.

\subsection{Cultivo de fibroblastos}

Fibroblastos humanos provenientes de pele normal foram obtidos a partir de excedentes de pele oriundos de pacientes do sexo feminino, faixa etária entre 20 e 35 anos e cor branca e parda. As amostras de pele foram doadas, para finalidade de pesquisa, por ocasião de sua ressecção cirúrgica e cedidas pelo Banco de Tecidos do ICHC para a realização deste estudo.

Paralelamente, foram cultivados fibroblastos obtidos a partir de fragmentos de cicatrizes hipertróficas provenientes de pacientes portadores de seqüela de queimadura há mais de dois anos, 
apresentando as mesmas características étnicas, etárias e localização anatômica do grupo anterior. Estas amostras de pele também foram doadas, para finalidade de pesquisa, pelo Banco de Tecidos do ICHC.

Fibroblastos obtidos a partir de cultura de pele não-cicatricial foram denominados NHF (normal human fibroblasts), enquanto fibroblastos provenientes de cicatrizes hipertróficas foram nomeados HSHF (hipertrophic scar human fibroblasts).

As células foram isoladas in vitro segundo a técnica de explante proposta por Carrel. ${ }^{142}$ As amostras de tecido cortadas em fragmentos de, aproximadamente, $1 \mathrm{~mm}^{2}$ foram depositadas em frascos de $25 \mathrm{~cm}^{2}$ contendo meio de cultura para fibroblastos, por nós denominado $D_{10}$, a saber: meio de Eagle Modificado por Dulbecco (DMEM) acrescido de $10 \%$ de soro bovino fetal (SBF) com estreptomicina $100 \mu \mathrm{g} / \mathrm{mL}$ / penicilina $100 \mathrm{UI} / \mathrm{mL}$ / anfotericina B 0,25 $\mu \mathrm{g} / \mathrm{mL}$. Os frascos foram mantidos em estufa a $37^{\circ} \mathrm{C}$ em atmosfera de $5 \%$ de $\mathrm{CO}_{2}$ e o meio de cultura trocado a cada 72 horas, até que um número suficiente de células tivesse migrado do fragmento de pele e aderido ao fundo das garrafas de cultura, formando aspecto de subconfluência celular (na periferia de cada fragmento), quando foi realizada ampliação das culturas (procedimento utilizado para transferir células de uma garrafa de cultura para outra).

Foram adicionados $5 \mathrm{~mL}$ de solução de tripsina 0,05\% + EDTA $0,02 \%$ às garrafas de cultura para que as células se destacassem da 
superfície de cultivo. As garrafas foram mantidas em estufa a $37^{\circ} \mathrm{C}$ e atmosfera de $5 \%$ de $\mathrm{CO}_{2}$ e, aproximadamente, a cada $5 \mathrm{~min}$, verificada a soltura das células à MO. Ocorrido este evento, a reação enzimática foi interrompida pela adição de solução contendo íon cálcio $(v / v)$. A suspensão de células resultante foi centrifugada a 1.500 rpm por $5 \mathrm{~min}$, o sobrenadante desprezado, o botão celular (pellet) novamente diluído em $\mathrm{D}_{10}$ e transferido a uma nova garrafa de cultura.

A cada amplificação, o número de células foi contado em câmara hemocitométrica de Neubauer.

Todos os experimentos foram realizados, em triplicata, entre a terceira e a quinta amplificação.

\subsection{Ensaios preliminares}

Foram realizados, previamente ao início dos experimentos envolvendo HSHF e NHF (principal escopo desta pesquisa), ensaios para determinar o número de amostras de tecido, a possível citotoxicidade da PTF na concentração escolhida e a curva de crescimento celular na presença e ausência de PTF.

\footnotetext{
"NOTA: No jargão específico, o ato de destacar células de uma superfície de cultivo, ou fragmento de tecido biológico, utilizando-se a enzima tripsina recebe o nome de tripsinização, um neologismo criado e incorporado pela área médica à língua portuguesa, do qual deriva o verbo tripsinizar.
} 


\subsubsection{Determinação do número de amostras de pele}

Em placas de 24 poços (área de $1,96 \mathrm{~cm}^{2} /$ poço), foram semeados, em $1 \mathrm{~mL}$ de meio de cultura $\mathrm{D}_{10}$, aproximadamente $1 \times 10^{4}$ NHF / poço $\left(0,5 \times 10^{4} / \mathrm{cm}^{2}\right)$ recém-tripsinizados. As placas foram incubadas em estufa a $37^{\circ} \mathrm{C}$ com atmosfera de $5 \%$ de $\mathrm{CO}_{2}$ por 18 horas, para que houvesse adesão das células à superfície de cada poço. Decorrido esse período, o meio de cultura foi retirado e substituído por $1 \mathrm{~mL}$ de $\mathrm{D}_{10}$ com e sem a adição de PTF 1.000 $\mu \mathrm{g} / \mathrm{mL}$. Após 96 horas, as culturas foram novamente tripsinizadas e o número de células contado em câmara hemocitométrica.

Os resultados obtidos foram submetidos a tratamento estatístico, possibilitando, assim, o cálculo do número de amostras de pele necessário à validação estatística desses resultados.

A análise estatística empregada na comparação dos efeitos de PTF sobre proliferação celular entre dois grupos (NHF e HSHF) foi o delineamento fatorial com dois fatores: o primeiro foi o tecido de origem das células (pele normal / cicatriz hipertrófica) e o segundo foi o uso ou não de PTF nas culturas.

\subsubsection{Mortalidade celular}

Para verificar a mortalidade celular na presença e ausência de PTF foram semeados, aproximadamente, $1 \times 10^{4} \mathrm{NHF} /$ poço em placas de 24 poços. As placas foram incubadas em estufa a $37^{\circ} \mathrm{C}$ com 
atmosfera de $5 \%$ de $\mathrm{CO}_{2}$ por 18 horas, tempo necessário para adesão das células vivas à superfície de cultura. Decorrido esse período, o meio de cultura foi substituído por $1 \mathrm{~mL}$ de $D_{10}$ acrescido ou não de PTF. Após 12 h, 24 h, 48 h, 72 h e 96 horas da última troca de meio (contendo ou não PTF), amostras do meio de cultura (sobrenadante) foram colhidas, coradas com o corante transmembrana Azul de Tripan e contadas em câmara hemocitométrica de Neubauer.

\subsubsection{Curva de proliferação celular}

Para avaliação preliminar da proliferação celular durante período de 96 horas na presença e ausência de PTF, foram semeados em $1 \mathrm{~mL}$ de $D_{10}$, aproximadamente, $1 \times 10^{4} \mathrm{NHF} /$ poço, em placas de 24 poços. Essas placas foram incubadas em estufa a $37^{\circ} \mathrm{C}$ e $5 \%$ de $\mathrm{CO}_{2}$ por 18 horas. Decorrido esse período, o meio de cultura foi substituído por $1 \mathrm{~mL}$ de $D_{10}$ acrescido ou não de PTF. Após $12 \mathrm{~h}$, 24 h, 48 h, 72 h e 96 horas da última troca de meio (contendo ou não PTF), o sobrenadante foi removido, os poços foram lavados com PBS (phosphate buffered solution), e as células, após nova tripsinização, foram contadas em câmara hemocitométrica de Neubauer.

Após a realização dos ensaios preliminares, teve início a seqüência de experimentos utilizando HSHF e NHF que foi, didaticamente, dividida em ensaios com cultura celular em 
monocamada e análise do comportamento do modelo tridimensional, conforme está esquematizado na Figura 3.

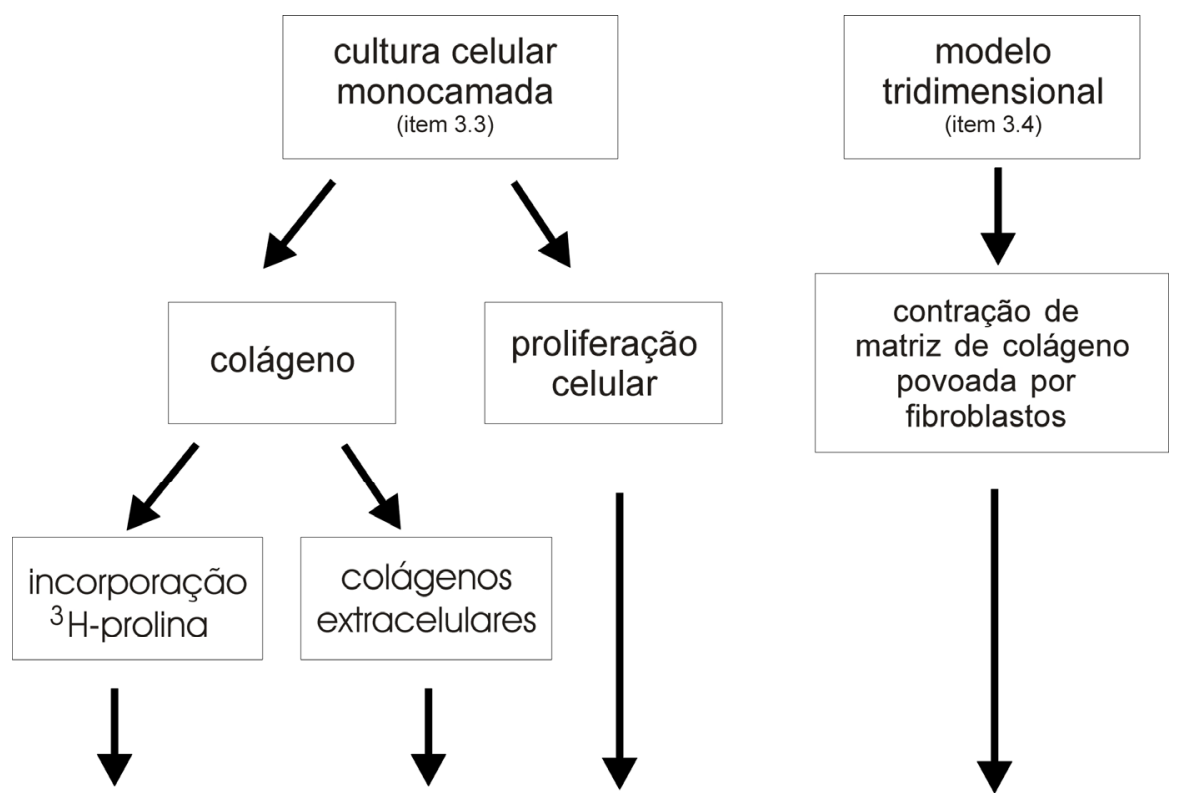

Figura 3 - Fluxograma dos experimentos realizados no estudo. Ressalte-se que os experimentos em cultura celular em monocamada correspondem ao Item 3.3, enquanto a avaliação do comportamento do modelo tridimensional corresponde ao Item 3.4

\subsection{Experimentos em cultura de célula em monocamada}

\subsubsection{Análise de colágeno}

\subsubsection{Avaliação quantitativa da incorporação de ${ }^{3} \mathrm{H}$-prolina}

O ensaio de produção intracelular de colágeno foi realizado em culturas de fibroblastos confluentes na presença de ácido ascórbico e prolina radiomarcada $\left({ }^{3} \mathrm{H}\right.$-prolina) por um período de 24 horas, como descrito a seguir. 
Foram semeados, em triplicata, $2,5 \times 10^{4}$ fibroblastos em placas multipoços de 96 poços $\left(0,45 \mathrm{~cm}^{2} /\right.$ poço) em $200 \mu \mathrm{L}$ de meio de cultura $D_{10}$ e incubados por 48 horas, até que fosse obtida monocamada de fibroblastos totalmente confluentes. O meio de cultura foi, então, substituído por $100 \mu \mathrm{L}$ de $\mathrm{D}_{10}$ acrescido de 50 $\mu \mathrm{g} / \mathrm{mL}$ de ácido ascórbico com e sem pentoxifilina $1.000 \mu \mathrm{g} / \mathrm{mL}$ em cada poço. As células foram incubadas por mais 48 horas.

Após esse período, adicionou-se [2,3- $\left.{ }^{3} \mathrm{H}\right]$-prolina (31 Ci/mmol) na concentração de $1,0 \mu \mathrm{Ci} / \mathrm{mL}$ diluída em $100 \mu \mathrm{L}$ de meio de cultura por poço. Aguardaram-se outras 24 horas, após as quais foram removidos os meios de cultura contendo $\left[2,3-{ }^{3} \mathrm{H}\right]$-prolina na presença e ausência de pentoxifilina. Essas soluções foram retiradas, os poços foram lavados com PBS, sendo, então, adicionados $100 \mu \mathrm{L}$ de hidróxido de sódio $(\mathrm{NaOH})$ 0,1 $\mathrm{M}$ a cada poço. A solução resultante foi transferida para frascos plásticos com tampa e foram adicionados $4 \mathrm{~mL}$ de coquetel de cintilação (Aquasol ${ }^{\circledR}$ ).

A radioatividade foi medida durante 1 minuto em equipamento analisador de cintilação e expressa em contagens por minuto (cpm). O resultado obtido foi a média aritmética desses experimentos, expressa na forma de cpm de ${ }^{3} \mathrm{H}$-colágeno. 


\subsubsection{Avaliação semiquantitativa de colágeno I e colágeno III extracelular}

Foram semeados, em triplicata, $1,5 \times 10^{5}$ fibroblastos sobre lamínulas de $13 \mathrm{~mm}$ em placas multipoços de 12 poços em $1 \mathrm{~mL}$ de meio de cultura $D_{10}$ e incubados por 18 horas, até que as células aderissem à superfície das lamínulas. Após esse período, o meio de cultura foi substituído por $1 \mathrm{~mL}$ de $D_{10}$ com e sem pentoxifilina 1.000 $\mu \mathrm{g} / \mathrm{mL}$ em cada poço. As lamínulas foram incubadas por mais 48 horas, até que fossem recobertas por fibroblastos em monocamada. Nesse momento, os meios de cultura foram retirados, as lamínulas lavadas com PBS e as células fixadas com $1 \mathrm{~mL}$ de paraformaldeido 4\%, por lamínula. Após sucessivas lavagens, as lamínulas foram incubadas em $5 \%$ de leite desnatado diluído em tampão fosfato $\mathrm{pH}$ 7,0. A seguir, foram realizadas as incorporações dos anticorpos primários, a saber: anticolágeno I policlonal, obtido de camundongos e diluído a 1:100 em PBS e anticolágeno III monoclonal (Oncogene; San Diego, USA) diluído a 1:50.

As lamínulas foram mantidas por 24 horas em câmara escura a $+4{ }^{\circ} \mathrm{C}$ e novamente lavadas sucessivas vezes com $0,05 \%$ Tween 20 (diluído em PBS) e incubadas por 90 minutos com anticorpo secundário (anti-lgG de camundongo conjugada com fluoresceína, Sigma; St Louis, Missouri, USA) diluído em PBS contendo 0,006\% de 
Azul de Evans. As lamínulas foram novamente lavadas em 0,05\% Tween 20 e montadas sobre lâminas com glicerina tamponada.

Essas lâminas foram analisadas, por dois avaliadores independentes, em microscópio de fluorescência (Nikon Instruments Inc. USA).

A imunomarcação para colágenos I e III não foi homogênea em toda a extensão das lamínulas. Assim, foi adotado método semiquantitativo de avaliação, de acordo com o seguinte escore:

Escore 1: quando, em 10 campos avaliados, 1 a $30 \%$ das fibras de colágeno presentes estavam intensamente imunomarcadas.

Escore 2: quando, em 10 campos avaliados, 31 a $60 \%$ das fibras de colágeno presentes estavam intensamente imunomarcadas.

Escore 3: quando, em 10 campos avaliados, 61 a $100 \%$ das fibras de colágeno presentes estavam intensamente imunomarcadas.

\subsubsection{Proliferação de HSHF e NHF}

Em placas de 24 poços, foram semeados em $1 \mathrm{~mL}$ de $D_{10}$, aproximadamente, $1 \times 10^{4}$ fibroblastos / poço $\left(0,5 \times 10^{4} / \mathrm{cm}^{2}\right)$ recémtripsinizados. As placas foram incubadas em estufa a $37^{\circ} \mathrm{C}$ com atmosfera de $5 \%$ de $\mathrm{CO}_{2}$ por 18 horas. Decorrido esse período, o meio de cultura foi retirado e substituído por $1 \mathrm{~mL}$ de meio de cultura com e sem a adição de PTF $1000 \mu \mathrm{g} / \mathrm{mL}$. Após 96 horas, as culturas 
foram novamente tripsinizadas e o número de células contado em câmara hemocitométrica.

\subsection{Modelo tridimensional de contração}

\subsubsection{Modelo de contração de matriz extracelular povoada por fibroblastos}

A matriz extracelular de colágeno utilizada neste experimento foi elaborada no LIM 04 da Faculdade de Medicina da USP, a partir de solução de colágeno de tendão de cauda de rato (Apêndice A).

Em placas de 24 poços (área de $1,96 \mathrm{~cm}^{2} /$ poço), no momento da confecção das matrizes de colágeno, foram combinados em cada poço: $100 \mu \mathrm{L}$ PBS (10 x concentrado); $100 \mu \mathrm{L} \mathrm{NaOH} \mathrm{0,1} \mathrm{M;} 4 \times 10^{5}$ células (suspensas em $400 \mu \mathrm{L}$ de PBS 1 x concentrado) e $400 \mu \mathrm{L}$ de solução de colágeno $1,21 \mathrm{mg} / \mathrm{mL}$. A cada item acrescentado, a solução em formação foi homogeneizada. As placas multipoços foram mantidas em estufa a $37^{\circ} \mathrm{C}$ e atmosfera de $5 \%$ de $\mathrm{CO}_{2}$, aguardando-se a formação da matriz durante 12 horas.

Uma vez ocorrida a formação da matriz extracelular, foi adicionado $1 \mathrm{~mL}$ de meio de cultura para fibroblastos acrescidos ou não de PTF $1.000 \mu \mathrm{g} / \mathrm{mL}$. As matrizes foram então, gentilmente, desprendidas das paredes e leito dos poços de cultura e as placas multipoços foram armazenadas novamente em estufa com $5 \%$ de $\mathrm{CO}_{2}$ a $37^{\circ} \mathrm{C}$. As matrizes contendo fibroblastos foram acompanhadas 
e avaliadas após 24 e 48 horas de seu descolamento dos poços de cultura.

A área do gel de colágeno povoado por fibroblastos foi fotografada nos momentos 24 h e 48 h, após o descolamento das matrizes, com câmera fotográfica digital (Sony CyberShot 3.2 Megapixels). A medida da área do gel foi realizada utilizando-se o software UTHSCSA Image Tool for Windows versão 3.0. ${ }^{143}$ A leitura foi realizada em triplicata e o valor utilizado como resultado foi a media aritmética das triplicatas.

\subsection{Análise estatística}

Com objetivo de comparar o comportamento de células entre os mesmos indivíduos, na presença e ausência de pentoxifilina, foi empregado um estudo longitudinal, também conhecido como estudo de coortes, estudo tipo follow-up ou dados de painel. Os resultados foram analisados utilizando-se Equações de Estimação Generalizadas (EEG). ${ }^{144} 145$ 
Resultados 


\section{Resultados}

\subsection{Cultivo de fibroblastos}

Os fragmentos de pele foram mantidos em frascos para cultivo celular (Figura 4A). Os fibroblastos migraram do fragmento de pele, aderindo à superfície de cultura dos frascos (Figura 4B), apresentando semelhança morfológica entre NHF (Figura 4C) e HSHF (Figura 4D) à microscopia óptica comum (MO).
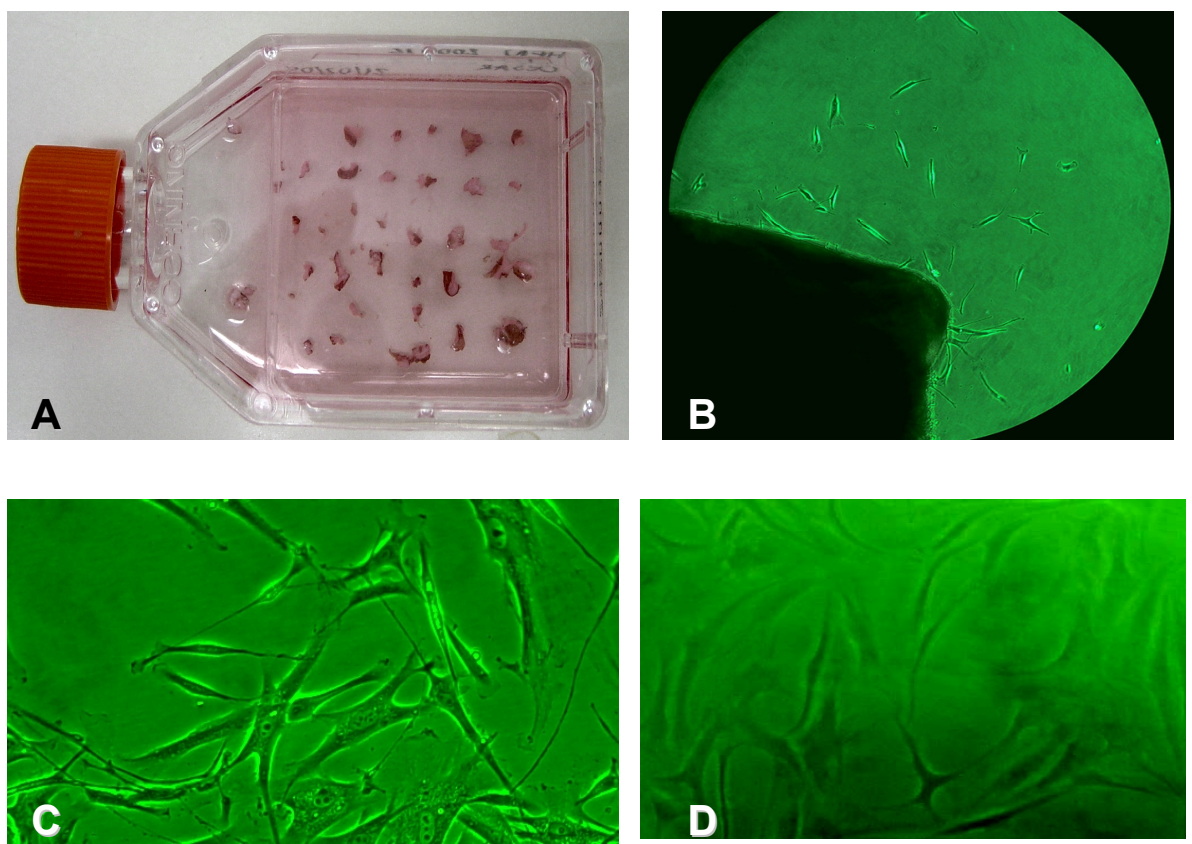

Figura 4 - Cultivo de fibroblastos

Em A: frasco de cultura contendo fragmentos de pele embebidos em meio de cultura; B: fibroblastos migrando a partir do fragmento de pele e aderindo à superfície de cultura do frasco (MO 100X); C: fibroblastos humanos normais (MO 100X); D: fibroblastos humanos derivados de cicatriz hipertrófica (MO 100X). 


\subsection{Ensaios preliminares}

\subsubsection{Determinação do número de amostras de pele}

Para cálculo do número de amostras de tecidos $(n)^{146}$ foi considerada a análise estatística por delineamento fatorial com os seguintes parâmetros previamente fixados: desvio padrão $=1 \times 10^{4}$ células; diferença mínima a ser detectada no número de células $=$ $2 \times 10^{4}$ células; nível de significância de 0,05 (ou $5 \%$ ); dois tipos distintos de tecidos e presença ou não de PTF. Determinou-se serem necessárias, ao menos, oito amostras de tecidos independentes, para que os resultados obtidos nos experimentos apresentassem poder do teste de $95 \%$.

\subsubsection{Mortalidade celular}

Não houve diferença estatisticamente significativa entre as médias de células mortas na presença e ausência de PTF, a cada momento analisado $(p<0,0001)$. Estes dados estão apresentados na Figura 5. 


\section{Mortalidade celular - NHF}

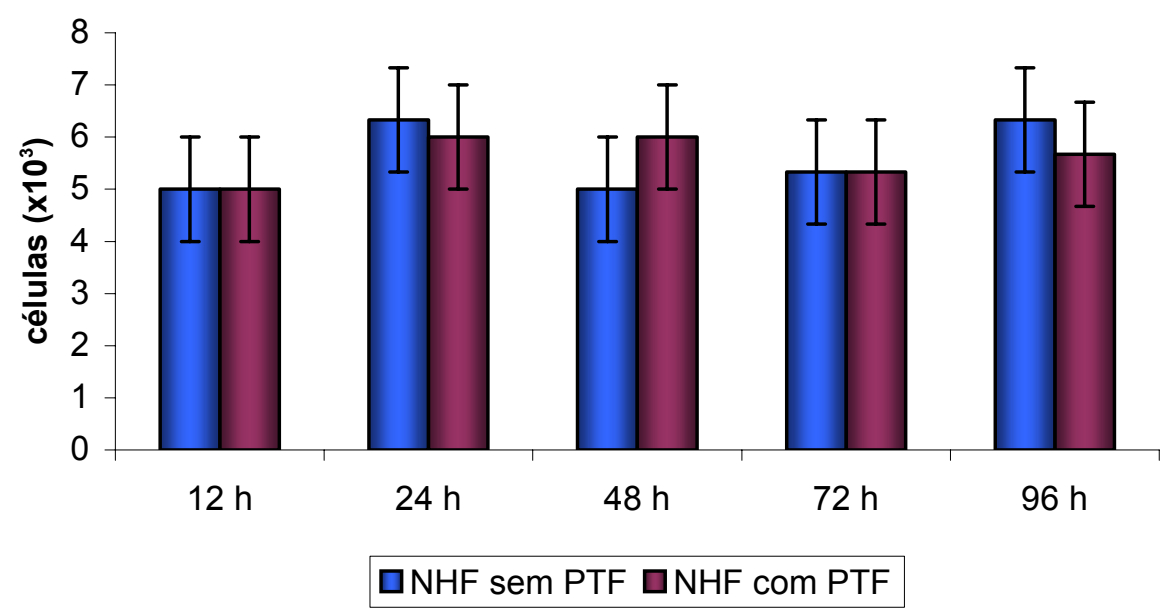

$p<0,0001$

Figura 5 - Comparação da média de células mortas na presença e ausência de PTF nos momentos $12 \mathrm{~h}, 24 \mathrm{~h}$, $48 \mathrm{~h}, 72 \mathrm{~h}$ e $96 \mathrm{~h}$

\subsubsection{Curva de proliferação celular}

A análise dos resultados mostrou que a cada intervalo de tempo houve aumento no número de células. No momento $12 \mathrm{~h}$, o número de células com e sem PTF era igual ( $p=0,0565$, ou seja, $>0,05$ ). Entre 12 h e 24 h, houve aumento discretamente maior no número de células que não foram expostas à PTF. Nos momentos 48 h, 72 h e 96 h, as células na ausência de PTF proliferaram mais.

No momento $48 \mathrm{~h}$, houve um aumento maior no número de NHF sem contato com pentoxifilina (média $2,5 \times 10^{4}$ ), enquanto as células em contato com PTF aumentaram apenas $1,5 \times 10^{4}$, nesse momento já encontramos uma diferença entre o número de células vivas nos dois grupos. Após 72 h de exposição (ou não) à PTF, a diferença 
entre o número de NHF foi da ordem de $3,2 \times 10^{4}$ células e no momento $96 \mathrm{~h}$ foi de, aproximadamente, $5,4 \times 10^{4}$, conforme apresentado na Figura 6.

\section{Curva de Proliferação NHF}

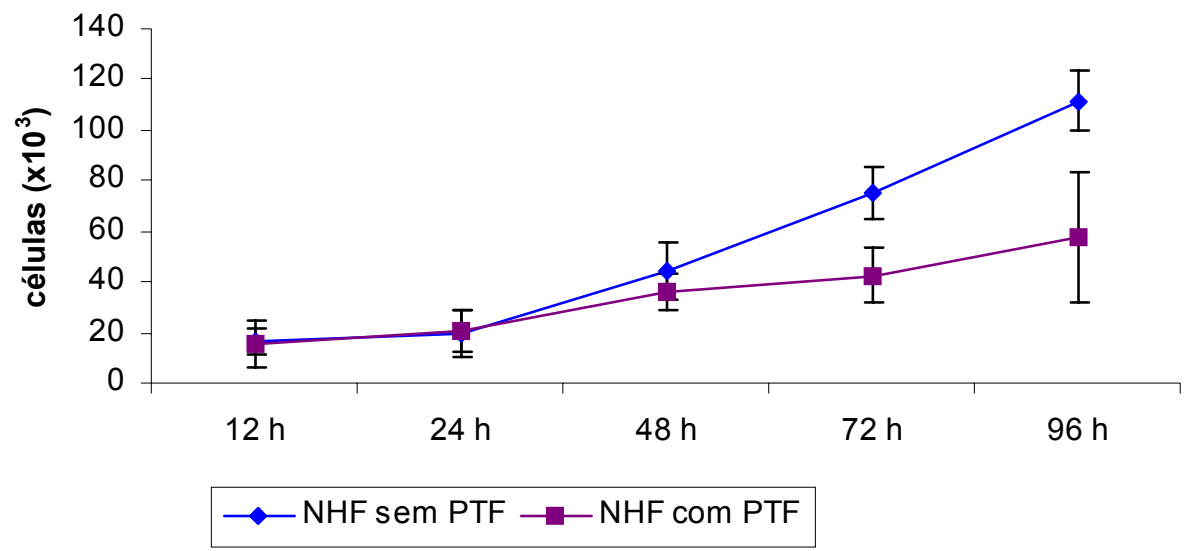

$p<0,0001$

Figura 6 - Curva de proliferação de NHF nos momentos 12 h, 24 h, 48 h, 72 h e 96 h, na presença e ausência de PTF

Tendo sido determinado o número de amostras (n), a ausência de citotoxicidade e o tempo de proliferação celular, descreveremos os resultados obtidos nos experimentos utilizando HSHF e NHF, cuja seqüência está representada na Figura 7. 


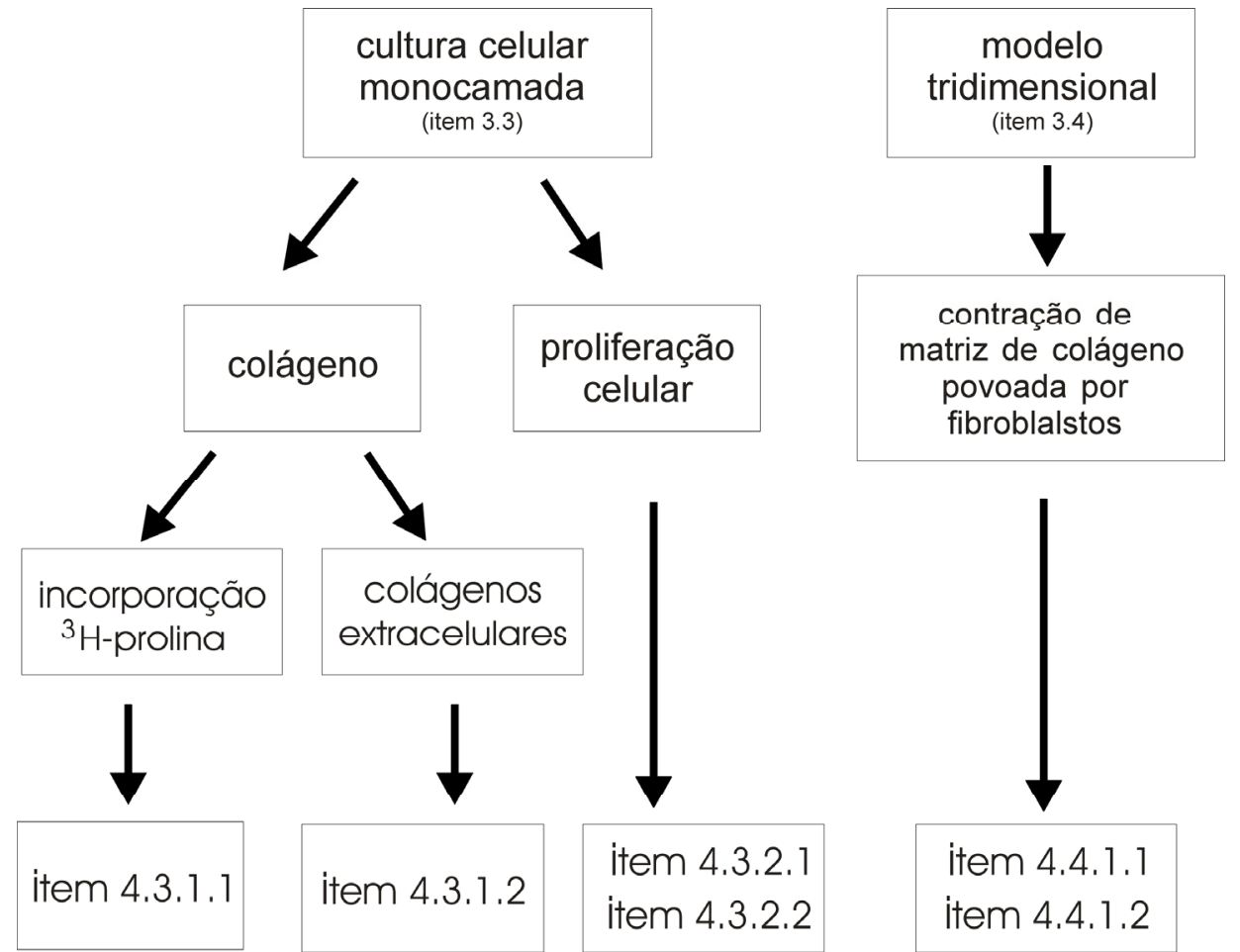

Figura 7 - Fluxograma dos resultados obtidos no estudo, destacando que os resultados correspondentes aos Itens 3.3 e 3.4 encontram-se nos Itens 4.3.1.1; 4.3.1.2; 4.3.2.1; 4.3.2.2;

5.4.1.1; 4.4.1.2

\subsection{Experimentos em cultura de célula em monocamada}

\subsubsection{Análise de colágeno}

\subsubsection{Avaliação quantitativa da incorporação de ${ }^{3} \mathrm{H}$-prolina}

Neste experimento foi avaliado o efeito da PTF sobre a incorporação intracelular de ${ }^{3} \mathrm{H}$-prolina durante a síntese de novas fibras de colágeno, em HSHF e NHF. Os valores médios encontrados em HSHF foram $1,5 \pm 0,4$ na presença de PTF, e $3,1 \pm 1,2\left(x 10^{3} \pm\right.$ DP cpm) na ausência de PTF, o que correspondeu a uma redução de, aproximadamente, $50,84 \%$. Nos NHF, os valores obtidos foram $0,9 \pm$ 
0,2 na presença de PTF e 2,1 $\pm 0,6\left(\times 10^{3} \pm \mathrm{DP}\right.$ cpm) na ausência do fármaco, correspondendo à redução de, aproximadamente, 43,80\% na incorporação de ${ }^{3} \mathrm{H}$-prolina (Figura 8).

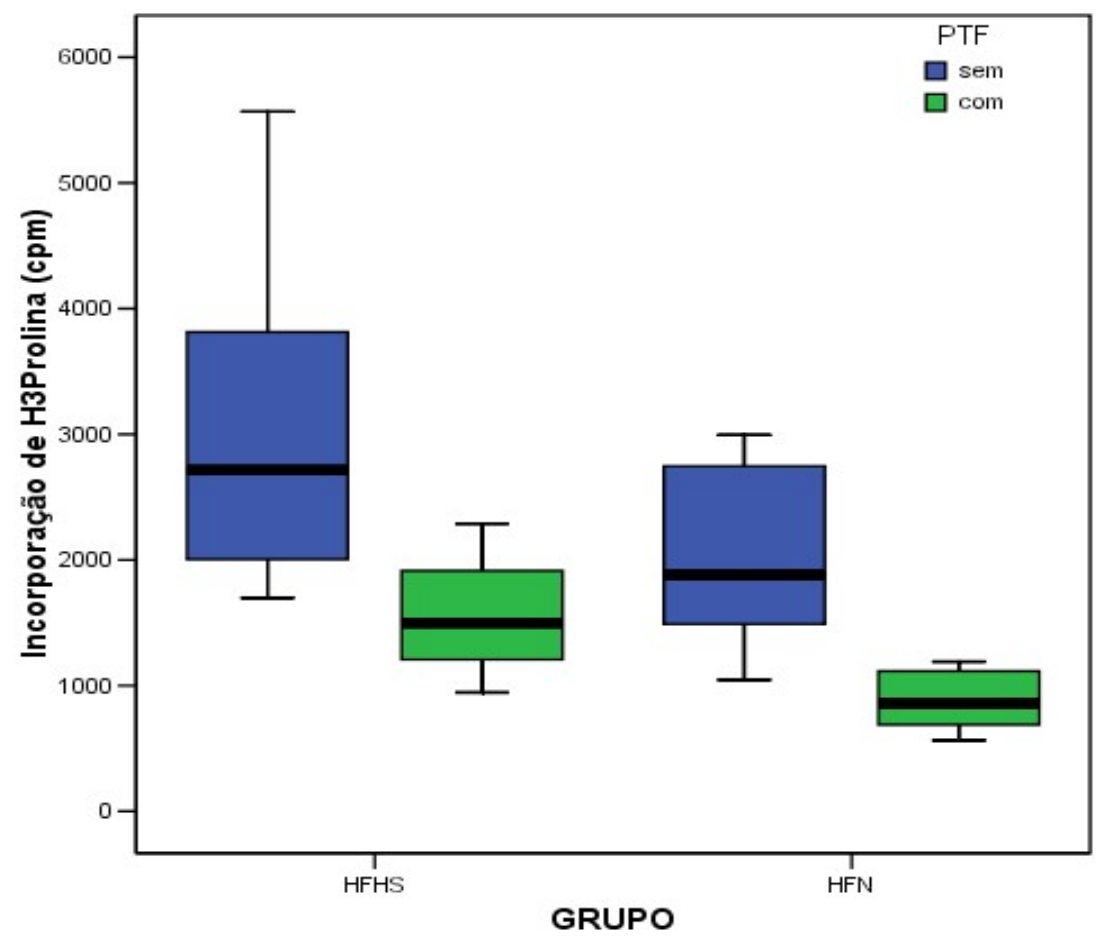

Figura 8 - Box plots (utilizando medianas, máximos e mínimos) comparativos de incorporação de ${ }^{3} \mathrm{H}$-prolina por HSHF e NHF, na presença (verde) e ausência (azul) de PTF

Os contrastes estatísticos das equações de estimação generalizada (EEG) demonstram que não houve interação estatística entre grupos (HSHF e NHF) e PTF, indicando, assim, que os eventos estudados não ocorreram ao acaso, mas sim por influência da PTF (Tabela 5). 
Tabela 5 - Contrastes para EEG de incorporação de ${ }^{3} \mathrm{H}$-prolina

Incorporação de ${ }^{3} \mathrm{H}-p r o l i n a$

ausência PTF / presença PTF

HFHS / HFN

\section{Diferença média}

1314,8

509,3

\section{p-valor}

$<0,0001$

$<0,0001$

Portanto, os níveis de incorporação de ${ }^{3} \mathrm{H}$-prolina foram sempre maiores na ausência de PTF, bem como em fibroblastos oriundos de cicatrizes hipertróficas (HSHF).

\subsubsection{Avaliação semiquantitativa de colágeno I e colágeno III extracelular}

Neste experimento foi avaliada de forma semiquantitativa a imunomarcação de colágeno extracelular tipo I (Foto 2) e tipo III (Foto 3) em culturas de HSHF e NHF, na presença e ausência de PTF. Os escores atribuídos à marcação extracelular de colágeno tipo I em culturas de HSHF diminuiu de 2,60 \pm 0,52, na ausência de PTF, para 2,30 $\pm 0,67$, na presença do fármaco. Já a variação na marcação de colágeno tipo III (em culturas de HSHF) foi de 2,80 \pm 0,42 , na ausência de PTF, para $1,70 \pm 0,48$ em sua presença ( $p<$ 0,0001). Demonstrando, assim, maior variação na marcação de colágeno tipo III (quando comparado ao tipo I) em culturas de HSHF expostas à PTF. 
Em culturas de NHF, notou-se diminuição na expressão de colágeno tipo I de 2,40 $\pm 0,52$, na ausência de PTF, para $1,30 \pm 0,48$ em sua presença. Quanto à imunomarcação de colágeno tipo III não houve modificação nos valores obtidos $(1,60 \pm 0,84)$ na presença ou ausência de PTF $(p<0,0001)$, conforme apresentado na Tabela 6.

Tabela 6 - Escore de fibras colágenas tipo I e III intensamente marcadas, expresso em média e desvios padrões, na presença e ausência de PTF em culturas de HSHF e NHF

\begin{tabular}{cccccc}
\hline Grupo & Tipo de colágeno / PTF & Média & DP & $\mathbf{n}$ \\
\hline \multirow{3}{*}{ HSHF } & tipo I sem PTF & 2,60 & 0,52 & 10 \\
\cline { 2 - 5 } & tipo I com PTF & 2,30 & 0,67 & 10 \\
\cline { 2 - 5 } & tipo III sem PTF & 2,80 & 0,42 & 10 \\
& tipo III com PTF & 1,70 & 0,48 & 10 \\
\hline \multirow{3}{*}{ NHF } & tipo I sem PTF & 2,40 & 0,52 & 10 \\
\cline { 2 - 5 } & tipo I com PTF & 1,30 & 0,48 & 10 \\
\cline { 2 - 5 } & tipo III sem PTF & 1,60 & 0,84 & 10 \\
& tipo III com PTF & 1,60 & 0,84 & 10 \\
\hline
\end{tabular}

A utilização das EEG permitiu comparações entre grupos celulares (HSHF e NHF), tipos de colágeno e presença ou não de PTF. Os resultados dessas comparações indicaram que a interação entre grupo de células (HSHF / NHF), tipo de colágeno (I ou III) e presença (ou não) de PTF, apresentou significância estatística ( $p<$ 0,0001). Essa interação estatística demonstrou que os escores atribuídos em presença e ausência de PTF (que traduzem o percentual de fibras colágenas intensamente imunomarcadas) são diferentes entre os tipos I e III de colágeno, dentro do mesmo grupo 
de fibroblastos (HSHF ou NHF) $(p<0,0001)$, conforme se observa nas Figuras 9 e 10.

Imunomarcação de colágeno extracelular em HSHF

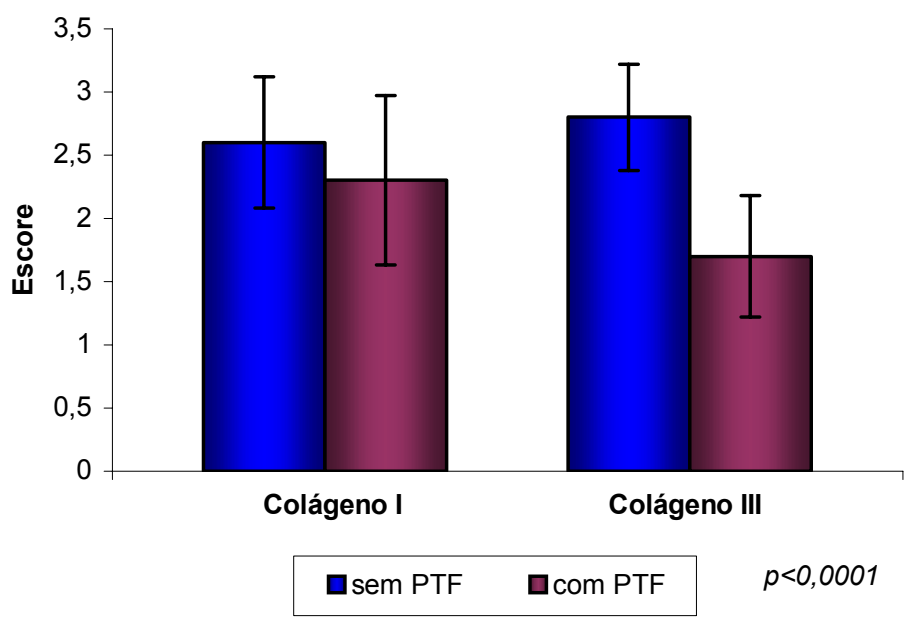

Figura 9 - Escore de imunomarcação de colágeno extracelular tipo I e tipo III em HSHF, na presença e ausência de PTF (média \pm DP)

Imunomarcação de colágeno extracelular em NHF

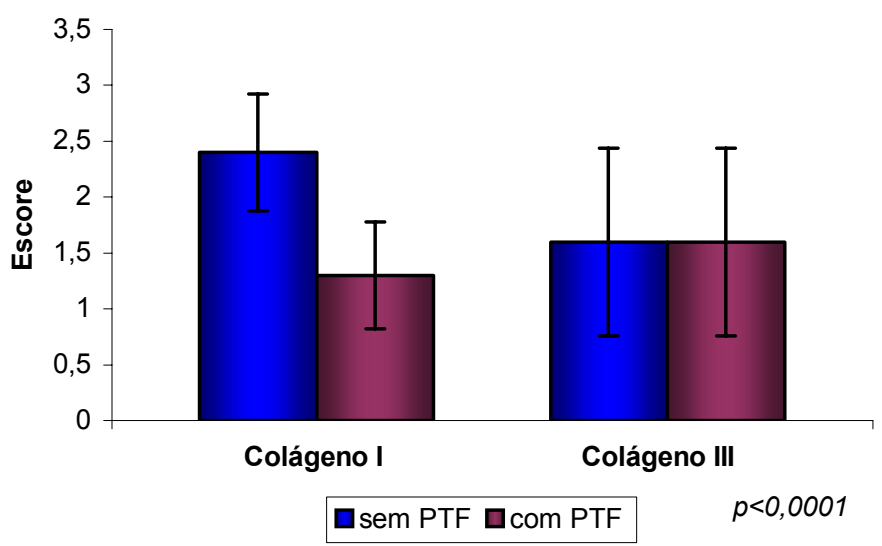

Figura.10 - Escore de imunomarcação de colágeno extracelular tipo I e tipo III em NHF, na presença e ausência de PTF (média \pm DP) 

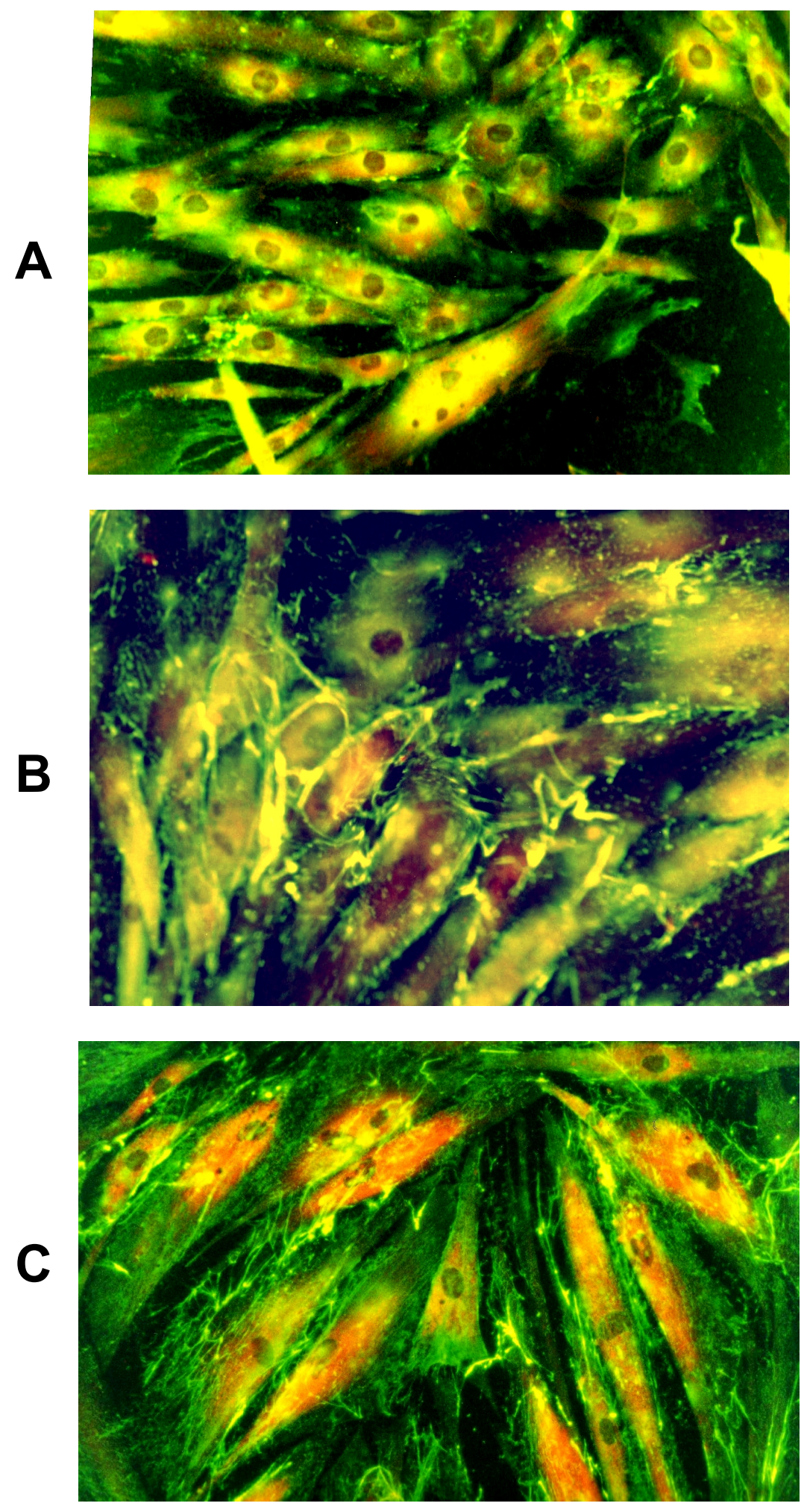

Foto 2 - Imunofluorescência extracelular para colágeno tipo III. Escore A. escore 1 (até 30\%); B. escore 2 (31 a 60\%); C. escore 3 (61 a 100\%) - 100x. 

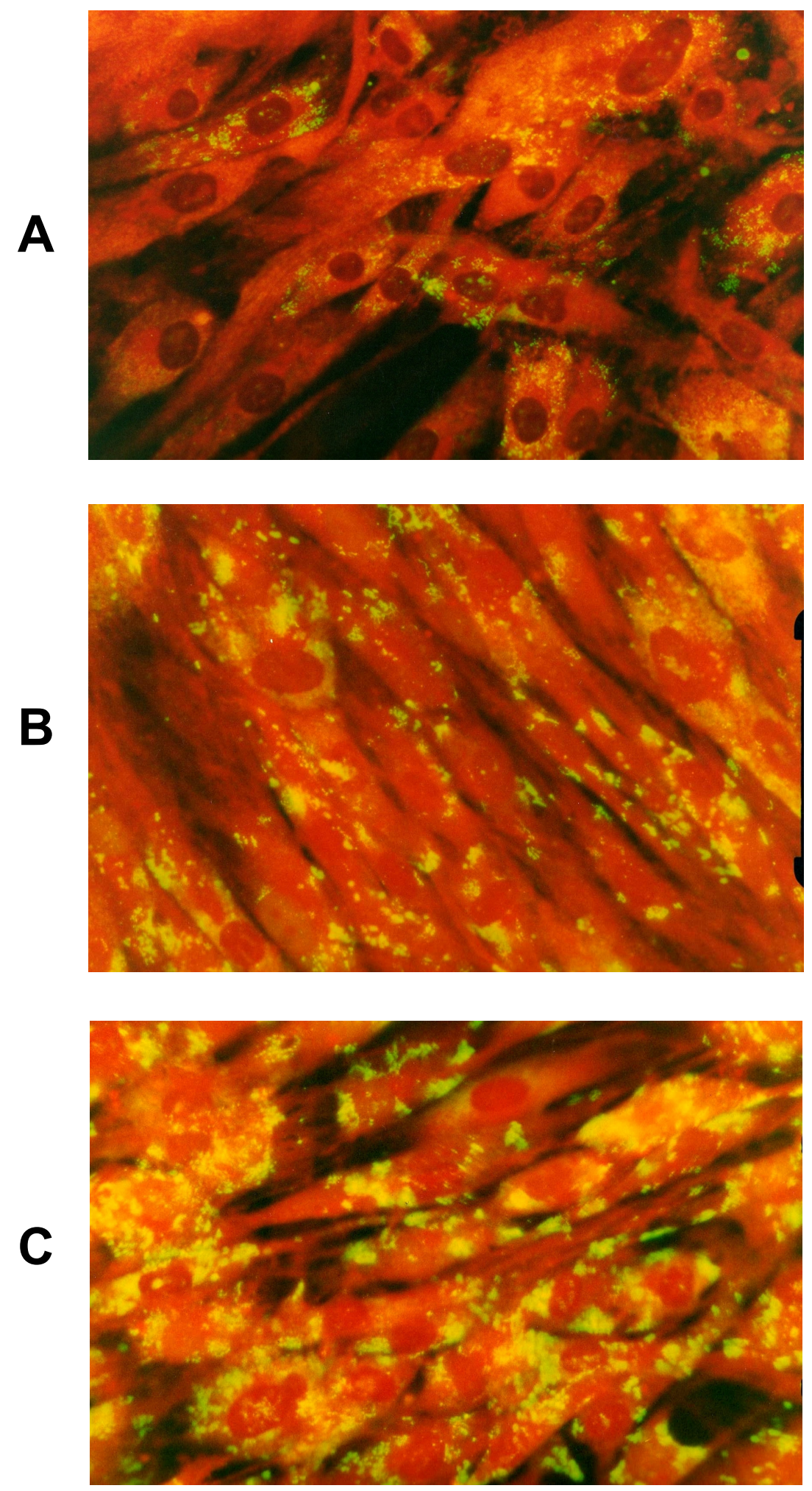

Foto 3 - Imunofluorescência extracelular para colágeno tipo III. Escore A. escore 1 (até $30 \%$ ); B. escore 2 (31 a 60\%); C. escore 3 (61 a 100\%) - 100x. 


\subsubsection{Proliferação de HSHF e NHF}

Recapitulando os resultados obtidos nos ensaios preliminares, temos que: (1) PTF (1.000 $\mu \mathrm{g} / \mathrm{mL})$ não é tóxica para fibroblastos; (2) mesmo na presença de PTF houve proliferação celular, durante as 96 horas de duração do experimento; (3) a proliferação celular estava diminuída na presença de PTF e essa inibição não decorreu de maior mortalidade celular. Considerando-se, ainda, que o número de células encontradas após 96 horas de cultivo representou a proliferação celular nesse período de tempo. Analisaremos, a seguir, os efeitos da PTF nas proliferações de NHF e HSHF.

\subsubsection{Proliferação HSHF}

Partindo-se de $1 \times 10^{4}$ células, após 96 horas de exposição, ou não, à pentoxifilina, verificamos que, na presença de PTF, a proliferação de HSHF diminuiu de 5,82 $\pm 1,8$ para 2,69 $\pm 1,1\left(\times 10^{4}\right.$ células), o que corresponde a $46 \%$ do total de células na ausência de PTF (Tabela 7 e Figura 11).

Tabela 7 - Número de HSHF após 96 horas de exposição (ou não) à PTF

\section{Proliferação HSHF $\left(\times 10^{4}\right.$ células $)$}

\begin{tabular}{lccc} 
GRUPO & PTF & Média & Desvio padrão \\
HFHS & não & 5,82 & 1,8 \\
& sim & 2,69 & 1,1 \\
\hline
\end{tabular}




\section{Proliferação HSHF}

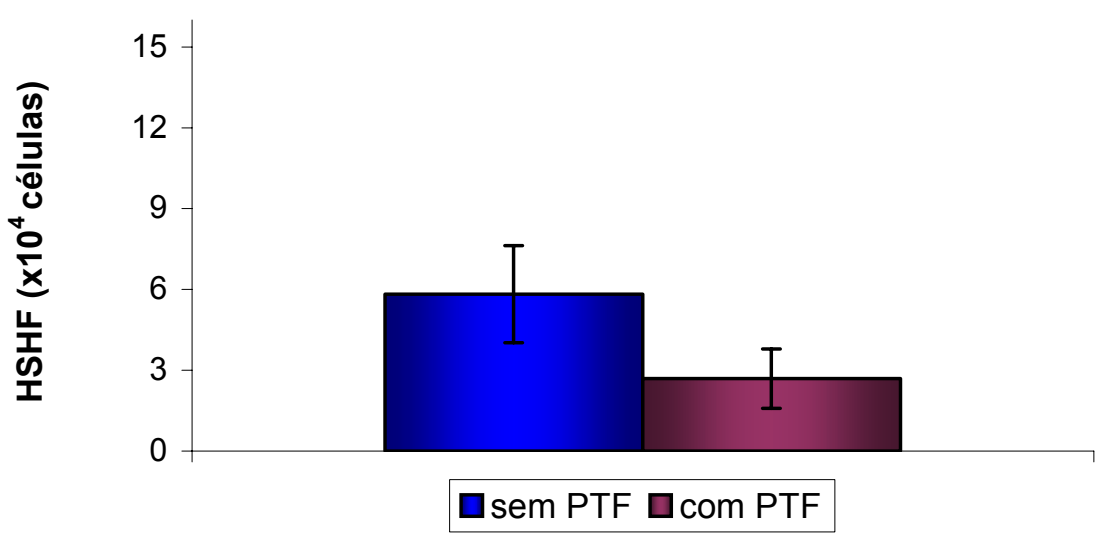

Figura 11 - Proliferação de HSHF na presença e ausência de PTF

\subsubsection{Proliferação NHF}

Partindo-se de $1 \times 10^{4}$ células, após 96 horas de exposição, ou não, à pentoxifilina, verificamos que a proliferação dos NHF diminuiu de $9,87 \pm 4,9$ para $3,73 \pm 2,6$ ( $\times 10^{4}$ células), o que corresponde a $38 \%$ do total de células na ausência de PTF (Tabela 8 e Figura 12)

Tabela 8 - Número de NHF após 96 horas de exposição (ou não) à PTF

\section{Proliferação NHF ( $\times 10^{4}$ células)}

\begin{tabular}{lccc} 
GRUPO & PTF & Média & Desvio padrão \\
\multirow{2}{*}{ NHF } & não & 9,87 & 4,9 \\
& sim & 3,73 & 2,6 \\
\hline
\end{tabular}




\section{Proliferação NHF}

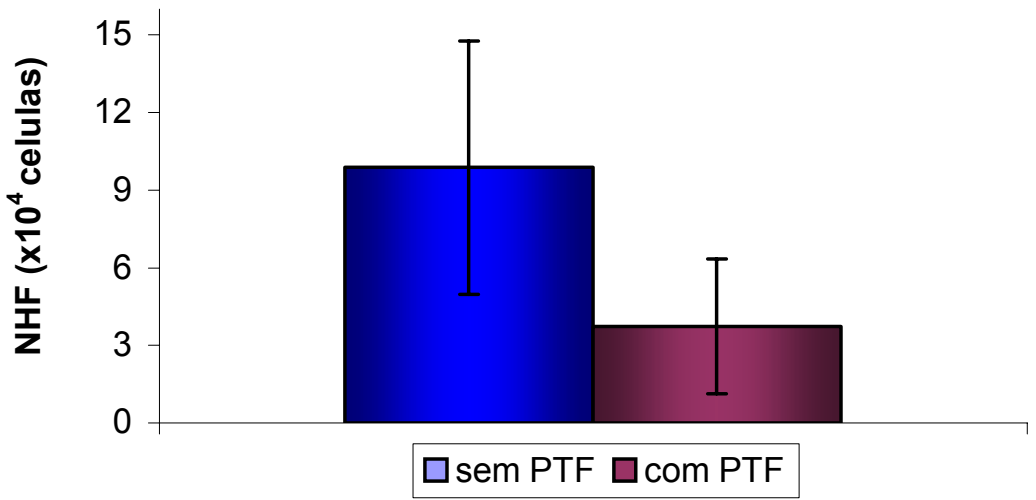

Figura 12 - Proliferação de NHF na presença e ausência de PTF

A análise dos contrastes das EEG para interação entre PTF e grupo celular (HSHF e NHF) revelou que a diferença entre o número de células na presença e ausência de PTF não é similar entre esses grupos. A pentoxifilina reduziu o número de células em ambos os grupos $(p<0,0001)$ (Tabela 9).

Tabela 9 - Contrastes para a EEG da interação entre uso de PTF e grupo celular (NHF e HSHF)

\begin{tabular}{|c|c|c|}
\hline Contraste & $\begin{array}{l}\text { Estimativa da diferença média } \\
\qquad\left(\times 10^{4} \text { células }\right)\end{array}$ & p-valor \\
\hline com / sem PTF - HSHF & $-3,2$ & $<0,0001$ \\
\hline com / sem PTF - NHF & $-6,1$ & $<0,0001$ \\
\hline
\end{tabular}




\subsection{Modelo tridimensional de contração}

A contração do modelo in vitro de matriz de colágeno povoado por células permite estabelecer a correlação com fenômenos in vivo.

\subsubsection{Modelo de contração de matriz extracelular de colágeno povoada por fibroblastos}

Utilizando o programa de computador Image Tool for Windows, versão 3.0, calculou-se o número de pixels correspondentes às áreas de matriz polimerizada e de seu respectivo poço. Como a área do poço é conhecida $\left(1,96 \mathrm{~cm}^{2}\right)$, foi possível converter esses valores e expressá-los em $\mathrm{cm}^{2}$.

\subsubsection{Contração de matriz povoada por HSHF}

As matrizes povoadas por HSHF, na presença ou ausência de PTF, apresentavam, no início do experimento, área igual à do poço de cultura, ou seja $1,96 \mathrm{~cm}^{2}$. Após 24 horas, o valor médio dessas áreas era 1,32 $\pm 0,20 \mathrm{~cm}^{2}$ na ausência de PTF e 1,52 \pm $0,13 \mathrm{~cm}^{2}$ na presença do fármaco, indicando inibição de contração, promovida pela PTF, de aproximadamente $13 \%$. Após 48 horas de exposição à PTF, as matrizes mediam 1,24 \pm $0,24 \mathrm{~cm}^{2}$ na ausência do fármaco e 1,44 $\pm 0,12 \mathrm{~cm}^{2}$ na presença 
de PTF. O que, novamente, indicou inibição da contração de aproximadamente 14\% (Tabela 10 e Figura 13).

Tabela 10 - Contração de matriz de colágeno povoada por HSHF

\begin{tabular}{ccccc}
\multicolumn{5}{c}{ Contração de matriz de colágeno povoada por $\mathrm{HSHF}\left(\mathbf{c m}^{2}\right)$} \\
PTF & Tempo & Média & Desvio padrão & p-valor \\
\hline \multirow{4}{*}{ sem } & $0 \mathrm{~h}$ & 1,96 & 0,0 & \\
& $24 \mathrm{~h}$ & 1,32 & 0,2 & $<0,0001$ \\
& $48 \mathrm{~h}$ & 1,24 & 0,24 & \\
\hline \multirow{4}{*}{ com } & $0 \mathrm{~h}$ & 1,96 & 0,0 & \\
& $24 \mathrm{~h}$ & 1,52 & 0,13 & $<0,0001$ \\
& $48 \mathrm{~h}$ & 1,44 & 0,12 & \\
\hline
\end{tabular}

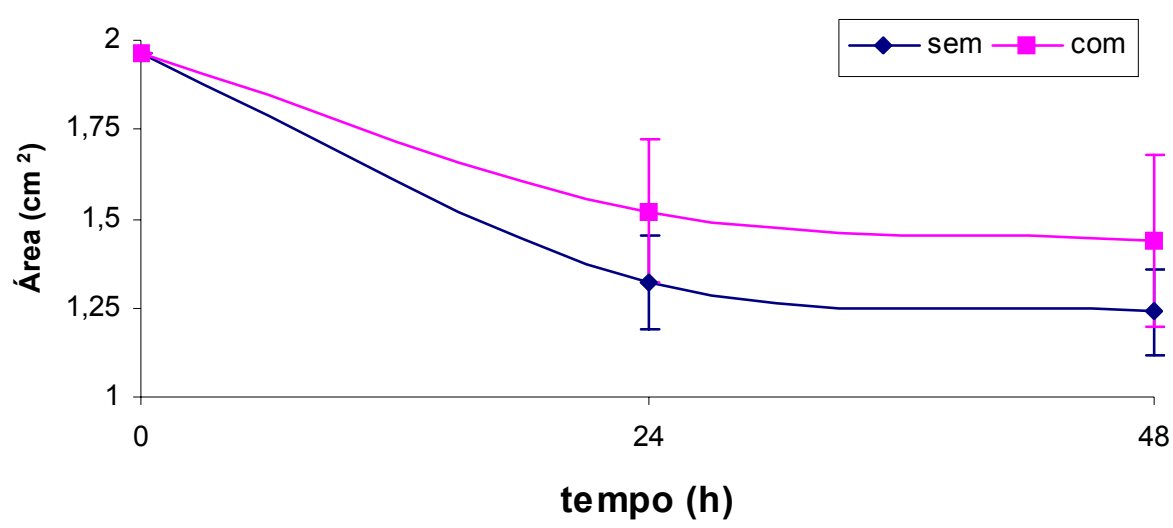

Figura 13 - Contração de matriz de colágeno povoada por HSHF na presença e ausência de PTF 


\subsubsection{Contração de matriz povoada por NHF}

As matrizes povoadas por NHF, na presença ou ausência de PTF, também apresentavam, no início do experimento, área igual à do poço de cultura, ou seja $1,96 \mathrm{~cm}^{2}$. Após 24 horas, o valor médio dessas áreas era 1,46 $\pm 0,11 \mathrm{~cm}^{2}$ na ausência de PTF e 1,59 $\pm 0,08 \mathrm{~cm}^{2}$ na presença do fármaco, indicando inibição de contração, promovida pela PTF, de aproximadamente $8 \%$. Após 48 horas de exposição à PTF, as matrizes mediam $1,37 \pm 0,12 \mathrm{~cm}^{2}$ na ausência do fármaco e 1,53 $\pm 0,09 \mathrm{~cm}^{2}$ na presença de PTF. O que, novamente, indicou inibição da contração de aproximadamente $10 \%$ (Tabela 11 e Figura 14).

Tabela 11 - Contração de matriz de colágeno povoada por NHF

\begin{tabular}{lcccc}
\multicolumn{4}{c}{ Contração de matriz de colágeno povoada por NHF $\left(\mathbf{c m}^{2}\right)$} \\
\hline PTF & Tempo & Média & Desvio padrão & $\mathrm{p}$ - valor \\
\hline \multirow{2}{*}{ Sem } & $0 \mathrm{~h}$ & 1,96 & 0,00 & \\
& $24 \mathrm{~h}$ & 1,46 & 0,11 & $<0,0001$ \\
& $48 \mathrm{~h}$ & 1,37 & 0,12 & \\
\hline \multirow{2}{*}{ Com } & $0 \mathrm{~h}$ & 1,96 & 0,00 & $<0,0001$ \\
& $24 \mathrm{~h}$ & 1,59 & 0,08 & \\
\hline
\end{tabular}




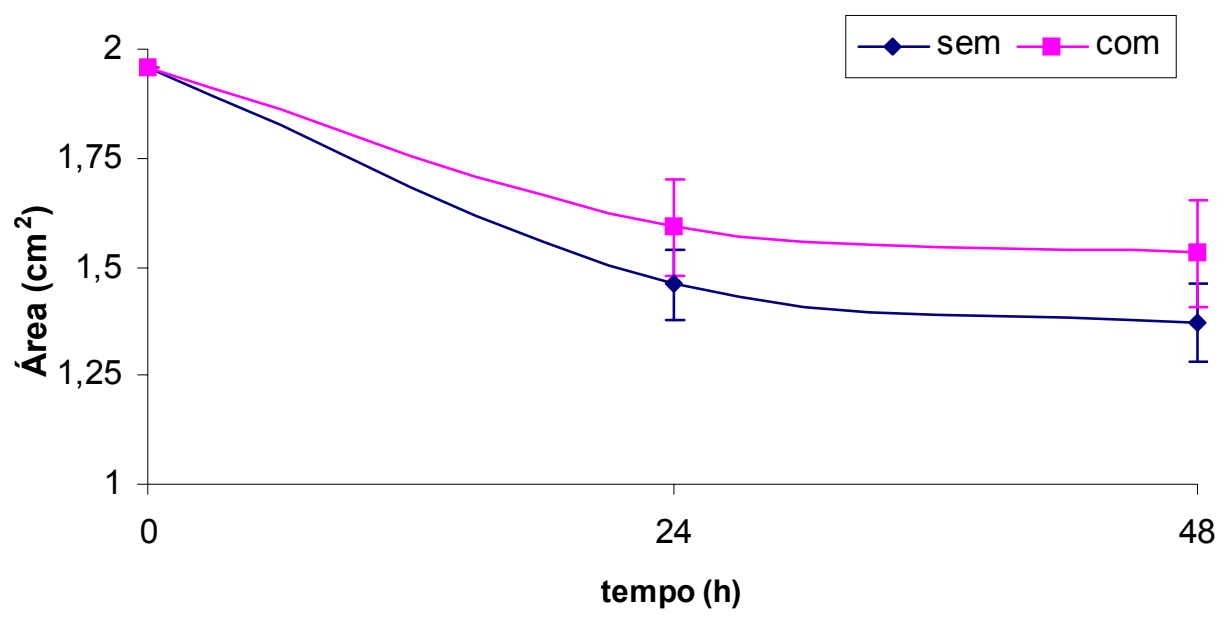

Figura 14 - Contração de matriz de colágeno povoada por NHF na presença e ausência de PTF

As interações entre presença ou ausência de PTF, grupo de células e tempo de experimento, utilizando Equações de Estimação Generalizada mostraram significância estatística $(p<0,0001)$. De acordo com essas equações, houve efeito da droga (as áreas se mostraram diferentes entre o uso ou não da droga), de tempo (as áreas são diferentes em pelo menos um dos três tempos) e de interação entre droga e tempo. A evolução (contração) da área no tempo é diferente entre o grupo com e sem a droga (as curvas não são paralelas).

Existem diversas possibilidades de comparações estatísticas entre o dados obtidos, mas nem todas apresentam significância estatística, conforme se pode observar na Tabela 12. 
Tabela 12 - Comparações (ou contrastes) entre grupo celular (NHF e HSHF), exposição ou não à pentoxifilina e tempo de exposição

\begin{tabular}{cc}
\hline Contrastes & $\mathbf{p}$ - valor \\
\hline Droga não X sim - 0h & 1,000 \\
Droga não X sim - 24h & 0,003 \\
Droga não X sim - 48h & 0,002 \\
\hline Droga não - 0h X 24h & $<0,0001$ \\
Droga não - Oh X 48h & $<0,0001$ \\
Droga não - 24h X 48h & 0,176 \\
\hline Droga sim - Oh X 24h & $<0,0001$ \\
Droga sim - 0h X 48h & $<0,0001$ \\
Droga sim - 24h X 48h & 0,240 \\
\hline
\end{tabular}

As comparações múltiplas (ou contrastes) indicaram que as áreas iniciais (hora zero) em ambos os grupos, com e sem PTF, eram iguais ( $p=$ $1,000)$, porém diferiam nos momentos $24 \mathrm{~h}(p=0,003)$ e $48 \mathrm{~h}(p=0,002)$.

Analisando o grupo sem uso de PTF, notamos que houve diminuição significativa do momento hora zero para o momento $24 \mathrm{~h}(p<0,0001)$, e que a área do momento hora zero era diferente daquela do momento $48 \mathrm{~h}(p<$ 0,0001), mas a comparação das áreas entre os momentos $24 \mathrm{~h}$ e $48 \mathrm{~h}$ indicou que estas eram estatisticamente iguais $(p=0,176)$. 0 mesmo ocorreu para o grupo com PTF. 


\section{Discussão}




\section{Discussão}

Os experimentos que compõem esta tese foram realizados com fibroblastos oriundos de pele não-cicatricial (denominada pele normal), obtidos dos excedentes dérmicos provenientes de mastoplastia, e fibroblastos oriundos de cicatrizes hipertróficas localizadas em tórax anterior, com mais de dois anos de existência, doados pelo Banco de Tecidos do $\mathrm{ICHC}$

A caracterização das cicatrizes hipertróficas foi clínica, observando-se: aspecto das cicatrizes, tempo de existência e localização. Como descrito anteriormente (Item 2.2.2), cicatrizes hipertróficas são elevadas acima da superfície da pele, mas não ultrapassam as bordas originais da lesão. Por existir possibilidade de regressão espontânea, foram selecionadas somente aquelas que não apresentavam modificação macroscópica havia mais de dois anos. Para que o comportamento das células HSHF e NHF pudesse ser pareado foram eleitas somente cicatrizes localizadas em tórax anterior de pacientes do sexo feminino, uma vez que a pele não-cicatricial era proveniente de excesso de mastoplastia e o tórax anterior é uma das regiões anatômicas de incidência desse tipo de cicatriz.

A técnica escolhida para obtenção de fibroblastos a partir de amostras de pele foi a descrita por Carrel em 1910 (na qual fragmentos dermoepidérmicos são depositados em garrafas apropriadas e as células migram 
destes fragmentos para a superfície de cultivo das garrafas), com meio de cultura apropriado para obtenção e multiplicação dos fibroblastos. ${ }^{141}$

A multiplicação dos fibroblastos (HSHF e NHF) dentro das garrafas de cultivo foi observada à microscopia óptica. Não foram visualizadas diferenças morfológicas entre HSHF e NHF permitindo-nos inferir que, apesar de apresentarem funções diferentes, essas células não evidenciaram, à MO, modificações em sua morfologia conforme é descrito na literatura ${ }^{147}$ (Figuras 4C e 4D - pág.86).

Pentoxifilina é uma substância derivada da dimetilxantina, consagrada no tratamento não-cirúrgico da claudicação intermitente e de outras complicações de insuficiência arterial periférica. ${ }^{148}$ Ely, ${ }^{149} \mathrm{em} \mathrm{1988,} \mathrm{relatou} \mathrm{o}$ amaciamento de quelóides gigantes em três pacientes que faziam uso desse fármaco para tratamento de outras enfermidades.

Duncan et al. ${ }^{130}$ demonstram que, dentre as diversas xantinas, a PTF, na concentração de $1000 \mu \mathrm{g} / \mathrm{mL}$, apresentava, não somente melhor desempenho inibidor de proliferação in vitro de fibroblastos, como também dificultava a expressão do fator nuclear 1 responsável pela produção dos pró-colágenos I e III, sugerindo, assim, provável "desvio" na síntese de colágeno. A concentração de PTF adotada neste estudo foi baseada nessa descrição.

Previamente aos ensaios de avaliação de colágeno, proliferação celular e contração de modelo experimental, foi realizado um ensaio de proliferação de NHF para determinarmos: (1) o número de amostras de tecido necessário para validação estatística dos resultados obtidos (Item 4.2.1); (2) se a 
pentoxifilina não poderia ser tóxica aos fibroblastos (Item 4.2.2) e (3) se haveria modificação na proliferação celular em presença desse fármaco (Item 4.2.3).

Para o cálculo do número de amostras de pele necessário para validação estatística, foi considerada a análise estatística por delineamento fatorial com os seguintes parâmetros previamente fixados: desvio padrão $=$ $1 \times 10^{4}$ células; diferença mínima a ser detectada no número de células = $2 \times 10^{4}$ células; nível de significância de 0,05 (ou 5\%); dois tipos distintos de tecidos e presença ou não de PTF. Dessa forma, foi determinado serem necessárias, ao menos, oito amostras de tecidos independentes, para que os resultados obtidos nos experimentos apresentassem poder do teste de 95\%. Optamos por realizar cada experimento com 10 (dez) amostras de tecidos independentes (pele não-cicatricial e cicatriz hipertrófica).

Neste estudo preliminar, pudemos ainda observar que não houve diferença estatisticamente significativa entre as médias de NHF mortos (nos momentos 12 h, 24 h, 48 h, 72 h e 96 h) na presença e ausência de PTF (Figura 5), o que corresponde aos achados descritos por Berman e Duncan. $^{15}$

Da mesma forma, notamos que o número de células vivas era diferente nas duas situações (presença e ausência de PTF), sendo maior na ausência do fármaco, quando comparado com o número de células expostas a ele. Essa diferença tornou-se mais evidente a partir do momento $24 \mathrm{~h}$, chegando a valores médios de $5,4 \times 10^{4}$ células no momento $96 \mathrm{~h}$, o que, uma vez mais, está de acordo com os autores supracitados. 
Os resultados obtidos neste estudo preliminar possibilitaram-nos, então, afirmar que houve interferência do fármaco no comportamento celular, uma vez que o número de fibroblastos humanos normais estava diminuído na presença de PTF e que essa interferência não se deveu à toxicidade celular, pois não foi observado aumento de mortalidade celular provocada pelo fármaco, mas sim a um efeito inibidor da proliferação celular (Figura 6).

$\mathrm{Na}$ análise estatística dos resultados de todos os experimentos, foram utilizados estudos longitudinais que são investigações cujo interesse é avaliar o comportamento de uma variável ao longo do tempo, ou de uma dimensão específica. Esse tipo de estudo também é conhecido como estudo de coortes, estudo tipo follow-up ou dados de painel. Pode-se incluir nos estudos longitudinais aqueles com interesse em dados correlacionados, ou seja, em que se evidenciam repetições da unidade de observação, neste caso, os pacientes.

Nossa unidade experimental foi o paciente (com amostras de pele expostas ou não à pentoxifilina), em algumas situações as amostras de pele foram avaliadas em diferentes momentos. Como as variáveis (respostas) são medidas em um mesmo paciente, é importante considerar a dependência entre os dados (correlação).

As Equações de Estimação Generalizadas (EEG) levam em consideração essa correlação, além de permitir o ajuste de outras distribuições da família exponencial, além da distribuição normal. 
Depois de construídas as EEG, os contrastes foram realizados para auxiliar a interpretação de seus parâmetros.

Com base nos resultados preliminares, iniciamos os ensaios para avaliar os efeitos in vitro da PTF sobre o colágeno produzido por fibroblastos.

Como descrito anteriormente (Item 2.2.1.9), as fibras colágenas são constituídas por uma escleroproteína denominada colágeno, cuja composição de aminoácidos é bem característica. O aminoácido glicina aparece no colágeno na proporção de $33,5 \%$, enquanto prolina e hidroxiprolina estão presentes na proporção de $12 \%$ e $10 \%$, respectivamente. O restante é formado por outros aminoácidos, sendo aminoácidos sulfurados e tirosina pouco freqüentes. Colágeno e elastina são as únicas proteínas que contêm hidroxiprolina em concentrações diferentes, assim, podemos determinar o teor dessas proteínas num tecido pela dosagem de prolina ou sua forma hidroxilada (hidroxiprolina). ${ }^{60150}$

Com isso, uma maneira indireta de se avaliar a síntese de colágeno por HSHF e NHF é medir a incorporação intracelular de prolina. Para tanto, foi utilizada ${ }^{3} \mathrm{H}$-prolina e sua incorporação foi medida em equipamento analisador de cintilação.

Berman e Duncan, ${ }^{15}$ utilizando metodologia semelhante àquela adotada por nós, descreveram redução de, aproximadamente, 34\% na incorporação de ${ }^{3} \mathrm{H}$-prolina por fibroblastos dérmicos normais (NHF), na presença de pentoxifilina Em nosso estudo, a presença de PTF diminuiu 43,80\% a 
incorporação de ${ }^{3} \mathrm{H}$-prolina $(p<0,0001)$. Esses dados foram concordantes com a literatura médica.

Quanto à incorporação de ${ }^{3} \mathrm{H}$-prolina por fibroblastos oriundos de cicatrizes hipertróficas, observamos que houve diminuição de 50,84\% na presença de pentoxifilina $(p<0,0001)$ (Figura 8). Não existem estudos na literatura mundial com os quais pudéssemos comparar nossos achados, porém (baseados na coincidência de resultados dos experimentos realizados em NHF), inferimos que nossos resultados sejam verdadeiros.

Os contrastes estatísticos das EEG (Tabela 5) demonstram que não houve interação estatística entre grupos (HSHF / NHF) e PTF, indicando, assim, que os eventos estudados não ocorreram ao acaso, mas por influência da PTF. Portanto, os níveis de incorporação de ${ }^{3} \mathrm{H}$-prolina foram sempre menores na presença de PTF.

Colágenos tipo I e III são os maiores constituintes da derme humana representando, respectivamente, 80 a $86 \%$ e 6 a $12 \%$ do total de colágenos presentes na pele. Esses colágenos são os que têm maior participação no processo de cura das feridas. Bezerra et al., ${ }^{151}$ em 2006, confirmam, em modelo animal, a interação entre colágenos I, III e V na remodelagem dérmica associada a processos fibróticos, como cicatrizes hipertróficas.

Em feridas agudas, a síntese de colágeno tipo III inicia-se imediatamente, enquanto a síntese do colágeno tipo I tem início aproximadamente 72 horas após a lesão. Nas feridas imaturas, a quantidade de colágeno tipo III torna-se superior à quantidade do colágeno tipo I. ${ }^{152}$ 
Verifica-se que durante o processo de reparo, a quantidade total de colágenos tipo I e III nas cicatrizes fisiológicas aumenta com o passar do tempo, porém a proporção entre eles não é constante, variando de $60 \%$ de colágeno tipo III na primeira semana pós-trauma a $28 \%$ nas cicatrizes maduras. ${ }^{112}$

Em cicatrizes excessivas, a quantidade de colágeno tipo III permanece aumentada, se comparada à pele normal ou à cicatriz fisiológica. ${ }^{114} \mathrm{~A}$ proporção entre colágenos tipo III e tipo I é variável. Na pele normal, essa relação é de aproximadamente $17 \%$ de colágeno tipo III, enquanto no quelóide corresponde a cerca de $61 \%$ do colágeno total ali presente (Tabela 4). No processo de reparação, essa relação tende a diminuir gradativamente até atingir a proporção normal em um período aproximado de dois anos. ${ }^{153}$

Em cicatrizes hipertróficas, as fibrilas de colágeno possuem maior solubilidade ácida, diminuição no número de ligações cruzadas dependentes de lisil-oxidase e deficiência de amadurecimento, quando comparadas ao colágeno normal. ${ }^{117}$

Como descrito anteriormente (Item 2.4), células mantidas em cultura freqüentemente apresentam características semelhantes à sua origem, ou seja, fibroblastos tendem a se comportar como se estivessem numa ferida aguda, reproduzindo in vitro o processo de reparo tissular (fisiológico, quando utilizamos culturas de NHF e patológico, quando as culturas forem de HSHF).

Em nossos experimentos de avaliação das quantidades de colágeno tipo I e tipo III na presença e ausência de PTF, foi adotado método 
semiquantitativo de escores atribuídos ao percentual de imunomarcação de fibras colágenas extracelulares, conforme empregado por Velosa, ${ }^{154} \mathrm{em}$ 2007, na sua tese de doutorado e validado na literatura médica. ${ }^{155}$

Nossos resultados indicaram seletividade na inibição do tipo de colágeno, ou seja, em culturas de HSHF houve inibição estatisticamente significativa de colágeno tipo III, sem alteração na quantidade de colágeno tipo I (Figura 9 - pág. 94), enquanto em culturas de NHF a inibição predominante foi de colágeno tipo I (Figura 10 - pág. 94).

A utilização das EEG permitiu comparações entre grupos celulares (HSHF e NHF), tipos de colágeno e presença ou não de PTF. Os resultados dessas comparações indicaram que a interação entre células (HSHF ou NHF), tipo de colágeno (I ou III) e presença (ou não) de PTF apresentou significância estatística $(p<0,0001)$. Essa interação estatística demonstrou que os escores atribuídos em presença e ausência de PTF (que traduzem o percentual de fibras colágenas intensamente imunomarcadas) são diferentes entre os tipos I e III de colágeno, dentro do mesmo grupo de fibroblastos (HSHF ou NHF) $(p<0,0001)$.

Apesar da significância estatística dos resultados, a metodologia empregada não nos permitiu identificar se essa seletividade inibitória decorreu de interação específica entre células (NHF ou HSHF) e pentoxifilina ou, se devido ao aumento de colágeno tipo III (abundantemente presente em cicatrizes hipertróficas. Item 2.2.3), pudemos observar essa tendência nos experimentos realizados em HSHF. Estudos complementares são necessários para elucidar esse fato. 
Não existem na literatura mundial estudos avaliando colágeno tipo I e tipo III em culturas de fibroblastos derivados de cicatrizes hipertróficas, na presença e ausência de PTF, com o qual pudéssemos comparar nossos achados (Item 4.3.1.2), porém os resultados obtidos utilizando-se NHF, nas mesmas condições, corresponderam àqueles descritos por Duncan et al. ${ }^{130}$ Outros estudos em modelo animal e in vitro também comprovaram o efeito inibidor de pentoxifilina sobre a síntese de colágenos. 156157158159

Outra característica do processo de reparo tissular que as culturas de fibroblastos reproduzem é a proliferação celular, ou seja, sua multiplicação num período de tempo. À medida que fibroblastos proliferam na ferida, sofrem modificação de fenótipo, ganhando motilidade, o que facilita a reconstrução da matriz extracelular perdida.

Em nosso estudo, partindo-se de $1 \times 10^{4}$ células, após 96 horas de exposição, ou não, à pentoxifilina, verificamos que, na presença de PTF, a proliferação de HSHF diminuiu de $5,82 \pm 1,8$ para $2,69 \pm 1,1$ (x10 ${ }^{4}$ células), $(p<0,0001)$, sendo equivalente a $46 \%$ do total de células obtido na ausência de PTF (Figura 11), enquanto a proliferação dos NHF diminuiu de 9,87 $\pm 4,9$ para $3,73 \pm 2,6\left(\times 10^{4}\right.$ células $)$, na presença de PTF $(p<0,0001)$, sendo equivalente a $38 \%$ do total de células obtido na ausência de PTF (Figura 12). Berman e Duncan, ${ }^{15}$ em experimentos semelhantes aos nossos (utilizando culturas de NHF), demonstraram que o número de fibroblastos em presença de PTF correspondia à aproximadamente $27,5 \%$ do total de células que não tiveram contato com PTF. 
Rawlins et al., ${ }^{17}$ realizando experimentos de proliferação celular em culturas de HSHF, também observaram que o número de fibroblastos em presença de PTF era aproximadamente $37 \%$ do total de células que não foram expostas ao fármaco.

Os achados supracitados confirmam os resultados por nós obtidos.

Outros estudos demonstram o efeito inibidor de pentoxifilina sobre a proliferação de fibroblastos humanos de origens diversas. ${ }^{15} 135160161162$

A terceira e última fase da cicatrização de feridas é a formação de matriz e remodelagem cicatricial, cujo início é concomitante à formação do tecido de granulação (Item 2.2.1.4).

Conforme postulado por Gomez, ${ }^{29}$ em 1995, na sua tese de doutorado, a capacidade de contração da ferida está relacionada aos miofibroblastos presentes e alta concentração de actina encontrada nos microfilamentos presentes na matriz extracelular. Além do mais, essas células alinham a si próprias e sua matriz recém-construída ao longo do eixo radial da ferida formando ligações "célula-célula" e "célula-matriz" (fibronexus), essa construção de arcabouço gera tensão na superfície e contração da ferida (Item 2.2.1.2).

Singer et al. ${ }^{52}$ acreditam que o fibronexus funciona como um complexo coesivo que transmite de maneira coletiva as forças geradas pela contração dos microfilamentos de actina por todos os miofibroblastos do tecido de granulação, promovendo, assim, a contração da ferida. Nos meses seguintes à dissolução da granulação, a matriz é constantemente alterada, 
com eliminação rápida da maior parte de fibronectina e acúmulo gradual de feixes de colágeno tipo I, que aumentam a força tensiva da cicatriz.

Estudos realizados em culturas de células da matriz também demonstram íntima associação entre fibronectina e colágenos. ${ }^{54}$ Pode-se, então, concluir que a deposição de fibronectina fibrilar extracelular é essencial à organização dos colágenos tipo I e III. ${ }^{55}$

Desde que foi desenvolvido por Bell, ${ }^{163}$ o modelo experimental de contração de matriz extracelular tem sido empregado em estudos de cura das feridas. Fibroblastos dispersos em matriz de colágeno apresentam comportamento mais semelhante aos fibroblastos in vivo do que aqueles cultivados em monocamada. De maneira semelhante, a proliferação é mais lenta nas células dispersas em matriz extracelular.

De forma genérica, modelos tridimensionais são mais bem indicados no estudo de relações e interferências entre componentes do sistema analisado, enquanto culturas em monocamada avaliam melhor $\mathrm{o}$ comportamento e a atividade celular.

O modelo experimental de contração de matriz extracelular povoado por fibroblastos utilizado neste estudo foi o proposto por Kamamoto et al. ${ }^{164}$ Segundo esses autores, a contração da matriz de colágeno tipo I depende diretamente da presença de fibroblastos. Esse fenômeno de contração inicia-se nas primeiras $12 \mathrm{~h}$ após sua polimerização e atinge seu máximo em $48 \mathrm{~h}$.

Utilizando modelo de contração de matriz de colágeno povoada por fibroblastos, Dans e Isseroff $^{16}$ demonstraram que a presença de PTF 
promoveu inibição dose dependente na contração dessa matriz povoada por fibroblastos humanos oriundos de prepúcio de neonatos. Em nosso estudo, utilizamos $4 \times 10^{5}$ fibroblastos / poço na confecção do modelo, baseados na experiência desses autores.

Quanto às matrizes povoadas por HSHF, Rawlins et al. ${ }^{17}$ descreveram percentual de inibição de contração promovido pela presença de PTF de aproximadamente $15 \%$. Nossos experimentos demonstraram inibição de contração na presença de PTF de aproximadamente 13\% nas primeiras 24 horas, ocorrendo após 48 horas de exposição à PTF inibição da contração de aproximadamente 14\% (Figura 13 - pág. 101), o que, corresponde aos dados da literatura.

Em nossos experimentos, as matrizes povoadas por NHF, na presença ou ausência de PTF, apresentaram, após 24 horas, percentual de inibição de contração promovida pela PTF de aproximadamente $8 \%$. Passadas 48 horas de exposição à PTF, esse percentual de inibição da contração era de aproximadamente 10\% (Figura 14 - pág. 103). Esses resultados também foram concordantes com a literatura.

As interações entre presença ou ausência de PTF, grupo de células e tempo de experimento, utilizando Equações de Estimação Generalizada (EEG), mostraram significância estatística $(p<0,0001)$. De acordo com essas equações, houve efeito de droga (as áreas se mostraram diferentes entre o uso ou não da droga), de tempo (as áreas são diferentes em pelo menos um dos três tempos) e de interação entre ambas. A evolução 
(contração) da área no tempo é diferente entre o grupo com e sem a droga (as curvas não são paralelas).

Analisando as comparações múltiplas ou contrastes (Tabela 12) podemos verificar que na variável tempo, em relação à presença ou ausência de droga, as áreas iniciais (hora zero) em ambos os grupos, com e sem PTF, eram iguais $(p=1,000)$, porém diferiam nos momentos $24 \mathrm{~h}(p=$ $0,003)$ e $48 \mathrm{~h}(p=0,002)$. Na variável tempo em ausência de droga, notamos que houve diminuição significativa do momento hora zero para o momento $24 \mathrm{~h}(p<0,0001)$, e que a área do momento hora zero era diferente daquela do momento $48 \mathrm{~h}(p<0,0001)$, mas a comparação das áreas entre os momentos $24 \mathrm{~h}$ e $48 \mathrm{~h}$ indicou que estas eram estatisticamente iguais ( $p=$ 0,176). O mesmo ocorreu na presença de PTF.

Pudemos, assim, concluir que, tanto para o grupo com PTF quanto para o grupo sem PTF, não houve diferença estatisticamente significativa entre as áreas nos momentos $24 \mathrm{~h}$ e $48 \mathrm{~h}$. A redução da área ocorreu do momento hora zero para o momento $24 \mathrm{~h}$. Todos os grupos começaram com mesma área. No momento $24 \mathrm{~h}$, essas áreas eram diferentes entre os grupos com / sem PTF, observando-se ainda que a área do grupo sem PTF teve maior redução (maior contração do gel) quando comparada com o grupo exposto à PTF.

Ao analisarmos o conjunto dos resultados notamos que: (1) sem interferências (PTF), HSHF apresentaram maior proliferação, maior incorporação de ${ }^{3} \mathrm{H}$-prolina e maior contração do modelo $3 \mathrm{D}$ quando comparados a NHF; (2) a presença de PTF inibiu igualmente estas 
atividades em ambos os grupos de células (HSHF e NHF) e (3) HSHF na presença de PTF têm tendência de comportamento (proliferação e contração de modelo 3D) semelhante a NHF sem PTF.

Estudos detalhados para ratificação, ou não, desta tendência de comportamento serão necessários. 
Conclusão 


\section{Conclusões}

Com todo o embasamento teórico, experimentos realizados e resultados obtidos, tornaram-se possíveis algumas conclusões para este estudo, expostas a seguir.

A presença de pentoxifilina em culturas de fibroblastos oriundos de cicatrizes hipertróficas pós-queimadura ou de pele não-cicatricial reduziu a incorporação de ${ }^{3} \mathrm{H}$-prolina. Portanto, podemos afirmar que a pentoxifilina inibe a produção in vitro de colágeno.

A pentoxifilina aplicada em culturas de fibroblastos oriundos de cicatrizes hipertróficas pós-queimadura ou de pele não-cicatricial reduziu a proliferação celular.

Constatou-se ainda que o uso de pentoxifilina reduziu in vitro a capacidade de fibroblastos oriundos de cicatrizes hipertróficas pósqueimadura ou de pele não-cicatricial gerarem contração em modelo experimental de matriz de colágeno. 
Anexos 


\section{Anexo A - Relatório estatístico*}

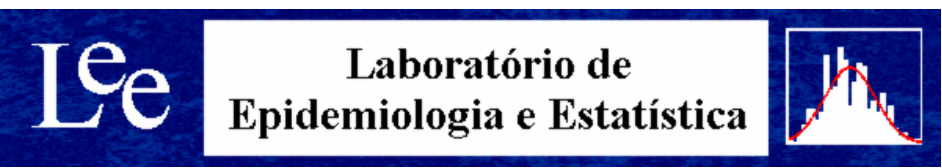

Pesquisador: César Isaac

Orientador: Mônica B. Mathor

e-mail: cesaris@uol.com.br

Instituição: FMUSP - Cirurgia Plástica

Data de inicio: 27/09/2004

Estatísticos Responsáveis: Valéria Troncoso Baltar

Finalidade: Doutorado

Título do Trabalho: Estudo comparativo do efeito in vitro da pentoxifilina em fibroblastos humanos oriundos de cicatrizes hipertróficas e de pele normal.

Objetivos: Avaliar o efeito da pentoxifilina em cicatrizes de queimados.

\section{Análise Estatística.}

Estudos longitudinais são investigações em que o interesse é a avaliação do comportamento de uma variável ao longo do tempo ou de uma dimensão específica. Este tipo de estudo também é conhecido como estudo de coortes, estudo tipo "follow-up" ou dados de painel. Podemos incluir nos estudos longitudinais aqueles com interesse em dados correlacionados, ou seja, os que temos repetições da unidade de observação, neste caso, pacientes.

Nossa unidade experimental é o paciente com amostras de pele submetidas ao uso de droga PTF ou não, em alguns casos a pele desses pacientes foi avaliada em diferentes momentos. Nesse estudo temos então repetição do mesmo paciente entre os tempos, entre as amostras (3 réplicas) e com ou sem PTF (mesmo paciente em duas situações). Como as variáveis respostas são medidas em um

\footnotetext{
* A transcrição deste documento é integral e literal.
} 
mesmo paciente, é importante levar em consideração a dependência entre os dados (correlação).

As Equações de Estimação Generalizadas (EEG) levam em consideração essa dependência além de permitir o ajuste de outras distribuições da família exponencial, além da distribuição Normal. A distribuição Gama é umas das distribuições dessa família, e será usada para as EEG na avaliação de área do gel (área sempre positiva e com distribuição assimétrica). A distribuição de Poisson será usada para avaliação de número de células (contagem de células). Depois de construídas as EEG os contrastes são realizados para auxiliar na interpretação dos parâmetros das EEG.

Cálculo do tamanho da amostra: A análise estatística que será usada para comparar os efeitos do remédio na multiplicação das células de pele, entre pele normal e não normal, será delineamento fatorial com dois fatores. O primeiro fator é o tipo de pele (normal/queimada), e o segundo fator é o uso do remédio (usou/não usou). Considerando uma diferença mínima a ser detectada de 20.000 células e um desvio-padrão de 10.000 células, com nível de significância de 0,05, uma amostra de 4 indivíduos com pele normal e 4 com queimada teria um poder de $95 \%$. Então considerando que seriam necessários 8 indivíduos independentes, sendo que ora usam PTF ora não, totalizamos 48 amostras, onde cada experimento apresenta três réplicas (Biometrika Tables for Statistics, Vol.2, by E.S. Pearson and H.O. Hartley, Cambridge University Press, Cambridge, 1972).

\section{ANÁLISE ESTATÍSTICA}

\section{Contagem de células totais}

Tabela 1.1: Estatísticas descritivas para a contagem de células entre os grupos, e com e sem PTF

\begin{tabular}{ccccccccc}
\hline & & \multicolumn{6}{c}{ Total de células } \\
\cline { 3 - 8 } GRUPO & PTF & \multicolumn{1}{c}{ Mínimo } & Mediana & Máximo & Média & Padrão & Padrão & $n$ \\
\hline \multirow{2}{*}{ HFHS } & não & 30000 & 60000 & 90000 & $58181,8217402,32$ & 3029,36 & 33 \\
& sim & 10000 & 30000 & 50000 & $26969,7011035,41$ & 1921,02 & 33 \\
\hline \multirow{2}{*}{ HFN } & não & 40000 & 90000 & 300000 & $98787,8849228,90$ & 8569,65 & 33 \\
& sim & 10000 & 30000 & 130000 & $37272,7326371,47$ & 4590,68 & 33 \\
\hline
\end{tabular}

$\overline{\mathrm{N}}=6$ amostras em 11 pacientes (com e sem PTF) 


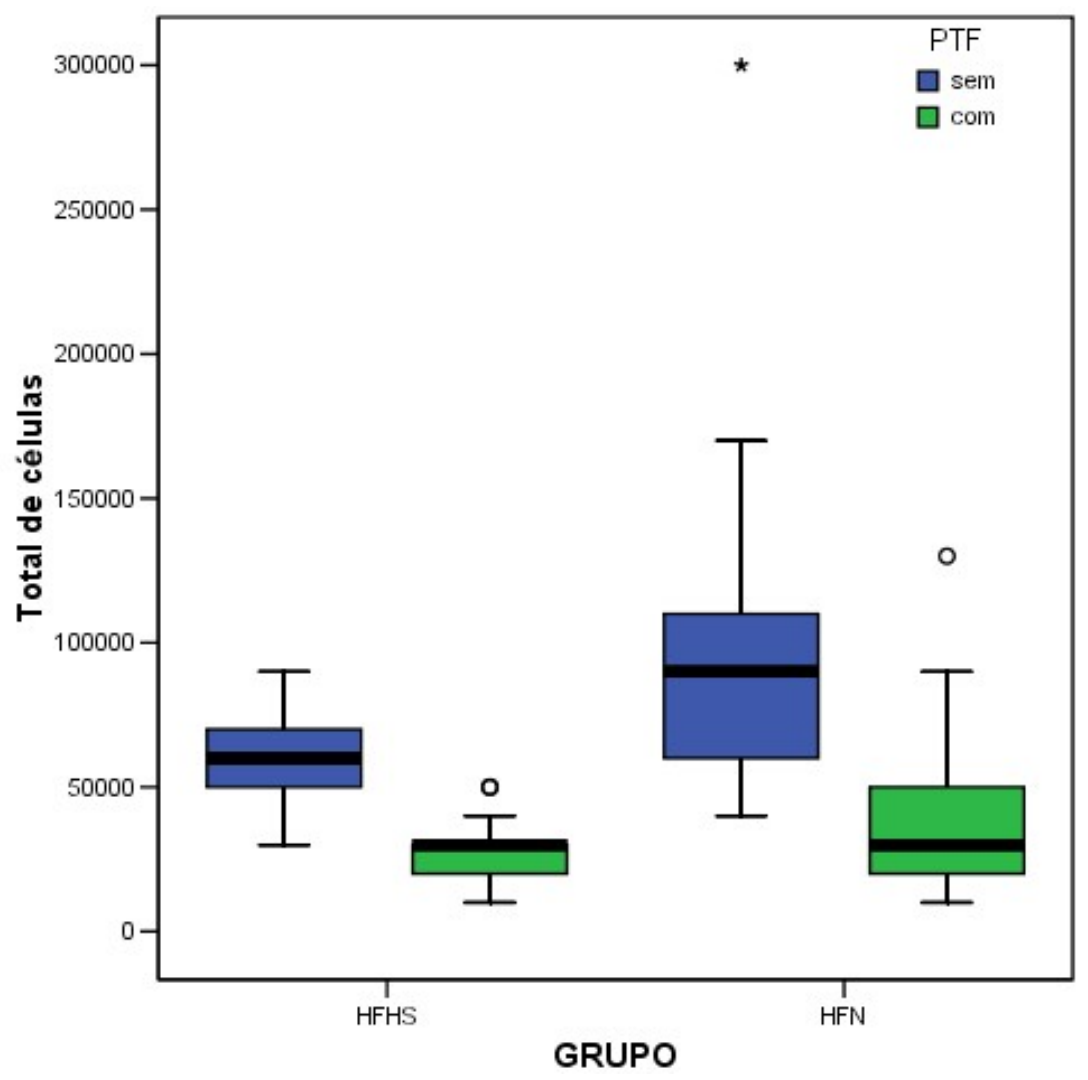

Fig. 1.1 - Desenho esquemático para contagem de células para HFHS e HFN com e sem PTF

abela 1.2: Resultados das EEG (incluindo a interação entre uso de PTF e GRUPO)

\begin{tabular}{lcc}
\hline & EEG-parâmetros & p-valor \\
\hline Grupo & $<0,0001$ \\
PTF & $<0,0001$ \\
GRUPO*PTF & 0,0006
\end{tabular}

GEE, distribuição de Poisson

Tabela 1.3: Contrastes para a EEG da Tabela 1.2

\begin{tabular}{lccccc}
\hline \multicolumn{1}{c}{ Contraste } & $\begin{array}{c}\text { Estimativa da } \\
\text { diferença média }\end{array}$ & EP & IC1 & IC2 & p-valor \\
\hline COM / SEM PTF - grupo HFHS & -31212 & 3382 & -37840 & -24584 & $<0,0001$ \\
COM / SEM PTF - grupo HFN & -61515 & 8203 & -77592 & -45438 & $<0,0001$ \\
\hline HFN / HFHS - sem PTF & 40606 & 9037 & 22895 & 58317 & $<0,0001$ \\
HFN / HFHS - com PTF & 10303 & 6155 & -1760 & 22366 & 0,0941 \\
\hline
\end{tabular}


A EEG descrita na Tabela 2.1 indica que a diferença entre o número de células em pele com e sem PTF é diferente entre os grupos HFS e HFHS. Com PTF apresenta menor número de células, e quando essa comparação é feita para células normais essa diferença é o dobro.A comparação entre normais e queimadas apresenta uma diferença maior para as células sem PTF (40 mil versus 10 mil), inclusive no grupo com PTF essa diferença não é significativa $(p=0,09)$

\section{Contagem de células por minuto para os grupos HFHS e HFN, com e sem PTF}

Tabela 2.1: Estatísticas descritivas para a contagem de células por minuto entre os grupos e com e sem PTF

\begin{tabular}{|c|c|c|c|c|}
\hline \multirow[b]{2}{*}{ GRUPO } & \multicolumn{4}{|l|}{ CPM } \\
\hline & PTF Mínimo Mediana Máximo Média & Desv. padrã & rro padrão & $n$ \\
\hline HFHS & sem $1698,342715,845567,433064,88$ & 1252,87 & 228,74 & 30 \\
\hline HFHS & com $944,341497,842290,341558,43$ & 413,98 & 75,58 & 30 \\
\hline HFN & sem 1045,69 1878,71 2993,722031,97 & 645,47 & 117,85 & 30 \\
\hline HFN & com 564,68 $860,691190,69890,05$ & 210,07 & 38,35 & 30 \\
\hline
\end{tabular}

$\mathrm{N}=3$ medidas em 20 pacientes

Tabela 2.2: Resultado das EEG para número de células por minuto

\begin{tabular}{|c|c|}
\hline EEG - parâmetros & p-valor \\
\hline Grupo & $<0,0001$ \\
\hline PTF & $<0,0001$ \\
\hline
\end{tabular}

Essas equações não apresentam interação entre grupo e PTF, o que significa que a diferença média de contagem por minutos entre os que usaram e os que não usaram PTF é similar entre os dois grupos. 


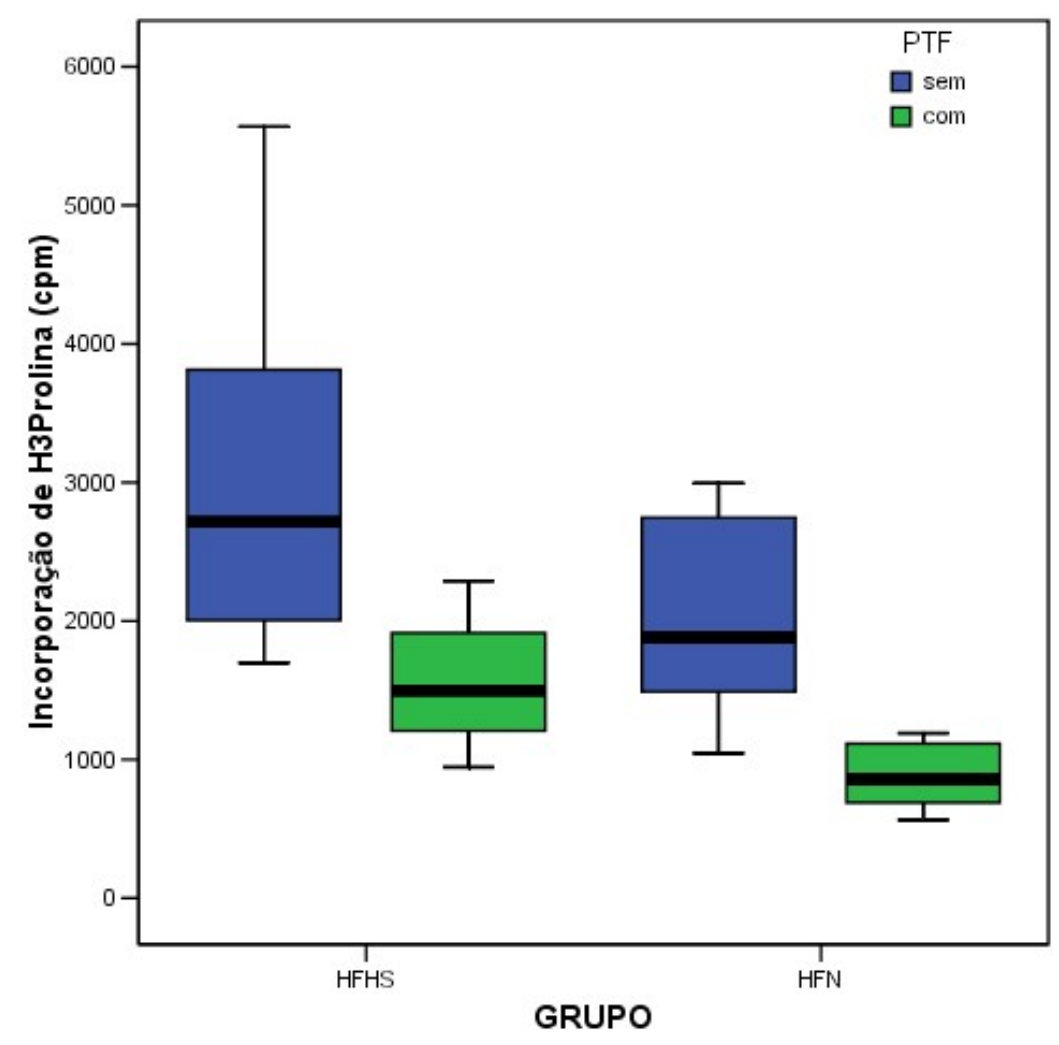

Fig. 2.1 - Desenho esquemático para contagem de células para HFHS e HFN com e sem PTF

Tabela 2.2: Contrastes para EEG de CPM

\begin{tabular}{lcc}
\hline & Diferença média & p-valor \\
\hline Sem PTF-com & 1314,8 & $<0,0001$ \\
HFHS-HFN & 509,3 & $<0,0001$
\end{tabular}

EEG, distribuição de Poisson

Desta maneira observamos que os níveis de contagem são sempre maiores entre os sem PTF e também entre os HFHS.

\section{Comparações do número de células entre tipo e uso ou não de PTF}

Este experimento tem o objetivo de avaliar a diminuição no número de células quando com a presença da droga PTF. Avaliando para dois tipos diferentes 
anticorpos anti-colágeno (I e III) optamos pelo uso de EEG (Equação de Estimação Generalizada) para avaliação da presença dos efeitos de droga, tipo anticorpo e grupo (HFHS e HFN).

Tabela 3.1: Estatísticas descritivas para o número de células

Desv.

\begin{tabular}{cccccccc} 
Grupo & PTF e Tipo & Mínimo Mediana & Máximo & Média & Padrão & $\mathbf{n}$ \\
\hline \multirow{2}{*}{ HFHS } & sem PTF - tipo I & 2 & 3 & 3 & 2,60 & 0,52 & 10 \\
\cline { 2 - 8 } & com PTF - tipo I & 1 & 2 & 3 & 2,30 & 0,67 & 10 \\
\cline { 2 - 8 } & sem PTF - tipo III & 2 & 3 & 3 & 2,80 & 0,42 & 10 \\
& com PTF - tipo III & 1 & 2 & 2 & 1,70 & 0,48 & 10 \\
\hline \multirow{2}{*}{ HFN } & sem PTF - tipo I & 2 & 2 & 3 & 2,40 & 0,52 & 10 \\
\cline { 2 - 8 } & com PTF - tipo I & 1 & 1 & 2 & 1,30 & 0,48 & 10 \\
\cline { 2 - 8 } & sem PTF - tipo III & 1 & 1 & 3 & 1,60 & 0,84 & 10 \\
& com PTF - tipo III & 1 & 1 & 3 & 1,60 & 0,84 & 10
\end{tabular}

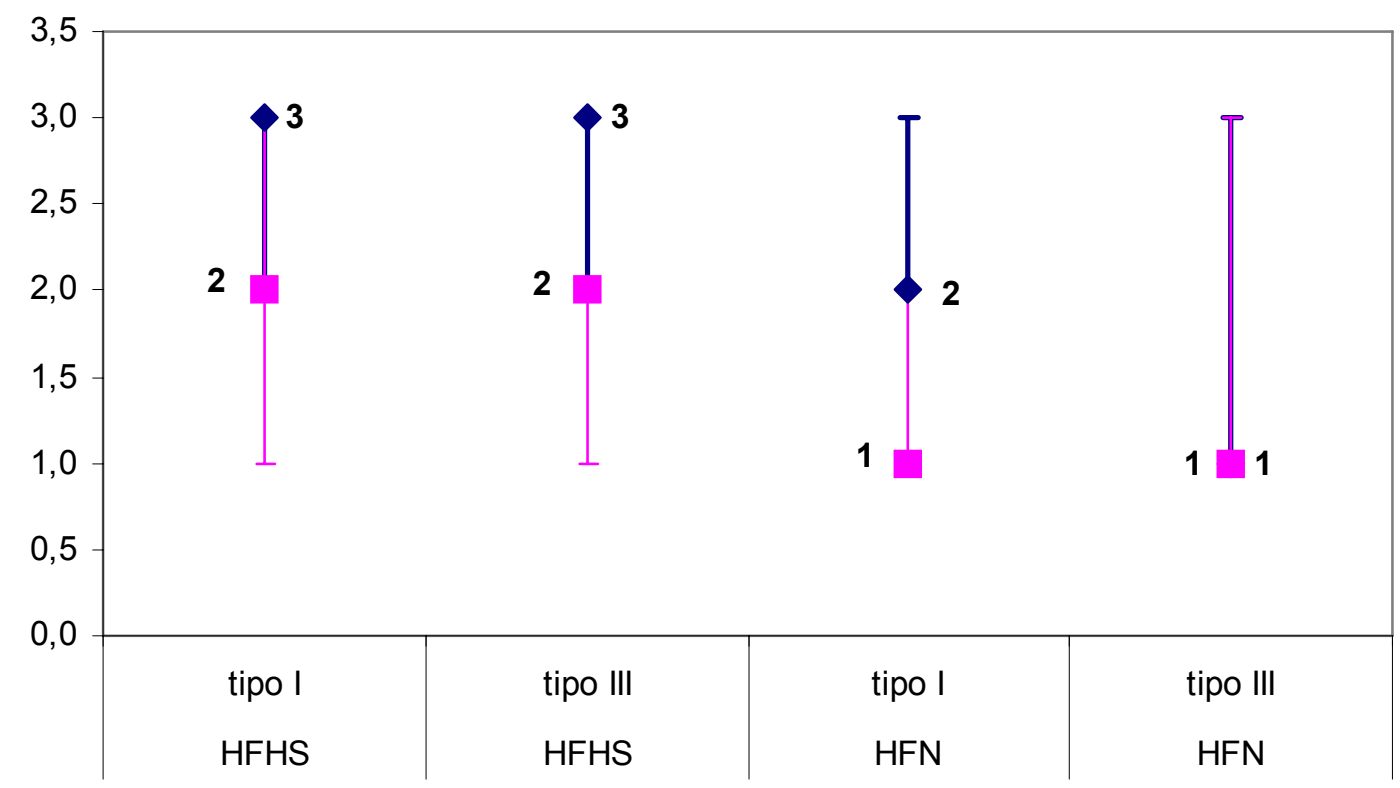

sem PTF a com PTF

Fig 3.1 - Mediana de células em cada grupo, considerando tipo e presença ou não de droga (mínimo e máximo). 
Tabela 3.2: Descrição dos resultados da EEG (considerando distribuição de Poisson para contagem de células)

\begin{tabular}{lcc}
\hline & EEG & p-valor \\
\hline GRUPO & 0,0002 \\
PTF & $<0,0001$ \\
TIPO & 0,216 \\
GRUPO*PTF & 0,193 \\
GRUPO*TIPO & 0,891 \\
PTF*TIPO & 0,239 \\
GRUPO*PTF*TIPO & $<0,0001$
\end{tabular}

*Poisson

Os resultados da Tabela 3.2 indicam que há um efeito de interação entre grupo, PTF e tipo. Isso significa que as diferenças entre os números de células para pele com a presença e com a ausência de PTF são diferentes entre os tipos, considerando os mesmos grupos.

Tabela 3.3: Contrastes para os resultados da Tabela 3.2

\begin{tabular}{lccccc}
\hline \multicolumn{1}{c}{ Contraste } & Estimativa & EP & IC1 & IC2 & p-valor \\
\hline HFHS - HFN: tipo I e sem PTF & 0,20 & 0,22 & $-0,23$ & 0,63 & 0,361 \\
HFHS - HFN: tipo I e com PTF & 1,00 & 0,25 & 0,51 & 1,49 & $<0,0001$ \\
HFHS - HFN: tipo III e sem PTF & 1,20 & 0,28 & 0,65 & 1,75 & $<0,0001$ \\
HFHS - HFN: tipo III e com PTF & 0,10 & 0,29 & $-0,47$ & 0,67 & 0,732 \\
\hline sem - com PTF: tipo I e HFHS & 0,30 & 0,14 & 0,02 & 0,58 & 0,038 \\
sem - com PTF: tipo I e HFN & 1,10 & 0,17 & 0,77 & 1,43 & $<0,0001$ \\
sem - com PTF: tipo III e HFHS & 1,10 & 0,09 & 0,91 & 1,29 & $<0,0001$ \\
sem - com PTF: tipo III e HFN & 0,00 & 0,00 & 0,00 & 0,00 & 1,000 \\
\hline tipo I - tipo III: HFHS e sem PTF & $-0,20$ & 0,19 & $-0,57$ & 0,17 & 0,292 \\
tipo I - tipo III: HFN e sem PTF & 0,80 & 0,34 & 0,13 & 1,47 & 0,019 \\
tipo I - tipo III: HFHS e com PTF & 0,60 & 0,21 & 0,19 & 1,01 & 0,004 \\
tipo I - tipo III: HFN e com PTF & $-0,30$ & 0,32 & $-0,92$ & 0,32 & 0,345 \\
\hline
\end{tabular}

As diferenças com relação ao número de células são mais elevadas entre pele com e sem droga PTF, para o tipo I no grupo HFN e no tipo III no grupo HFHS. Há diferença entre com e sem PTF para o tipo I no grupo HFHS e não há diferença para tipo III no grupo HFN. 
Os grupos se diferem apenas entre tipo I com PTF e tipo III sem PTF. Já os tipos se diferem no grupo HFN sem PTF e no HFHS com PTF.

4. Avaliação da contração da área do gel para três momentos, por grupo com e sem uso de PTF

Tabela 4.1: Estatísticas descritivas para contração da área do gel em três momentos para os dois grupos com e sem PTF

\begin{tabular}{|c|c|c|c|c|c|c|c|c|c|}
\hline \multirow[b]{3}{*}{ GRUPO } & \multirow[b]{3}{*}{ PTF } & \multirow[b]{3}{*}{ Momentos } & \multicolumn{7}{|c|}{ Contração da área do gel } \\
\hline & & & \\
\hline & & & Mínimo & Mediana I & Máximo & Média & Padrão & Padrão & $\mathbf{n}$ \\
\hline & & Ohs & 1,96 & 1,96 & 1,96 & 1,960 & 0,000 & 0,000 & 33 \\
\hline \multirow[t]{3}{*}{ HFHS } & sem & $24 \mathrm{hs}$ & 0,78 & 1,40 & 1,54 & 1,324 & 0,199 & 0,035 & 33 \\
\hline & & 48hs & 0,66 & 1,34 & 1,51 & 1,238 & 0,242 & 0,042 & 33 \\
\hline & & Ohs & 1,96 & 1,96 & 1,96 & 1,960 & 0,000 & 0,000 & 33 \\
\hline \multirow[t]{3}{*}{ HFN } & sem & 24hs & 1,24 & 1,43 & 1,62 & 1,448 & 0,109 & 0,019 & 33 \\
\hline & & 48hs & 1,21 & 1,34 & 1,63 & 1,361 & 0,112 & 0,019 & 33 \\
\hline & & Ohs & 1,96 & 1,96 & 1,96 & 1,960 & 0,000 & 0,000 & 33 \\
\hline \multirow[t]{3}{*}{ HFHS } & com & $24 \mathrm{hs}$ & 1,19 & 1,51 & 1,71 & 1,519 & 0,128 & 0,022 & 33 \\
\hline & & 48hs & 1,10 & 1,47 & 1,67 & 1,445 & 0,132 & 0,023 & 33 \\
\hline & & Ohs & 1,96 & 1,96 & 1,96 & 1,960 & 0,000 & 0,000 & 33 \\
\hline \multirow[t]{2}{*}{ HFN } & com & $24 \mathrm{hs}$ & 1,42 & 1,59 & 1,72 & 1,592 & 0,073 & 0,013 & 33 \\
\hline & & 48hs & 1,40 & 1,51 & 1,73 & 1,528 & 0,084 & 0,015 & 33 \\
\hline
\end{tabular}




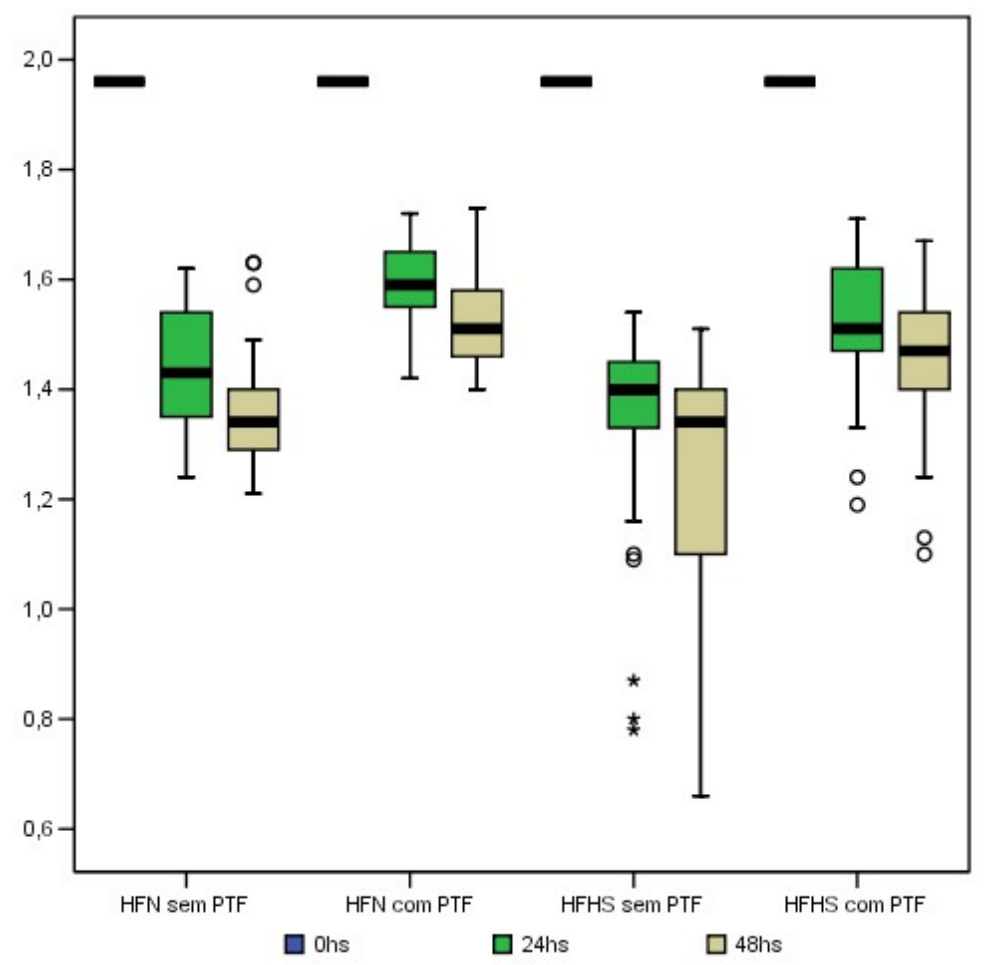

Fig.4.1- Desenho esquemático para área de contração do gel nos três momentos para grupos com e sem uso PTF

Tabela 4.2: Resultados da EEG para área de contração do gel

\begin{tabular}{lc}
\hline \multicolumn{1}{c}{ EEG } & p-valor \\
\hline Grupo & 0,069 \\
PTF & $<0,0001$ \\
Momento & $<0,0001$ \\
PTF $^{*}$ momento & $<0,0001$
\end{tabular}

EEG, distribuição Gama

Tabela 4.3: Contrastes de área de contração do gel para os efeitos da EEG da Tabela 4.2

\begin{tabular}{lccccc}
\hline \multicolumn{1}{c}{ Contraste } & Estimativa & EP & IC1 & IC2 & p-valor \\
\hline com / sem PTF - Oh & 0 & 0 & 0 & 0 & 1 \\
com / sem PTF - 24h & 0,17 & 0,02 & 0,13 & 0,22 & $<0,0001$ \\
com / sem PTF - 48h & 0,19 & 0,02 & 0,14 & 0,23 & $<0,0001$ \\
\hline 24h / Oh - sem PTF & $-0,58$ & 0,04 & $-0,65$ & $-0,51$ & $<0,0001$ \\
24h / Oh - com PTF & $-0,41$ & 0,02 & $-0,45$ & $-0,36$ & $<0,0001$ \\
\hline
\end{tabular}




\begin{tabular}{lccccc}
\hline 48h / 24h - sem PTF & $-0,09$ & 0,01 & $-0,11$ & $-0,06$ & $<0,0001$ \\
48h / 24h - com PTF & $-0,07$ & 0,01 & $-0,09$ & $-0,05$ & $<0,0001$ \\
\hline 48h / Oh - sem PTF & $-0,66$ & 0,04 & $-0,75$ & $-0,58$ & $<0,0001$ \\
48h / Oh - com PTF & $-0,48$ & 0,02 & $-0,52$ & $-0,43$ & $<0,0001$ \\
\hline HFHS / HFN & $-0,17$ & 0,09 & $-0,35$ & 0,01 & 0,069 \\
\hline
\end{tabular}

A tabela 4.2 indica que a área de contração do gel varia de maneira diferente no tempo para células com e sem PTF. Não há diferença entre os grupos mas há para uso de PTF.

$\mathrm{Na}$ Tabela 4.3 podemos observar que no tempo Oh não há diferença para células com e sem PTF. No momento $24 \mathrm{~h}$ já há uma diferença média de 0,17 e noi momento $48 \mathrm{~h}$ essa diferença sobe para 0,19 . A redução da área é mais intensa para as céluas sem PTF.

\section{Estudo preliminar - Análise da Proliferação de Células - HFN}

Tabela 5.1: Estatísticas descritivas para proliferação de células vivas (HFN) entre as que estavam com PTF e sem PTF

\begin{tabular}{ccccccccc}
\hline PTF Células VivasMínimoMedianaMáximo Média Desv. padrãoErro Padrão \\
\hline \multirow{4}{*}{ sem } & $12 \mathrm{~h}$ & 0 & 15 & 40 & 16,33 & 9,28 & 1,69 & 30 \\
& $24 \mathrm{~h}$ & 0 & 20 & 30 & 19,33 & 7,85 & 1,43 & 30 \\
& $48 \mathrm{~h}$ & 30 & 50 & 60 & 44,67 & 7,30 & 1,33 & 30 \\
& $72 \mathrm{~h}$ & 60 & 70 & 110 & 75,00 & 10,42 & 1,90 & 30 \\
& & & & & 111,6 & & & \\
& $96 \mathrm{~h}$ & 60 & 110 & 160 & 7 & 25,34 & 4,63 & 30 \\
\hline \multirow{4}{*}{$\operatorname{com}$} & $12 \mathrm{~h}$ & 10 & 15 & 20 & 15,00 & 5,09 & 0,93 & 30 \\
& $24 \mathrm{~h}$ & 0 & 20 & 40 & 20,67 & 9,07 & 1,66 & 30 \\
& $48 \mathrm{~h}$ & 20 & 35 & 50 & 36,00 & 11,33 & 2,07 & 30 \\
& $72 \mathrm{~h}$ & 30 & 40 & 70 & 42,67 & 10,48 & 1,91 & 30 \\
& $96 \mathrm{~h}$ & 40 & 60 & 80 & 57,67 & 12,23 & 2,23 & 30 \\
\hline
\end{tabular}


Tabela 5.2: Estatísticas descritivas para proliferação de células mortas (HFN) entre as que estavam com PTF e sem PTF

\section{Desv.}

PTF Células mortasMínimoMedianaMáximoMédia Padrão Erro Padrão n

\begin{tabular}{ccccccccc}
\hline \multirow{4}{*}{ sem } & $12 \mathrm{~h}$ & 0 & 5 & 10 & 5,00 & 5,09 & 0,93 & 30 \\
& $24 \mathrm{~h}$ & 0 & 10 & 20 & 6,33 & 5,56 & 1,02 & 30 \\
& $48 \mathrm{~h}$ & 0 & 5 & 10 & 5,00 & 5,09 & 0,93 & 30 \\
& $72 \mathrm{~h}$ & 0 & 10 & 10 & 5,33 & 5,07 & 0,93 & 30 \\
& $96 \mathrm{~h}$ & 0 & 5 & 20 & 6,33 & 7,18 & 1,31 & 30 \\
\hline \multirow{6}{*}{ com } & $12 \mathrm{~h}$ & 0 & 0 & 20 & 5,00 & 7,77 & 1,42 & 30 \\
& $24 \mathrm{~h}$ & 0 & 0 & 20 & 6,00 & 7,24 & 1,32 & 30 \\
& $48 \mathrm{~h}$ & 0 & 5 & 20 & 6,00 & 6,75 & 1,23 & 30 \\
& $72 \mathrm{~h}$ & 0 & 5 & 20 & 5,33 & 5,71 & 1,04 & 30 \\
& $96 \mathrm{~h}$ & 0 & 5 & 30 & 5,67 & 6,79 & 1,24 & 30 \\
\hline
\end{tabular}

Tabela 5.3: EEG para avaliação da evolução do número de células, considerando os fatores "viva" (0/1) e "PTF" (0/1)

\begin{tabular}{|c|c|}
\hline EEG- parâmetros & p-valor \\
\hline$\overline{\text { PTF }}$ & $<0,0001$ \\
\hline tempo & $<0,0001$ \\
\hline Viva & $<0,0001$ \\
\hline tempo*Viva & $<0,0001$ \\
\hline tempo*PTF & $<0,0001$ \\
\hline PTF*Viva & $<0,0001$ \\
\hline tempo*PTF*Viva & $<0,0001$ \\
\hline
\end{tabular}

*Poisson

As EEG da Tabela 53 indicam que há efeito de todas as interações. A evolução entre células vivas e mortas é diferente e entre as com e sem PTF também. As tabelas de contrastes ajudarão a entender este fato. 
Tabela 5.4: Contrastes para uso ou não de PTF

\begin{tabular}{lcc}
\hline & Diferença média & p-valor \\
\hline PTF/não no 12h mortas & 0,00 & 1,0000 \\
PTF/não no 24h mortas & $-0,33$ & 0,8412 \\
PTF/não no 48h mortas & 1,00 & 0,3884 \\
PTF/não no 72h mortas & 0,00 & 1,0000 \\
PTF/não no 96h mortas & $-0,67$ & 0,6926 \\
\hline PTF/não no 12h vivas & $-1,33$ & 0,0565 \\
PTF/não no 24h vivas & 1,33 & 0,3233 \\
PTF/não no 48h vivas & $-8,67$ & 0,0002 \\
PTF/não no 72h vivas & $-32,33$ & $<0,0001$ \\
PTF/não no 96h vivas & $-54,00$ & $<0,0001$ \\
\hline
\end{tabular}

Com relação às células mortas, em todos os momentos o número de células com PTF e sem PTF se igualam.

No caso das células vivas temos que nos momentos $8 \mathrm{~h}, 72 \mathrm{~h}$ e $96 \mathrm{~h}$ as células sem PTF proliferaram mais. Em $48 \mathrm{~h}$ a proliferação foi em média $8 \times 10^{3}$ a mais, no momento $72 \mathrm{~h}$ foi 32 , e no momento $96 \mathrm{~h}$ foi de 54 .

Tabela 5.5: Contrastes no tempo para o número de células vivas

\begin{tabular}{lcc}
\hline & Diferença média & p-valor \\
\hline 24h - 12h sem PTF e vivas & 3,00 & 0,006 \\
48h - 24h sem PTF e vivas & 25,33 & $<0,0001$ \\
72h - 48h sem PTF e vivas & 30,33 & $<0,0001$ \\
96h - 72h sem PTF e vivas & 36,67 & $<0,0001$ \\
\hline 24h - 12h com PTF e vivas & 5,67 & 0,0003 \\
48h - 24h com PTF e vivas & 15,33 & $<0,0001$ \\
$72 h$ - 48h com PTF e vivas & 6,67 & 0,0003 \\
$96 h-72 h$ com PTF e vivas & 15,00 & $<0,0001$ \\
\hline
\end{tabular}

A cada aumento no tempo, há um aumento no número de células vivas, em $12 \mathrm{~h}$ na tabela anterior, vimos o número de células com PTF e sem PTF eram iguais $(p=0,0565>0,05)$, então há um aumento maior do $12 \mathrm{~h}$ para $24 \mathrm{~h}$ para aquelas com 
PTF, que foi um aumento médio de 5,67 enquanto para as sem PTF foi de 3 . Mas no momento $24 \mathrm{~h}$ temos que o número de células permanece igual, então a conclusão é que o aumento de 3 e o de 5,67 não são realmente muito diferentes, pois ainda mantém o grupo com e sem droga com mesmo número de células. No momento 48h há um aumento maior. As ce'lulas sem PTF aumentam em média 25 e as com apenas 15, neste momento já encontramos uma diferença entre o número de células vivas nos dois grupos, o grupo sem PTF apresenta uma média maior (em $8 \times 10^{3}$ unidades).

Tabela 5.6: Contrastes no tempo para o número de células mortas

\begin{tabular}{lcc}
\hline & Diferença média & p-valor \\
\hline $24 \mathrm{~h}-12 \mathrm{~h}$ sem PTF e mortas & 1,33 & 0,215 \\
$48 \mathrm{~h}-24 \mathrm{~h}$ sem PTF e mortas & $-1,33$ & 0,057 \\
$72 \mathrm{~h}-48 \mathrm{~h}$ sem PTF e mortas & 0,33 & 0,651 \\
$96 \mathrm{~h}-72 \mathrm{~h}$ sem PTF e mortas & 1,00 & 0,523 \\
$24 \mathrm{~h}-12 \mathrm{~h}$ com PTF e mortas & 1,00 & 0,292 \\
$48 \mathrm{~h}-24 \mathrm{~h}$ com PTF e mortas & 0,00 & 1,000 \\
$72 \mathrm{~h}-48 \mathrm{~h}$ com PTF e mortas & $-0,67$ & 0,651 \\
$96 \mathrm{~h}-72 \mathrm{~h}$ com PTF e mortas & 0,33 & 0,866 \\
\hline
\end{tabular}

A Tabela 5.6 indica que a evolução de células mortas não se altera. $O$ número médio de células mortas em cada momento é o mesmo, entre as que tinham e as que não tinham PTF. 


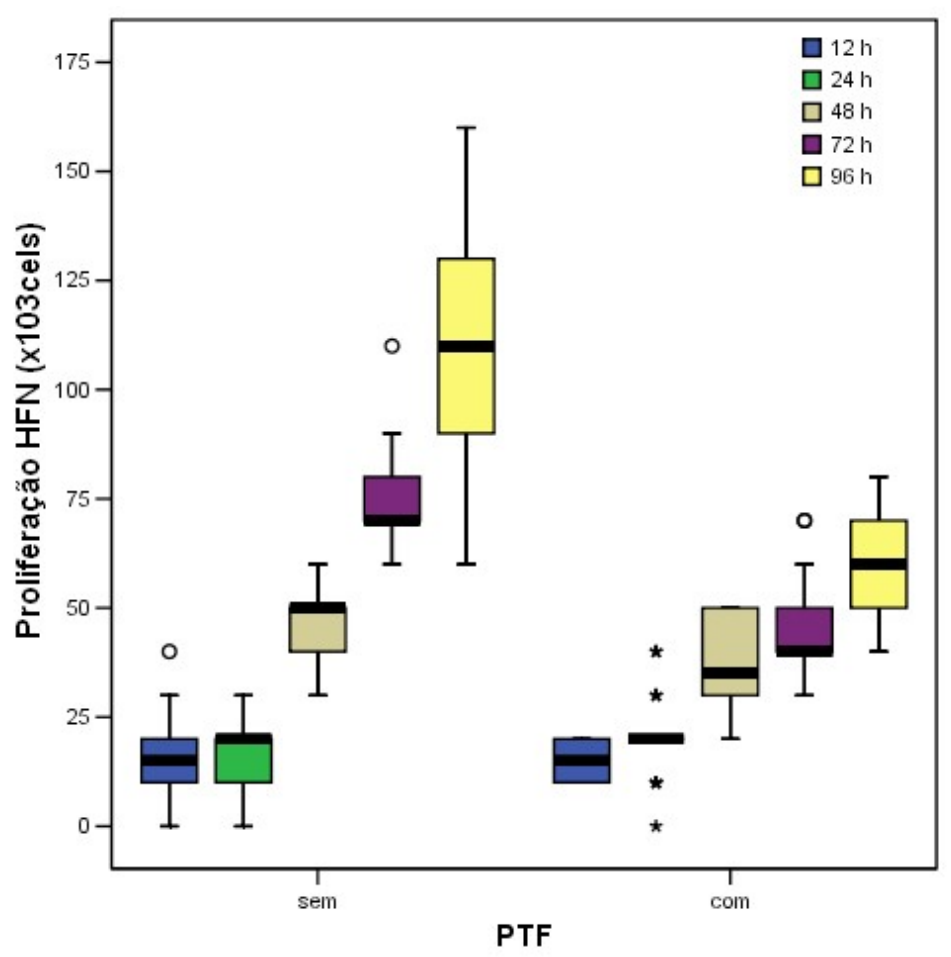

Fig. 5.1 - Desenho esquemático para evolução das células vivas

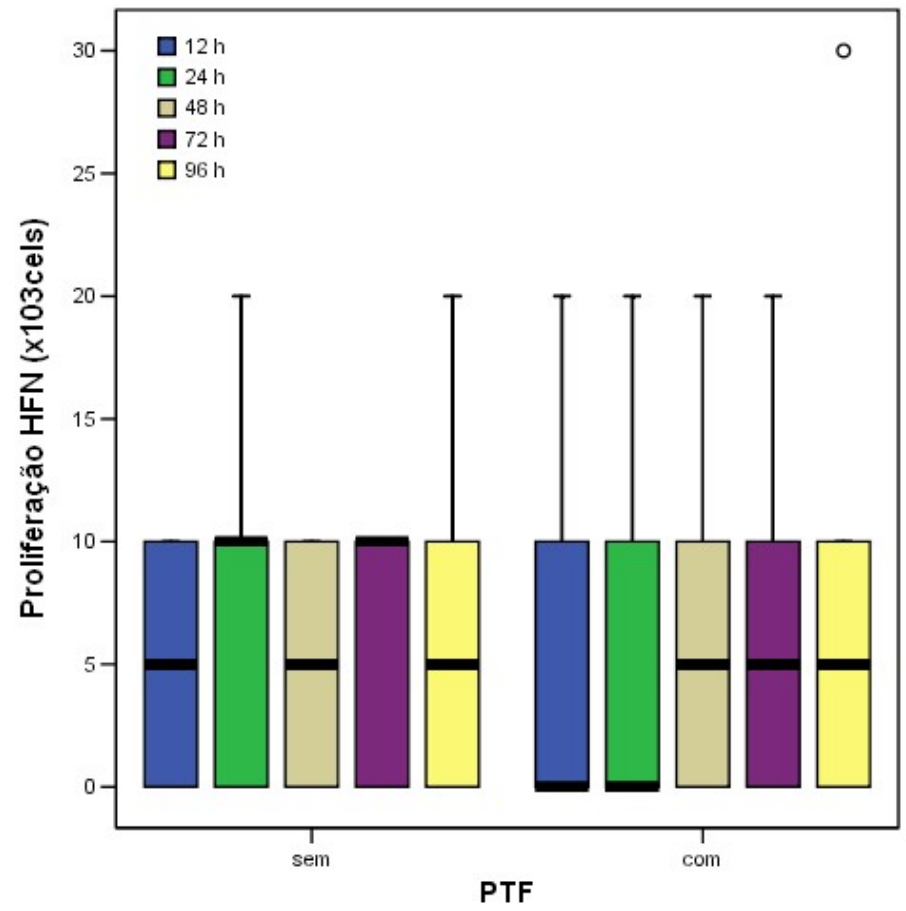

Fig. 5.2 - Desenho esquemático para evolução das células mortas

\section{Referências}

Jos W.R. Twisk; Applied Longitudinal Data Analysis for Epidemiology. A Practical Guide. Cambridge University Press.2003. 
Hardin J.W, Hilbe J.M. Generalized Estimating Equations. Chapman \& Hall. 2003. 


\section{Referências}

1 Alster TS, West TB. Treatment of scars: A review. Ann Plas Sur. 1997;39(4): 419-432.

2 Ketchum LD, Cohen IK, Masters FW. Hypertrofic scars and keloids: a collective review. Plast Reconst Surg. 1974;53:140-151.

3 Ehrlich HP, Desmoulière A, Diegelman RF, Cohen IK, Compton CC, Garner WL, Kapanci Y, Gabbini G . Morphological and immunochemical differences between keloid and hypertrophic scar. Am J Pathol. 1994;145:105-113.

4 Eckes B, Aumailley M, Krieg T. Collagens and reestablishment of dermal integrity. In: Clark RAF, editor. The molecular and cellular biology of wound repair. New York: Plenum Press; 1996. p. 493-512.

5 Costa AMA, Desmoulière A. Mechanisms and factors involved in development of hypertrophic scars. Eur J Plast Surg. 1998;21:19-23.

6 Grinnell F. Fibroblasts, myofibroblasts and wound contraction. J Cell Biol. 1994; 124: 401-404.

7 Zhang K, Rekhter MD, Gordon D, Phan SH. Myofibroblasts and their role in lung collagen gene expression during pulmonary fibrosis. A combined immunohistochemical and in situ hybridization study. $A m \mathrm{~J}$ Pathol.1994;145:114-125.

8 Schürch W, Seemayer TA, Gabbiani G. Myofibroblast. In: Sternberg, SS. (ed). Histology for pathologists. Philadelphia: Lippincott-Raven; 1997. p. 129165.

9 Chang CC, Wu YC, Chiu HC, LiuYL, Lu YC. Pentoxifylline inhibits the proliferation of human fibroblasts derived from normal, hypertrophic scar and keloid skin and their mitochondrial activity and collagen synthesis. Eur $\mathrm{J}$ Dermatol. 1991;1:214-220. 
10 Rippe M Lorenzen AI, Brenner DA. Regulatory elements in the 5'-flanking region of and the first intron contribute to translational control of the mouse alpha 1 type I collagen gene. Mol Cell Biol. 1989;9:2224-7.

11 Rossi P Karsenty G, Roberts AB. A nuclear factor 1 binding site mediates the transcriptional activation of a type I collagen promoter by transforming growth factor-[beta]. Cell. 1988;52:405-14.

12 Baum BJ Moss J, Breul SD, et al. Effect of cyclic AMP on the intracellular degradation of newly synthetized collagen. J Biol Chem. 1980;255:2843-7.

13 Pinzani M Marra F, Caligiuri A. Inhibition by pentoxifylline of extracellular signal-regulated kinase activation by platelet-derived growth factor in hepatic stellate cells. Br J Pharmacol. 1996;119:1117-24.

14 Chasin M, Harris DN. Inhibitors and activators of cyclic nucleotide phosphodiesterase. In: Greengard P, Robison GA, editors. Advances in cyclic nucleotide research. New York: Raven Press; 1976. 225-64. v. 7.

15 Berman B, Duncan MR. Pentoxifylline inhibits normal human dermal fibroblast in vitro proliferation, collagen, glycosaminoglycan and fibronectin production and increase collagenase activity. J Invest Dermatol. 1989;92:605-610.

16 Dans MJ, Isseroff R. Inhibition of Collagen Lattice Contraction by Pentoxifylline and Interferon-Alpha, -Beta and -Gama. Jorn Invest Dermatol. 1994;102(1):118-21.

17 Rawlins JM Lam WL, Karoo RO, Naylor IL, Sharpe Dt. Pentoxifylline inhibits mature burn scar fibroblasts in culture. Burns. 2006;32(1):42-5.

$18 \mathrm{Chu} \mathrm{DH}$ Haake AR, Holbrook K, Loomis CA. The structure and development of skin. In: Freedberg IM et al., editors. Fitzpatrick's dermatology in general medicine. New York: McGraw-Hill; 2003. p. 58-88.

19 Kanitakis J, Petruzzo P, Dubernard JM. Turnover of epidermal Langerhans cells. New England Journal of Medicine. 2004 Dec. 16;351(25):2661-2662,. 
20 Cameli N, Ortonne J P, Picardo M, Peluso A M, Tosti A. Distribution of Merkel cells in adult human nail matrix. British Journal of Dermatology. 1998 Sep.;139(3):541- 541.

21 Querleux B Richard S, Bittoun J et al. In vivo hydration profile in skin layers by high resolution magnetic resonance imaging. Skin Pharmacol. 1994;7:210-16.

22 Burton JL. Essentials of Dermatology. $3^{\text {rd }}$ ed. Edinburgh: Churchill Livingstone; 1990. p.57- 63.

23 Rabe JH Mamelak AJ, McElgunn PJS, Morison WL, Sauder Dn. Photoaging: mechanisms and repair. Journal of the American Academy of Dermatology. 2006 July;55(1):1-19,.

24 Lindsay WK, Birch JR. Thin skin healing. [Journal Article] Acta Chirurgiae Plasticae. 1965;7(3):153-70.

25 Eriksson G. Healing in second degree burns. An electron microscopy study Nordisk Medicin. 1971 July 29;86(30):909,.

26 Khomullo GV, Kokoreva GA. Skin regeneration and metabolic level on administration of thyrostimulin. Biulleten Eksperimentalnoi Biologii $i$ Meditsiny. 1976; 81(4):480-2.

27 Dyson M, Moodley S, Verjee L, Verling W, Weinman J, Wilson P. Wound healing assessment using $20 \mathrm{MHz}$ ultrasound and photography. Skin Research \& Technology. 2003 May;9(2):116-21.

28 Shoshan S. The role of collagen in pathophysiology of the skin. A microreview. Current Problems in Dermatology. 1978;7:53-7.

29 Gomez DS. Contribuição para o estudo da pele restaurada: pesquisa da contração e miofibroblastos. [tese]. São Paulo: Faculdade de Medicina, Universidade de São Paulo; 1995.

30 Russo AC. Queimaduras. São Paulo: Luso-Espanhola e Brasileira; 1959. p 53. 
31 Mariani U, Gomez DS, Carvalho DA, Ferreira MC. The tegument resulting from the healing of burns. Rev Hosp Clin Fac Med Sao Paulo. 1995 MayJune;50(3):140-6.

32 Hunt TK. Wound healing and wound infection: theory and surgical practice. New York: Appleton-Century-Crofts; 1980. p.189- 190

33 Winter GD. Formation of the scab and the rate of epithelialization of superficial wounds in the skin of the young domestic pig. Nature 1962;193: 293-294.

34 Gabbiani G, Chapponier C, Huttner I. Cytoplasmic filaments and gap junctions in epithelial cells and myofibroblasts during wound healing. $J$ Cell Biol. 1978; 76:561-568.

35 Stenn KS, Madri JA, Roll FJ. Migrating epidermis produces AB2 collagen and requires continued collagen synthesis for movement. Nature. 1979;277:229-232.

36 Cohen S. Isolation of a mouse submaxillary gland protein accelerating incisor eruption and eyelid opening in the new born animal. $J$ Biol Chem. 1962;237:1555-1562.

37 Gabbiani G. The role of contractile proteins in wound healing and fibrocontractive disease. Methods Achev Exp Pathol. 1979; 9:187-206.

38 Majno G. The history of the myofibroblasts. Am Surg Pathol. 1979;3:535542.

39 Gabbiani G, Ryan GB, Majno G. Presence of modified fibroblasts in granulation tissue and their possible role in wound contraction. Experientia. 1971;27: 549-590.

40 Boya J, Carboneli AL, Martinez A. Myofibroblasts in human palatal mucosa. Acta Anat. 1988;131:161-165.

41 Kapanci Y, Assimacopulus A, Irle C, Zwahlen A, Gabbiani G . Contractile interstitial cells in pulmonary septa: a possible regulator of ventilation- 
perfusion ratio? Ultrastructural, imunofluorecence and in vitro studies. J Cell Biol. 1974;60:375-392.

42 Seemayer A, Lagace R, Schürch W, Tremblay G. Myofibroblasts in the stroma of invasive and metastatic carcinoma: a possible host response to neoplasia. Am J Surg Pathol. 1979;3:525-533.

43 Schürch W, Seemayer A, Lagace R. Stromal myofibroblast in primary invasive and metastatic carcinoma. A combined immunological, light and electron microscopic study. Virchows Arch A. 1981;391:125-139.

44 Gabbiani G, Majno G. Dupuytren's contracture: fibroblast contraction an ultrastructural study. Am J Pathol. 1972;66:131-146.

45 Larson DL, Abston S, Willis B, Linhares $\mathrm{H}$ et al. Contracture and scars formation in the burn patient. Clin Plast Surg. 1974;1:653-656.

46 Schürch W, Seemayer A, Gabbiani G. The myofibroblast: a quarter century after its discovery. Am J Surg Pathol. 1998;22:141-147.

47 Vandekerckhove J, Weber K. Mammalian cytoplasmic actins are the products of at least two genes and differ in primary structure in at least 25 identified positions from skeletal muscle actin. Proc Natl Acad Sci USA. 1978;75:1106-1110.

48 Desmoulière A, GabbianiG. The hole of myofibroblast in wound healing and fibrocontractive diseases. In: Clark RAF, editor. The molecular and cellular biology of wound repair. New York: Plenum Press; 1996. p. 391-423.

49 Caplan Al, Fiszman MY, Eppemberger HM. Molecular and cell isoforms during development. Science. 1983;221:921-927.

50 Darby I, Skalli O, Gabbiani G. a-Smooth muscle actin is transiently expressed by myofibroblasts during experimental wound healing. Lab Ivest. 1990; 63:21-29.

51 Desmoulière A, Redard M, Darby I, Gabbiani G. Apoptosis mediates the decrease in cellularity during the transition between granulation tissue and scars. Am J Pathol. 1995;146:56-66. 
52 Singer I, Kawka DW, Kanazis DM, Clark RAF. In vivo codistribution of fibronectin and actin fibers ins granulation tissue: immunofluorescence and electron microscope studies of the fibronexus at the myofibroblast surface. $J$. Cell Biol. 1984;98:2091-2106.

53 Arora, PD, McCulloch CAG. Dependence of collagen remodeling on $\alpha-$ smooth muscle actin expression by fibroblasts. J Cell Physiol. 1994;159:161175.

54 Bornstein P, Ash TF. Cell surface-associated structural proteins in connective tissue cells. Proc Natl Acad Sci USA. 1977;74:2480-2484.

55 McDonald JA, Kelley DG, Broekelmann TJ. Role of fibronectin in collagen deposition: Fab' antibodies to the gelatin-binding domain of fibronectin inhibits both fibronectin and collagen organization in fibroblast extracellular matrix. J Cell Biol. 1982; 92:485-492.

56 Chen LB, Murray A, Segal RA, et al. Studies on intracellular LETS glycoprotein matrices. Cell. 1978;14:377-391.

57 Sato H, Takino T, Okada $Y$ et al. A matrix metalloproteinase expressed on the surface of invasive tumour cells. Nature. 1994;370:61-5.

58 Bently JP. Rate of chondroitin surfate formation in wound healing. Ann Surg. 1967;165:186-191.

59 Junqueira LC, Carneiro J. Histologia Básica. Rio de Janeiro: GuanabaraKoogan; 1982. p. 94.

60 Lehninger AL et cols. Princípios de bioquímica. São Paulo: Savier; 1995. p. 58.

61. Weber, L., Meigel, W. N., and Spier, W. Collagen polymorphism in pathologic human scars. Arch. Dermatol. Res. 1978;261: 63- 63.

62 Burgeson RE. Genetic heterogeneity of collagens. J Onvest Dermato. 1982;79:25-35. 
63 Kuhn K. Structure and biochemistry of collagen. Aesth Plast Surg. 1988; 9:141- 141.

64 Junqueira LC, Carneiro J. Histologia Básica. Rio de Janeiro: GuanabaraKoogan; 1982. p. 102.

65 Coiffman F et cols. Cirurgia plastica, reconstrutiva y estetica. Bogotá: Masson; 1994. p. 153.

66 Border WA, Noble NA. Transforming growth factor beta in tissue fibrosis. N Engl J Med. 1994;331:1286- 1286.

67 Peltonen J, Hsiao LL, Jaakkola S et al. Activation of collagen gene expression in keloids: co-localization of type I and $\mathrm{VI}$ collagen and transforming growth factor-beta 1 mRNA. J Invest Dermatol. 1991; 97:240.

68 Duncan MR, Hasan A, Berman B. Oncostatin M stimulates collagen and glycosaminoglycan production by cultured normal dermal fibroblasts: Insensitivity of sclerodermal and keloidal fibroblasts. J Invest. Dermatol. 1995;104:128.

69 Postlethwaite AE, Seyer JM. Fibroblast chemotaxis induction by human recombinant interleukin-4. Identification by synthetic peptide analysis of two chemotactic domains residing in amino acid sequences 70-88 and 89-122. J. Clin Invest. 1991;87:2147.

70 Dvorak HF. Tumors: wounds that do not heal. $N$ Engl $J$ Med. 1986;315(26):1650-1659.

71 Breasted JH. The Edwin Smith surgical papyrus (hieroglyphic translation and commentary). Chicago: University of Chicago Press; 1930. p. 403-406. v. 1.

72 Berman B, Bieley HC. Keloids. J Am Acad Dermatol. 1995;33:117.

73 Mancini RE, Quaife JV. Histogenesis of experimentally produced keloids. J Invest Dermatol. 1962;38:143-181. 
74 Peacock Jr EE, Madden JW, Trier W. C. Biologic basis for the treatment of keloids and hypertrophic scars. South Med J. 1970; 63:755.

75 Rockwell WB, Cohen IK, Ehrlich HP. Keloids and hypertrophic scars: a comprehensive review [see comments]. Plast Reconstr Surg. 1989;84:827.

76 Pollack SV, Goslen JB. The surgical treatment of keloids. J Dermatol Surg Oncol. 1982;8:1045.

77 Muir IF. On the nature of keloid and hypertrophic scars. $\mathrm{Br} J$ Plast Surg. 1990;43:61.

78 Norris JE. Hypertrophic scar and keloid (Letter). Plast Reconstr Surg. $1991 ; 88: 372$.

79 Tuan TL, Nichter LS. The molecular basis of keloid and hypertrophic scar formation. Mol Med Today. 1998;4:19.

80 Moustafa MF. Abdel Fattah MA, Abdel Fattah DC. Presumptive evidence of the effect of pregnancy estrogens on keloid growth. Case report. Plast Reconstr Surg. 1975;56:450.

81 Murray JC. Keloids and hypertrophic scars. Clin Dermatol. 1994;12:27.

82 Oluwasanmi JO. Keloids in the African. Clin Plast Surg. 1974;1:179.

83 Alhady SM, Sivanantharajah K. Keloids in various races: a review of 175 cases. Plast Reconstr Surg. 1969;44:564.

84 Ford T, Widgerow AD. Umbilical keloid: an early start. Ann Plast Surg. 1990;25:214.

85 Curtis AS, Seehar GM. The control of cell division by tension or diffusion. Nature. 1978;274:52.

86 Su CW, Alizadeh K, Boddie A, Lee RC. The problem scar. Clin Plast Surg. 1998;25:451.

87 Oliver N, Babu M, Diegelmann R. Fibronectin gene transcription is enhanced in abnormal wound healing. J Invest Dermatol. 1992;99:579. 
88 Tredget EE, Nedelec B, Scott PG, Ghahary A. Hypertrophic scars, keloids and contractures. The cellular and molecular basis for therapy. Surg Clin North Am. 1997;77:701.

89 Deitch EA, Wheelahan TM, Rose P, Clothier J, Cotter J. Hypertrophic burn scars: analysis of variables. J Trauma. 1983;23:895.

90 Castagnoli C, Trombotto C, Ondei S, et al. Characterization of T-cell subsets infiltrating post-burn hypertrophic scar tissues. Burns. 1997;28:565.

91 Dinarello CA. Interleukin-1 and interleukin-1 antagonism. Blood. 1991;77:1627.

92 Postlethwaite AE, Lachman LB, Mainardi CL, Kang AH. Interleukin 1 stimulation of collagenase production by cultured fibroblasts. $J$ Exp Med. 1983;157:801.

93 Machesney M, Tidman N, Waseem A, Kirby L, Leigh I. Activated keratinocytes in the epidermis of hypertrophic scars. Am $J$ Pathol. 1998;152:1133.

94 Russell JD, Witt WS. Cell size and growth characteristics of cultured fibroblasts isolated from normal and keloid tissue. Plast Reconstr Surg. 1976;57: 207.

95 Younai S, Nichter LS, Wellisz T, Reinisch J, Nimni ME, Tuan TL. Modulation of collagen synthesis by transforming growth factor-beta in keloid and hypertrophic scar fibroblasts. Ann. Plast. Surg. 1994;33:148.

96 Kischer CW, Hendrix MJ. Fibronectin (FN) in hypertrophic scars and keloids. Cell Tissue Res. 1983;231:29.

97 Younai S, Venters G, Vu S, Nichter L, Nimni ME, Tuan TL. Role of growth factors in scar contraction: An in vitro analysis. Ann Plast Surg. 1996;36:495.

98 Benton LD, Khan M, Greco RS. Integrins, adhesion molecules and surgical research. Surg Gynecol Obstet. 1993;177:311. 
99 Alaish SM, Yager DR, Diegelmann RF, Cohen IK. Hyaluronic acid metabolism in keloid fibroblasts. J Pediatr Surg. 1995;30:949.

100 Brennan MJ, Oldberg A, Ruoslahti E, Brown K, Schwartz N. Immunological evidence for two distinct chondroitin sulfate proteoglycan core proteins: Differential expression in cartilage matrix deficient mice. Dev Biol. 1983;98:139.

101 Bronson RE, Argenta JG, Siebert EP, Bertolami CN. Distinctive fibroblastic subpopulations in skin and oral mucosa demonstrated by differences in glycosaminoglycan content. In Vitro Cell Dev Biol. 1988;24:1121.

102 Linares HA, Larson DL. Early differential diagnosis between hypertrophic and nonhypertrophic healing. J Invest Dermatol. 1974;62:514.

103 Shetlar MR, Dobrkovsky M, Linares HA, Villarante R, Shetlar CL, Larson, DL. The hypertrophic scar: Glycoprotein and collagen components of burn scars. Proc Soc Exp Biol Med. 1971;138:298.

104 Huttenlocher A, Werb Z, Tremble P, Huhtala P, Rosenberg L, Damsky C. $\mathrm{H}$. Decorin regulates collagenase gene expression in fibroblasts adhering to vitronectin. Matrix Biol. 1996;15:239.

105 Hunzelmann N, Anders S, Sollberg S, Schonherr E, Krieg T. Co-ordinate induction of collagen type I and biglycan expression in keloids. $\mathrm{Br} J$ Dermatol. 1996;135:394.

106 Fleischmajer R, Fisher LW, MacDonald ED, Jacobs Jr L, Perlish JS, Termine JD. Decorin interacts with fibrillar collagen of embryonic and adult human skin. J Struct Biol. 1991;106:82.

107 Bidanset DJ, Guidry C, Rosenberg LC, Choi HU, Timpl R, Hook M. Binding of the proteoglycan decorin to collagen type VI. J Biol Chem. 1992;267:5250. 
108 Scott PG, Dodd CM, Ghahary A, Shen YJ, Tredget, EE. Fibroblasts from post-burn hypertrophic scar tissue synthesize less decorin than normal dermal fibroblasts. Clin Sci. 1998;94:541.

109 Haukipuro K, Melkko J, Risteli L, Kairaluoma M, Risteli J. Synthesis of type I collagen in healing wounds in humans. Ann. Surg. 1991;213:75.

110 Diegelmann RF, Rothkopf LC, Cohen IK. Measurement of collagen biosynthesis during wound healing. J Surg Res. 1975;19:239.

111 Betz P, Nerlich A, Wilske J, et al. The time-dependent rearrangement of the epithelial basement membrane in human skin woundsimmunohistochemical localization of collagen IV and VII. Int $J$ Legal Med. 1992;105: 93.

112 Horslev-Petersen K, Kim KY, Pedersen LR et al. Serum aminoterminal type III procollagen peptide. Relation to biosynthesis of collagen type III in exper-imentally induced granulation tissue in rats. APMIS. 1988;96:793.

113 Hayakawa T, Hashimoto $\mathrm{Y}$, Myokei $\mathrm{Y}$, Aoyama H, Izawa $\mathrm{Y}$. Changes in type of collagen during the development of human post-burn hypertrophic scars. Clin Chim Acta. 1979;93:119.

114 Uitto J, Perejda AJ, Abergel RP, Chu ML, Ramirez F. Altered steadystate ratio of type I/III procollagen mRNAs correlates with selectively increased type I procollagen biosynthesis in cultured keloid fibroblasts. Proc Natl Acad Sci USA. 1985;82:5935.

115 Lee KS, Song JY, Suh MH. Collagen mRNA expression detected by in situ hybridization in keloid tissue. J Dermatol Sci. 1991;2:316.

116 Kischer CW. Comparative ultrastructure of hypertrophic scars and keloids. Scan Electron Microsc. 1984;1:423.

117 Di Cesare PE, Cheung DT, Perelman N, Libaw E, Peng L, Nimni ME. Alteration of collagen composition and cross-linking in keloid tissues. Matrix. 1990;10:172. 
118 Castagnoli C, Stella M, Magliacani G, Alasia ST, Richiardi P. Anomalous expression of HLA class II molecules on keratinocytes and fibroblasts in hypertrophic scars consequent to thermal injury. Clin Exp Immunol. 1990;82:350.

119 McCauley RL, Chopra V, Li YY, Herndon DN, Robson MC. Altered cytokine production in black patients with keloids. J Clin Immunol. 1992;12:300.

120 Larrabee Jr WF, East CA, Jaffe HS, Stephenson C, Peterson KE. Intralesional interferon gamma treatment for keloids and hypertrophic scars. Arch. Otolaryngol. Head Neck Surg. 1990;116:1159.

121 Linares HA. Pathophysiology of the burn scar. In: Herndon DN, editor. Total burn care. London: Saunders; 1996. p.383-397.

122 Pittet $B$, Rubbia-Brandt L, Desmoulière $A$, Sappino AP, Roggero $P$, Guerret S, Grimaud JA, Montandon D, Gabbiani G. Effect of g-interferon on the clinical and biologic evolution of hypertrophic scars and Dupuytrens disease: an open pilot sutdy. Plast Reconstr Surg. 1994;93:1224-1235.

123 Lee $\mathrm{RC}$, Doong $\mathrm{H}$, Jellema $A F$. The response of burn scars to intralesional verapamil. Arch. Surg. 1994;129:107-111.

124 Perkins K, Davey RB, Walis KA. Silicone gel: a new treatment for burn scars and contractures. Burns. 1982;9:118-121.

125 Sproat JE, Dalcin A, Weitauer N, Roberts RS. Hypertrophic sternal scars: silicone gel sheet versus kenalog injection treatment. Plast Reconst Surg. 1992;90:988-992.

126 Ward A, Clissold SP. Pentoxifylline.-A review of its pharmacodynamic and pharmacokinetic properties, and its therapeutic efficacy. Drugs 1987;34:50-97. 
127 Lossnitzer K, Raptis S, Grebe B, Muller R. The influence of 3,7-dimethyl1-(5-oxo-hexyl)-xanthine (pentoxifylline, BL 191) on serum calcium and magnesium levels. [Journal Article]. Arzneimittel-Forschung. 1973 July;23(7):938-40.

128 Traumann KJ. Treatment of peripheral occlusive vascular disease with pentoxifylin (author's transl.). [German] [Journal Article]. Medizinische Klinik. 1976 Mar. 12;71(11):465-8,

129 Samlaska CP, Winfield EA. Pentoxifylline: clinical review. J Am Acad .Dermatol. 1994;30:603-621.

130 Duncan MR, Hasan A, Berman B. Pentoxyfilline and interferon decrease type I and III procollagen mRNA levels in dermal fibroblasts: evidence for mediation by nuclear factor 1 down-regulation. J Invest Dermatol. 1995;104:1-5.

131 Gressner AM. The cell biology of liver fibrogenesis-an imbalance of proliferation, growth arrest and apoptosis of myofibroblasts. Cell Tissue Res. 1998;292:447-52.

132 Friedman SL. The cellular basis of hepatic fibrosis. New Engl J Med 1993;328:1828-35.

133 Guerrini M, Pecchi S, Rossi C et al. Effects of pentifylline on blood hyperviscosity and peripheral hemodynamics in patients with peripheral obliterating arterial disease. Pharmacotherapeutica. 1983;3 (suppl 1):52-66.

134 Koppenhagen K, Wenig HG. The effect of pentoxifylline on liver perfusion: A comparative study in patients with liver diseases and in normal subjects, using 198Au-colloid-scintigraphy. Med Klin. 1979;35:1254-6.

135 Desmouliere A, Xu G, Costa AMA, et al. Effect of pentoxifylline on early proliferation and phenotypic modulation of fibrogenic cells in two rat models of liver fibrosis and on cultured hepatic stellate cells. J Hepatology. 1999; 30:621-631. 
136 Fazely F, Dezube BJ, Allen-Ryan J, Pardee AB, Ruprecht RM. Pentoxiphyline decreases the replication of the human immunodeficiency virus type I in human peripheral blood mononuclear cells and in cultured T cells. Blood. 1991;77:1653-1656.

137 Asaga H, Kikuchi S, Yoshizato K. Collagen gel contraction by fibroblasts requires cellular fibronectin but not plasma fibronectin. Exp Cell Res. 1991; 193:167-174.

138 Docherty R, Forrester JV, Lackie JM, Gregory DW. Glycosaminoglycans facilitate the moviment of fibroblasts throught three-dimensional collagen matrices. J Cell Sci. 1989;92(2):263-270.

139 Chang CC, Chang TC, Kao SCS, Kuo YF, Chien LF. Pentoxifylline inhibits the proliferation and glycosaminoglycan synthesis of cultured fibroblasts derived from patients with Graves' ophthalmopathy and pretibial mixoedema. Acta Endocrinol. 1993;129:322-327.

140 Andreass L. History of keratinocyte cultivation. Burns. 1992;18:s2-s4.

141 Carrel A, Burrows MT. Cultivation of tissues in vitro and its technique. $J$ Exp Med. 1911Mar.;13:387-396.

142 Carrel A, Burrows MT. Cultivation of adult tissues and organs outside the body. JAMA. 1910;55:1379.

143 UTHSCSA Image Tool for Windows versão 3.0. developed in the Department of Dental Diagnostic Science at The University of Texas Health Science Center, San Antonio, Texas by Wilcox CD, Dove SB, McDavid WD, Greer DB. Disponível em: http://ddsdx.uthscsa.edu/dig/itdesc.html .

144 Twisk JWR, Applied longitudinal data analysis for epidemiology. a practical guide. Cambridge: Cambridge University Press; 2003.

145 Hardin JW, Hilbe JM. Generalized estimating equations. Boca Raton FL: Chapman \& Hall; 2003. 
146 Pearson ES, Hartley HO. Biometrika tables for statistics. Cambridge: Cambridge University Press; 1972. v. 2.

147 Boemi L, Allison GM, Graham WP, M.D.; Krummel TM, Ehrlich HP. Differences between Scar and Dermal Cultured Fibroblasts Derived from a Patient with Recurrent Abdominal Incision Wound Herniation. Plastic \& Reconstructive Surgery. 1999 Oct.;104(5):1397-1405.

148 Dettelbach HR, Aviado DM. Clinical pharmacology of pentoxifylline with special reference to its hemorrheologic effect for the treatment of intermittent claudicatio. J Clin Pharmacol. 1985;25:8.

149 Ely H. Pentoxifylline therapy in dermatology. A review of localized hyperviscosity and its effects on the skin. Dermatol Clin. 1988 Oct;6(4):585608. Review.

150 Bergman JC. The determination of hidroxyproline in urine hydrolysates. Clin Chim Acta. 1970;v.27, p. 347.

151 Bezerra MC. Teodoro WR. de Oliveira CC. Velosa AP. Ogido LT. Gauditano G. Parra ER. Capelozzi VL. Yoshinari NH. Scleroderma-like remodeling induced by type $\mathrm{V}$ collagen. [Comparative Study. Journal Article. Research Support, Non-U.S. Gov't] Archives of Dermatological Research. 2006 July;298(2):51- 57.

152 Moseley R, Stewart JE, Stephens P, Waddington RJ, Thomas DW, Extracellular matrix metabolites as potential biomarkers of disease activity in wound fluid: lessons learned from other inflammatory diseases? British Journal of Dermatology. 2004 Mar.;150(3):401-413.

153 Rawlins JM MRCS; Lam, Wee L. MRCS; Karoo, Richard O. MRCS; Naylor, lan L. PhD; Sharpe, David T. OBE, FRCS. Quantifying collagen type in mature burn scars: a novel approach using histology and digital image analysis. Journal of Burn Care \& Research. 2006;27(1):60-65. 
154 Velosa APP. Indução de tolerância nasal com colágeno tipo $V$ em modelo experimental de escleroderma. [tese]. São Paulo: Faculdade de Medicina, Universidade de São Paulo; 2007.

155 Velosa AP, Teodoro WR, de Oliveira CC, Dos Santos Filho A, Moutinho RF, Santos AG, Vendramini MB, Bueno C, Parra ER, Capelozzi VL, Yoshinari NH. Collagen V nasal tolerance in experimental model of systemic sclerosis. Arch Dermatol Res. 2007;299(4):177-89. [Epub 2007 Feb. 13]

156 van de Bovenkamp M, Groothuis GM, Meijer DK, Olinga P. Precision-cut fibrotic rat liver slices as a new model to test the effects of anti-fibrotic drugs in vitro. J Hepatol. 2006;45(5):696-703. [Epub 2006 May 26].

157 Lin SL, Chen RH, Chen YM, Chiang WC, Lai CF, Wu KD, Tsai TJ. Pentoxifylline attenuates tubulointerstitial fibrosis by blocking Smad3/4activated transcription and profibrogenic effects of connective tissue growth factor. J Am Soc Nephrol. 2005 Sep;16(9):2702- 2713. [Epub 2005 June 29]

158 Chen YM, Ng YY, Lin SL, Chiang WC, Lan HY, Tsai TJ. Pentoxifylline suppresses renal tumour necrosis factor-alpha and ameliorates experimental crescentic glomerulonephritis in rats. Nephrol Dial Transplant. 2004 May;19(5):1106- 1115. [Epub 2004 Feb. 19].

159 Raetsch C, Jia JD, Boigk G, Bauer M, Hahn EG, Riecken EO, Schuppan D. Pentoxifylline downregulates profibrogenic cytokines and procollagen I expression in rat secondary biliary fibrosis. Gut. 2002 Feb.;50(2):241- 247.

160 Strutz F, Heeg M, Kochsiek T, Siemers G, Zeisberg M, Muller GA. Effects of pentoxifylline, pentifylline and gamma-interferon on proliferation, differentiation, and matrix synthesis of human renal fibroblasts. Nephrol Dial Transplant. 2000 Oct.;15(10):1535- 1546.

161 Hewitson TD, Martic M, Kelynack KJ, Pedagogos E, Becker GJ. Pentoxifylline reduces in vitro renal myofibroblast proliferation and collagen secretion.Am J Nephrol. 2000 Jan./Feb.;20(1):82- 88. 
162 Saika S, Yamanaka O, Okada Y, Tanaka S, Ohnishi Y, Ooshima A. Pentoxifylline and pentifylline inhibit proliferation of human tenon's capsule fibroblasts and production of type-I collagen and laminin in vitro. Ophthalmic Res. 1996;28(3):165-70.

163 Bell E, Ivarsson B, Merill C. Production of a tissue-like structure by contraction of collagen lattices by human fibroblasts of different proliferative potential in vitro. Proc Nat Acad Sci USA. 1979;76:1274.

164 Kamamoto F, Paggiaro AO, Rodas A, Herson MR, Mathor MB, Ferreira MC. A wound contraction experimental model for studying keloids and wound-healing modulators. [Journal article]. Artificial Organs. 2003;27(8):701-705. 
Apêndices 


\section{Apêndice A - Preparo da matriz extracelular de colágeno}

A matriz de colágeno, utilizada no experimento de avaliação da contração de modelo tridimensional de matriz extracelular de colágeno povoada por fibroblastos, foi elaborada no LIM 04 da Faculdade de Medicina da USP, a partir de solução de colágeno de tendão de cauda de rato.

\section{Obtenção da matriz amorfa de colágeno em solução}

A solução de colágeno foi preparada segundo protocolo proposto por Bell et al., exposto a seguir: Erro! Indicador não definido. caudas de ratos tipo WistarFurth foram lavadas com escova cirúrgica e sabão e imersas em álcool etílico $70 \%$ por 24 horas. Os quatro tendões existentes nas caudas dos ratos foram retirados assepticamente e colocados em recipiente com ácido acético diluído 1:1.000, empregando-se $250 \mathrm{~mL}$ para cada cauda. A mistura foi mantida por 48 horas em agitação magnética a $4^{\circ} \mathrm{C}$ e armazenada, a seguir, sob refrigeração $\left(4^{\circ} \mathrm{C}\right)$. Após duas semanas, obteve-se uma solução viscosa que, centrifugada a 500 rpm, durante uma hora, gerou duas fases: a fração sobrenadante contendo principalmente colágeno tipo I solubilizado, que foi retirada e guardada a $4^{\circ} \mathrm{C}$ (ácido solúvel), e a restante, representando a fração de colágeno ácido insolúvel, que foi descartada. 


\section{Determinação da concentração de colágeno}

Para padronização dos experimentos, a concentração de colágeno tipo I da solução obtida foi determinada indiretamente, calculando-se a concentração de hidroxiprolina (HOP), um dos principais aminoácidos constituintes do colágeno tipo I, correspondendo a aproximadamente $13 \%$ dos aminoácidos existentes nesse colágeno.

Assim sendo, foram retiradas amostras de $1 \mathrm{~mL}$, em triplicata, da solução de colágeno para cálculo de sua concentração, a saber:

\section{Fase de hidrólise}

A cada alíquota de $1 \mathrm{~mL}$ de solução de colágeno foram adicionados 5 $\mathrm{mL}$ de ácido clorídrico $(\mathrm{HCl}) 6 \mathrm{~N}$, passando-se o material para ampolas vedadas, mantidas por aproximadamente 22 horas em estufa a $110^{\circ} \mathrm{C}$ para efetivação da hidrólise ácida. Esse procedimento resulta na liberação de hidroxiprolina livre, que pode ser dosada por espectrofotometria de massa.

\section{Fase de neutralização}

De cada alíquota hidrolisada, obtiveram-se amostras em triplicata de 1 $\mathrm{mL}$, que foram neutralizadas e tituladas pela adição de: $20 \mu \mathrm{g}$ fenolftaleína 1\% em solução alcoólica; 1 a 2 mL de solução saturada de hidróxido de lítio ( $\mathrm{LiOH})$, até mudança de cor da solução, de incolor para rosada, e 10 a $20 \mu \mathrm{L}$ 
de $\mathrm{HCl} 6 \mathrm{~N}$ até obtenção, novamente, de uma solução incolor. A neutralização do $\mathrm{pH}$ foi confirmada com papel de tornassol $(\mathrm{pH}=7)$.

\section{Fase de oxidação}

A seguir, em tubos de ensaio, foram dispostos soluções e reagentes, conforme apresentado na Tabela 13 abaixo.

Tabela 13 - Distribuição de soluções e reagentes em tubos de ensaio para reação de oxidação do colágeno testado

\begin{tabular}{|c|c|}
\hline \multicolumn{2}{|c|}{ Fase de oxidação - soluções e reagentes } \\
\hline 1 tubo solução blank (branca) & $1 \mathrm{~mL}$ água $+2 \mathrm{~mL}$ isopropanol \\
\hline $\begin{array}{l}1 \text { tubo solução padrão colágeno } \\
(\text { HOP } 20 \mu \mathrm{g} / \mathrm{mL})\end{array}$ & $1 \mathrm{~mL}$ água $+2 \mathrm{~mL}$ isopropanol + \\
\hline $\begin{array}{l}1 \text { tubo solução padrão aminoácidos (HOP } \\
20 \mu \mathrm{g} / \mathrm{mL} \text { ) }\end{array}$ & $0.02 \mathrm{~mL}(4 \mu \mathrm{g})$ sol. padrão \\
\hline 3 tubos para cada amostra & $1 \mathrm{~mL}$ amostra $+2 \mathrm{~mL}$ isopropanol \\
\hline
\end{tabular}

Para que ocorresse a oxidação foram adicionados, a cada tubo de ensaio (exceto blank), $1 \mathrm{~mL}$ de mistura oxidante (cloramina $\mathrm{T}+$ solução tampão 1:4), aguardando-se 4 minutos em temperatura ambiente para que houvesse oxidação do material. 


\section{Fase de coloração}

O processo de coloração do material foi realizado pela adição de $2 \mathrm{~mL}$ de reagente de Ehrlich (27,4 mL de ácido sulfúrico em $200 \mathrm{~mL}$ de etanol; o conjunto foi adicionado à solução de $120 \mathrm{~g}$ de p-dimetilaminobenzaldeído em $200 \mathrm{~mL}$ de etanol), esse reagente se liga aos $\mathrm{H}^{+}$das hidroxilas livres. Após encubação em banho termostatizado a $60^{\circ} \mathrm{C}$ por 20 minutos, procedeu-se à leitura de absorbância da amostra em aparelho de espectrofotometria no comprimento de onda de $565 \mathrm{~nm}$, calibrando-se a solução blank como zero. Após essa medida, foi possível determinar a concentração do colágeno solubilizado utilizando-se a seguinte fórmula:

[HOP] $=$ [absorbância da amostra $x$ fator $x$ diluição de LiOH $x(5 x$ vol de $\mathrm{HCI})]$ massa de colágeno

Obs: fator $=4 /$ Absorbância padrão

Para o cálculo da concentração de colágeno tipo I da amostra, a partir da concentração de HOP, multiplicou-se o valor obtido pela constante de conversão 7,5 .

\section{Correção da concentração de colágeno}

Uma vez determinada a concentração de colágeno I na solução analisada, este valor foi corrigido, pela adição de ácido acético 1:1000, para 
a concentração de $1,21 \mathrm{mg} / \mathrm{mL}$ de colágeno I preconizada no protocolo da Collagen Biomaterials, utilizando-se a fórmula:

$$
C_{1} \times V_{1}=C_{2} \times V_{2}
$$

Onde: $\mathrm{C}_{1}=$ concentração inicial

$\mathrm{C}_{2}=$ concentração final

$\mathrm{V}_{1}=$ volume inicial

$V_{2}=$ volume final 


\section{Apêndice $B$ - Banco de dados}

\begin{tabular}{|c|c|c|c|c|c|c|c|c|c|c|c|c|}
\hline \multicolumn{13}{|c|}{ Tabela 14 - Curva de proliferação HFN ( $\times 10^{3}$ cels) } \\
\hline \multirow{3}{*}{$\begin{array}{l}\text { Paciente } \\
01\end{array}$} & \multirow{3}{*}{$\begin{array}{l}\text { Amostra } \\
1\end{array}$} & \multirow[b]{2}{*}{ 0/1 PTF } & \multirow{2}{*}{\multicolumn{2}{|c|}{$\begin{array}{l}12 \mathrm{~h} \\
\text { viva morta }\end{array}$}} & \multicolumn{2}{|c|}{$24 \mathrm{~h}$} & \multicolumn{2}{|c|}{$48 \mathrm{~h}$} & \multicolumn{2}{|c|}{$72 \mathrm{~h}$} & \multicolumn{2}{|l|}{$96 \mathrm{~h}$} \\
\hline & & & & & viva & morta & viva & morta & viva & morta & viva & morta \\
\hline & & 0 & 10 & 10 & 20 & 0 & 50 & 0 & 60 & 0 & 70 & 10 \\
\hline & 2 & 0 & 20 & 0 & 10 & 0 & 50 & 0 & 70 & 10 & 130 & 0 \\
\hline & 3 & 0 & 20 & 10 & 20 & 10 & 50 & 10 & 80 & 0 & 90 & 20 \\
\hline & 4 & 1 & 10 & 0 & 20 & 0 & 20 & 10 & 40 & 20 & 70 & 0 \\
\hline & 5 & 1 & 20 & 0 & 40 & 0 & 50 & 10 & 50 & 0 & 50 & 10 \\
\hline & 6 & 1 & 10 & 10 & 20 & 10 & 30 & 0 & 40 & 0 & 40 & 0 \\
\hline \multirow[t]{6}{*}{02} & 1 & 0 & 30 & 0 & 10 & 10 & 30 & 10 & 90 & 10 & 100 & 10 \\
\hline & 2 & 0 & 10 & 0 & 30 & 0 & 40 & 0 & 80 & 10 & 110 & 0 \\
\hline & 3 & 0 & 10 & 10 & 10 & 10 & 40 & 10 & 80 & 10 & 110 & 10 \\
\hline & 4 & 1 & 10 & 20 & 20 & 20 & 30 & 0 & 40 & 10 & 80 & 0 \\
\hline & 5 & 1 & 20 & 0 & 30 & 10 & 40 & 10 & 40 & 0 & 70 & 0 \\
\hline & 6 & 1 & 20 & 0 & 10 & 0 & 50 & 0 & 50 & 10 & 50 & 0 \\
\hline \multirow[t]{6}{*}{03} & 1 & 0 & 20 & 10 & 20 & 10 & 50 & 10 & 80 & 0 & 110 & 10 \\
\hline & 2 & 0 & 20 & 0 & 20 & 0 & 50 & 0 & 60 & 10 & 120 & 0 \\
\hline & 3 & 0 & 0 & 10 & 20 & 0 & 50 & 0 & 60 & 0 & 90 & 10 \\
\hline & 4 & 1 & 10 & 10 & 20 & 10 & 40 & 0 & 50 & 0 & 60 & 0 \\
\hline & 5 & 1 & 20 & 0 & 20 & 0 & 50 & 10 & 70 & 10 & 80 & 0 \\
\hline & 6 & 1 & 10 & 0 & 20 & 0 & 20 & 0 & 40 & 0 & 60 & 10 \\
\hline \multirow[t]{6}{*}{04} & 1 & 0 & 10 & 10 & 10 & 10 & 40 & 10 & 80 & 10 & 110 & 10 \\
\hline & 2 & 0 & 10 & 0 & 30 & 0 & 40 & 0 & 80 & 0 & 130 & 0 \\
\hline & 3 & 0 & 20 & 0 & 20 & 10 & 50 & 10 & 70 & 10 & 80 & 10 \\
\hline & 4 & 1 & 10 & 20 & 20 & 20 & 30 & 20 & 30 & 10 & 50 & 10 \\
\hline & 5 & 1 & 20 & 0 & 20 & 10 & 50 & 10 & 50 & 0 & 60 & 10 \\
\hline & 6 & 1 & 20 & 0 & 10 & 10 & 40 & 0 & 40 & 0 & 70 & 10 \\
\hline \multirow[t]{6}{*}{05} & 1 & 0 & 20 & 0 & 20 & 10 & 50 & 10 & 70 & 10 & 80 & 0 \\
\hline & 2 & 0 & 10 & 10 & 20 & 10 & 50 & 0 & 90 & 0 & 140 & 10 \\
\hline & 3 & 0 & 20 & 10 & 20 & 20 & 60 & 10 & 110 & 10 & 160 & 0 \\
\hline & 4 & 1 & 10 & 10 & 20 & 10 & 40 & 0 & 40 & 10 & 70 & 0 \\
\hline & 5 & 1 & 20 & 0 & 20 & 0 & 50 & 10 & 60 & 0 & 70 & 10 \\
\hline & 6 & 1 & 10 & 0 & 20 & 0 & 20 & 10 & 40 & 0 & 50 & 10 \\
\hline \multirow[t]{6}{*}{$\overline{06}$} & 1 & 0 & 30 & 0 & 30 & 10 & 30 & 0 & 70 & 0 & 90 & 0 \\
\hline & 2 & 0 & 10 & 0 & 30 & 0 & 40 & 0 & 80 & 10 & 120 & 0 \\
\hline & 3 & 0 & 10 & 10 & 10 & 10 & 40 & 10 & 80 & 10 & 140 & 10 \\
\hline & 4 & 1 & 10 & 20 & 0 & 20 & 30 & 20 & 50 & 10 & 50 & 0 \\
\hline & 5 & 1 & 20 & 0 & 20 & 0 & 30 & 0 & 30 & 10 & 60 & 0 \\
\hline & 6 & 1 & 20 & 0 & 30 & 10 & 50 & 10 & 50 & 0 & 70 & 0 \\
\hline \multirow[t]{2}{*}{07} & 1 & 0 & 20 & 0 & 20 & 10 & 50 & 0 & 70 & 10 & 130 & 0 \\
\hline & 2 & 0 & 20 & 10 & 20 & 10 & 50 & 10 & 80 & 0 & 80 & $\begin{array}{c}0 \\
\text { ua) }\end{array}$ \\
\hline
\end{tabular}




\begin{tabular}{|c|c|c|c|c|c|c|c|c|c|c|c|c|}
\hline \multicolumn{13}{|c|}{ Tabela 14 - Curva de proliferação HFN (x10³ cels) (conclusão) } \\
\hline \multirow[b]{2}{*}{ Paciente } & \multirow[b]{2}{*}{ Amostra } & \multirow[b]{2}{*}{ 0/1 PTF } & \multirow{2}{*}{\multicolumn{2}{|c|}{$\begin{array}{l}12 \mathrm{~h} \\
\text { viva morta }\end{array}$}} & \multicolumn{2}{|c|}{$24 \mathrm{~h}$} & \multicolumn{2}{|c|}{$48 \mathrm{~h}$} & \multicolumn{2}{|c|}{$72 \mathrm{~h}$} & \multicolumn{2}{|l|}{$96 \mathrm{~h}$} \\
\hline & & & & & viva & morta & viva & morta & viva & morta & viva & morta \\
\hline & 3 & 0 & 10 & 10 & 20 & 0 & 50 & 0 & 70 & 10 & 140 & 10 \\
\hline & 4 & 1 & 10 & 10 & 10 & 10 & 30 & 0 & 40 & 0 & 50 & 10 \\
\hline & 5 & 1 & 20 & 0 & 40 & 0 & 50 & 0 & 70 & 0 & 70 & 10 \\
\hline & 6 & 1 & 10 & 0 & 20 & 0 & 20 & 10 & 30 & 10 & 40 & 0 \\
\hline \multirow[t]{6}{*}{08} & 1 & 0 & 10 & 10 & 0 & 10 & 40 & 10 & 70 & 10 & 140 & 0 \\
\hline & 2 & 0 & 10 & 0 & 30 & 0 & 40 & 0 & 80 & 0 & 140 & 0 \\
\hline & 3 & 0 & 30 & 0 & 10 & 10 & 40 & 10 & 70 & 0 & 140 & 0 \\
\hline & 4 & 1 & 10 & 20 & 20 & 20 & 20 & 20 & 40 & 10 & 50 & 10 \\
\hline & 5 & 1 & 20 & 0 & 20 & 10 & 40 & 10 & 30 & 10 & 40 & 10 \\
\hline & 6 & 1 & 20 & 0 & 10 & 0 & 30 & 0 & 40 & 10 & 70 & 10 \\
\hline \multirow[t]{6}{*}{$\overline{09}$} & 1 & 0 & 20 & 0 & 20 & 0 & 50 & 0 & 70 & 10 & 110 & 0 \\
\hline & 2 & 0 & 30 & 10 & 30 & 10 & 50 & 10 & 70 & 0 & 110 & 20 \\
\hline & 3 & 0 & 0 & 10 & 20 & 0 & 50 & 0 & 60 & 0 & 60 & 20 \\
\hline & 4 & 1 & 10 & 10 & 20 & 10 & 40 & 10 & 40 & 0 & 60 & 0 \\
\hline & 5 & 1 & 20 & 0 & 40 & 0 & 50 & 0 & 40 & 0 & 40 & 10 \\
\hline & 6 & 1 & 10 & 0 & 20 & 0 & 20 & 10 & 40 & 0 & 50 & 30 \\
\hline \multirow[t]{6}{*}{10} & 1 & 0 & 10 & 10 & 10 & 10 & 40 & 10 & 80 & 10 & 110 & 10 \\
\hline & 2 & 0 & 10 & 0 & 30 & 0 & 40 & 0 & 70 & 0 & 80 & 20 \\
\hline & 3 & 0 & 40 & 0 & 20 & 10 & 30 & 10 & 70 & 0 & 130 & 0 \\
\hline & 4 & 1 & 10 & 20 & 20 & 20 & 30 & 0 & 30 & 10 & 40 & 10 \\
\hline & 5 & 1 & 20 & 0 & 30 & 10 & 50 & 0 & 40 & 10 & 50 & 0 \\
\hline & 6 & 1 & 20 & 0 & 10 & 0 & 30 & 0 & 30 & 10 & 60 & 0 \\
\hline
\end{tabular}

0/1 PTF = ausência ou presença de PTF

\begin{tabular}{|c|c|c|c|c|c|c|c|}
\hline Paciente & Amostra & 0/1 PTF & CPM & $\begin{array}{l}\text { (Inesp) } \\
144,67\end{array}$ & Média & DV & $\begin{array}{l}\text { Máx. } \\
73.560,35\end{array}$ \\
\hline \multirow[t]{6}{*}{11} & 1 & 0 & $2.802,01$ & $2.657,34$ & 2221,67 & 471,94 & \\
\hline & 2 & 0 & $1.865,01$ & $1.720,34$ & & & \\
\hline & 3 & 0 & $2.432,01$ & $2.287,34$ & & & \\
\hline & 4 & 1 & $1.269,00$ & $1.124,33$ & 1285,00 & 187,04 & \\
\hline & 5 & 1 & $1.385,00$ & $1.240,33$ & & & \\
\hline & 6 & 1 & $1.635,00$ & $1.490,33$ & & & \\
\hline \multirow[t]{6}{*}{12} & 1 & 0 & $3.066,01$ & $2.921,34$ & 2969,34 & 222,92 & \\
\hline & 2 & 0 & $2.919,01$ & $2.774,34$ & & & \\
\hline & 3 & 0 & $3.357,02$ & $3.212,35$ & & & \\
\hline & 4 & 1 & $1.233,00$ & $1.088,33$ & 1589,67 & 625,31 & \\
\hline & 5 & 1 & $1.535,01$ & $1.390,34$ & & & \\
\hline & 6 & 1 & $2.435,01$ & $2.290,34$ & & & \\
\hline \multirow[t]{6}{*}{13} & 1 & 0 & $2.150,01$ & $2.005,34$ & 2009,34 & 313,02 & \\
\hline & 2 & 0 & $1.843,01$ & $1.698,34$ & & & \\
\hline & 3 & 0 & $2.469,02$ & $2.324,35$ & & & \\
\hline & 4 & 1 & $1.135,01$ & 990,34 & 1305,01 & 275,88 & \\
\hline & 5 & 1 & $1.564,01$ & $1.419,34$ & & & \\
\hline & 6 & 1 & $1.650,01$ & $1.505,34$ & & & (continua) \\
\hline
\end{tabular}


Tabela 15 - Incorporação de ${ }^{3} \mathrm{H}$-Prolina por HSHF (conclusão)

\begin{tabular}{|c|c|c|c|c|c|c|c|}
\hline Paciente & Amostra & 0/1 PTF & CPM & $\begin{array}{l}\text { (Inesp) } \\
144,67\end{array}$ & Média & DV & $\begin{array}{l}\text { Máx. } \\
73.560,35\end{array}$ \\
\hline \multirow[t]{6}{*}{14} & 1 & 0 & $3.541,03$ & $3.396,36$ & 3691,36 & 266,40 & \\
\hline & 2 & 0 & $3.908,03$ & $3.763,36$ & & & \\
\hline & 3 & 0 & $4.059,03$ & $3.914,36$ & & & \\
\hline & 4 & 1 & $1.811,01$ & $1.666,34$ & 1989,34 & 294,63 & \\
\hline & 5 & 1 & $2.203,01$ & $2.058,34$ & & & \\
\hline & 6 & 1 & $2.388,02$ & $2.243,35$ & & & \\
\hline \multirow[t]{6}{*}{$\overline{15}$} & 1 & 0 & $2.373,02$ & $2.228,35$ & 2245,68 & 87,30 & \\
\hline & 2 & 0 & $2.313,02$ & $2.168,35$ & & & \\
\hline & 3 & 0 & $2.485,02$ & $2.340,35$ & & & \\
\hline & 4 & 1 & $1.445,01$ & $1.300,34$ & 1433,34 & 126,17 & \\
\hline & 5 & 1 & 1.593 .01 & $1.448,34$ & & & \\
\hline & 6 & 1 & $1.696,01$ & $1.551,34$ & & & \\
\hline \multirow[t]{6}{*}{16} & 1 & 0 & $3.658,04$ & $3.513,37$ & 3698,37 & 185,00 & \\
\hline & 2 & 0 & $3.843,04$ & $3.698,37$ & & & \\
\hline & 3 & 0 & $4.028,04$ & $3.883,37$ & & & \\
\hline & 4 & 1 & $1.805,02$ & $1.660,35$ & 1822,35 & 208,32 & \\
\hline & 5 & 1 & $1.894,02$ & $1.749,35$ & & & \\
\hline & 6 & 1 & $2.202,02$ & $2.057,35$ & & & \\
\hline \multirow[t]{6}{*}{17} & 1 & 0 & $2.072,02$ & $1.927,35$ & 1993,69 & 116,63 & \\
\hline & 2 & 0 & $2.070,03$ & $1.925,36$ & & & \\
\hline & 3 & 0 & $2.273,03$ & $2.128,36$ & & & \\
\hline & 4 & 1 & $1.164,01$ & $1.019,34$ & 1103,01 & 213,20 & \\
\hline & 5 & 1 & $1.089,01$ & 944,34 & & & \\
\hline & 6 & 1 & $1.490,02$ & $1.345,35$ & & & \\
\hline \multirow[t]{6}{*}{18} & 1 & 0 & $3.958,05$ & $3.813,38$ & 4625,06 & 791,36 & \\
\hline & 2 & 0 & $4.812,07$ & $4.667,40$ & & & \\
\hline & 3 & 0 & $5.539,08$ & $5.394,41$ & & & \\
\hline & 4 & 1 & $1.904,02$ & $1.759,35$ & 1952,69 & 277,27 & \\
\hline & 5 & 1 & $1.973,03$ & $1.828,36$ & & & \\
\hline & 6 & 1 & $2.415,03$ & $2.270,36$ & & & \\
\hline \multirow[t]{6}{*}{19} & 1 & 0 & $1.902,03$ & $1.757,36$ & 1730,36 & 27,00 & \\
\hline & 2 & 0 & $1.848,03$ & $1.703,36$ & & & \\
\hline & 3 & 0 & $1.875,03$ & $1.730,36$ & & & \\
\hline & 4 & 1 & $1.169,02$ & $1.024,35$ & 1127,35 & 93,64 & \\
\hline & 5 & 1 & $1.352,02$ & $1.207,35$ & & & \\
\hline & 6 & 1 & $1.295,02$ & $1.150,35$ & & & \\
\hline \multirow[t]{6}{*}{20} & 1 & 0 & $5.608,60$ & $5.463,93$ & 5463,93 & 103,51 & \\
\hline & 2 & 0 & $5.505,09$ & $5.360,42$ & & & \\
\hline & 3 & 0 & $5.712,10$ & $5.567,43$ & & & \\
\hline & 4 & 1 & $2.058,03$ & $1.913,36$ & 1976,53 & 63,01 & \\
\hline & 5 & 1 & $2.184,04$ & $2.039,37$ & & & \\
\hline & 6 & 1 & $2.121,53$ & $1.976,86$ & & & \\
\hline
\end{tabular}

0/1 PTF = ausência ou presença de PTF 


\section{Tabela 16 - Incorporação de ${ }^{3} \mathrm{H}$-Prolina por NHF}

\begin{tabular}{|c|c|c|c|c|c|c|c|}
\hline Paciente & Amostra & 0/1 PTF & CPM & $\begin{array}{l}\text { (Inesp) } \\
158,34\end{array}$ & Média & DV & $\begin{array}{l}\text { Máx. } \\
6.931,90\end{array}$ \\
\hline \multirow[t]{6}{*}{01} & 1 & 0 & $2.261,04$ & $2.102,70$ & 1894,37 & 188,47 & \\
\hline & 2 & 0 & $2.003,04$ & $1.844,70$ & & & \\
\hline & 3 & 0 & $1.894,04$ & $1.735,70$ & & & \\
\hline & 4 & 1 & $1.253,02$ & $1.094,68$ & 964,68 & 147,96 & \\
\hline & 5 & 1 & $1.154,02$ & 995,68 & & & \\
\hline & 6 & 1 & 962,02 & 803,68 & & & \\
\hline \multirow{6}{*}{02} & 1 & 0 & $3.152,06$ & $2.993,72$ & 2870,05 & 123,50 & \\
\hline & 2 & 0 & $2.905,06$ & $2.746,72$ & & & \\
\hline & 3 & 0 & $3.028,06$ & $2.869,72$ & & & \\
\hline & 4 & 1 & $1.349,03$ & $1.190,69$ & 1141,02 & 43,02 & \\
\hline & 5 & 1 & $1.274,03$ & $1.115,69$ & & & \\
\hline & 6 & 1 & $1.275,03$ & $1.116,69$ & & & \\
\hline \multirow[t]{6}{*}{03} & 1 & 0 & $1.204,03$ & $1.045,69$ & 1159,36 & 98,72 & \\
\hline & 2 & 0 & $1.367,03$ & $1.208,69$ & & & \\
\hline & 3 & 0 & $1.382,03$ & $1.223,69$ & & & \\
\hline & 4 & 1 & 782,02 & 623,68 & 615,01 & 46,61 & \\
\hline & 5 & 1 & 815,02 & 656,68 & & & \\
\hline & 6 & 1 & 723,02 & 564,68 & & & \\
\hline \multirow[t]{6}{*}{04} & 1 & 0 & $3.012,06$ & $2.853,72$ & 2783,39 & 99,36 & \\
\hline & 2 & 0 & $2.985,06$ & $2.826,72$ & & & \\
\hline & 3 & 0 & $2.828,06$ & $2.669,72$ & & & \\
\hline & 4 & 1 & $1.309,03$ & $1.150,69$ & 1122,36 & 39,93 & \\
\hline & 5 & 1 & $1.298,03$ & $1.139,69$ & & & \\
\hline & 6 & 1 & $1.235,03$ & $1.076,69$ & & & \\
\hline \multirow[t]{6}{*}{05} & 1 & 0 & $1.629,04$ & $1.470,70$ & 1827,37 & 411,58 & \\
\hline & 2 & 0 & $1.892,04$ & $1.733,70$ & & & \\
\hline & 3 & 0 & $2.436,05$ & $2.277,71$ & & & \\
\hline & 4 & 1 & 772,02 & 613,68 & 760,35 & 128,29 & \\
\hline & 5 & 1 & $1.010,02$ & 851,68 & & & \\
\hline & 6 & 1 & 974,02 & 815,68 & & & \\
\hline \multirow[t]{6}{*}{06} & 1 & 0 & $1.298,03$ & $1.139,69$ & 1224,02 & 84,50 & \\
\hline & 2 & 0 & $1.467,03$ & $1.308,69$ & & & \\
\hline & 3 & 0 & $1.382,03$ & $1.223,69$ & & & \\
\hline & 4 & 1 & 812,02 & 653,68 & 623,35 & 46,61 & \\
\hline & 5 & 1 & 805,02 & 646,68 & & & \\
\hline & 6 & 1 & 728,02 & 569,68 & & & \\
\hline \multirow[t]{6}{*}{07} & 1 & 0 & $1.649,04$ & $1.490,70$ & 1595,37 & 101,65 & \\
\hline & 2 & 0 & $1.852,04$ & $1.693,70$ & & & \\
\hline & 3 & 0 & $1.760,04$ & $1.601,70$ & & & \\
\hline & 4 & 1 & 992,02 & 833,68 & 868,35 & 79,86 & \\
\hline & 5 & 1 & $1.118,02$ & 959,68 & & & \\
\hline & 6 & 1 & 970,02 & 811,68 & & & \\
\hline \multirow[t]{5}{*}{08} & 1 & 0 & $2.247,06$ & $2.088,72$ & 2268,38 & 521,26 & \\
\hline & 2 & 0 & $2.019,05$ & $1.860,71$ & & & \\
\hline & 3 & 0 & $3.014,04$ & $2.855,70$ & & & \\
\hline & 4 & 1 & 853,02 & 694,68 & 902,68 & 225,11 & \\
\hline & 5 & 1 & $1.030,02$ & 871,68 & & & continua \\
\hline
\end{tabular}




\begin{tabular}{llllllll}
\hline \multicolumn{6}{c}{ Tabela 16 - Incorporação de ${ }^{3} \mathrm{H}$-Prolina por NHF (conclusão) } \\
\hline Paciente & Amostra & 0/1 PTF & CPM & (Inesp) & Média & DV & Máx. \\
& & & & 158,34 & & & $6.931,90$ \\
\hline 09 & 1 & 0 & $2.055,05$ & $1.896,71$ & 1867,38 & 145,24 & \\
& 2 & 0 & $2.154,06$ & $1.995,72$ & & & \\
& 3 & 0 & $1.868,05$ & $1.709,71$ & & & \\
& 4 & 1 & $1.028,03$ & 869,69 & 784,02 & 90,89 & \\
& 5 & 1 & 847,02 & 688,68 & & & \\
\hline 10 & 1 & 952,02 & 793,68 & & & \\
& 1 & 0 & $3.112,06$ & $2.953,72$ & 2830,05 & 110,83 & \\
& 1 & 0 & $2.955,06$ & $2.796,72$ & & & \\
& 3 & 0 & $2.898,06$ & $2.739,72$ & & & \\
& 4 & 1 & $1.319,03$ & $1.160,69$ & 1118,69 & 54,81 & \\
& 5 & 1 & $1.297,03$ & $1.138,69$ & & & \\
6 & 1 & $1.215,03$ & $1.056,69$ & & & \\
\hline
\end{tabular}

0/1 PTF = ausência ou presença de PTF

Tabela 17- Escore para imunomarcação de colágeno tipo I e tipo III

Desvio

\begin{tabular}{llllllll} 
Grupo & PTF e Tipo & Mínimo & Mediana Máximo & Média & Padrão & $\mathbf{n}$ \\
\hline & sem PTF - tipo I & 2 & 3 & 3 & 2,6 & 0,52 & 10
\end{tabular}

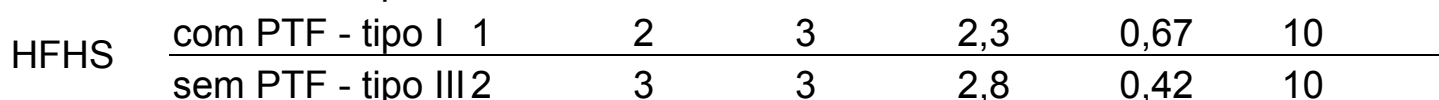

\begin{tabular}{llllll} 
com PTF - tipo III 1 & 2 & 2 & 1,7 & 0,48 & 10 \\
\hline sem PTF - tipo I 2 & 2 & 3 & 2,4 & 0,52 & 10
\end{tabular}

\begin{tabular}{lllllll} 
HFN & com PTF - tipo I 1 & 1 & 2 & 1,3 & 0,48 & 10 \\
\cline { 2 - 7 } & sem PTF - tipo III 1 & 1 & 3 & 1,6 & 0,84 & 10 \\
com PTF - tipo III 1 & 1 & 3 & 1,6 & 0,84 & 10 \\
\hline
\end{tabular}

\begin{tabular}{|c|c|c|c|c|}
\hline \multicolumn{5}{|c|}{ Tabela 18 - Proliferação de fibroblastos } \\
\hline Grupo & Paciente & Amostra & $0 / 1$ PTF & Total cels. \\
\hline 1 & 01 & 1 & 0 & 60.000 \\
\hline 1 & & 2 & 0 & 30.000 \\
\hline 1 & & 3 & 0 & 70.000 \\
\hline 1 & & 4 & 1 & 30.000 \\
\hline 1 & & 5 & 1 & 20.000 \\
\hline 1 & & 6 & 1 & 30.000 \\
\hline$\overline{1}$ & 02 & 1 & 0 & 60.000 \\
\hline 1 & & 2 & 0 & 90.000 \\
\hline 1 & & 3 & 0 & 90.000 \\
\hline 1 & & 4 & 1 & 30.000 \\
\hline 1 & & 5 & 1 & 40.000 \\
\hline
\end{tabular}




\begin{tabular}{|c|c|c|c|c|}
\hline Grupo & Paciente & Amostra & 0/1 PTF & Total cels. \\
\hline 1 & & 6 & 1 & 50.000 \\
\hline$\overline{1}$ & 03 & 1 & 0 & 90.000 \\
\hline 1 & & 2 & 0 & 70.000 \\
\hline 1 & & 3 & 0 & 50.000 \\
\hline 1 & & 4 & 1 & 20.000 \\
\hline 1 & & 5 & 1 & 40.000 \\
\hline 1 & & 6 & 1 & 10.000 \\
\hline 1 & 04 & 1 & 0 & 60.000 \\
\hline 1 & & 2 & 0 & 40.000 \\
\hline 1 & & 3 & 0 & 50.000 \\
\hline 1 & & 4 & 1 & 30.000 \\
\hline 1 & & 5 & 1 & 40.000 \\
\hline 1 & & 6 & 1 & 30.000 \\
\hline 1 & 05 & 1 & 0 & 60.000 \\
\hline 1 & & 2 & 0 & 40.000 \\
\hline 1 & & 3 & 0 & 30.000 \\
\hline 1 & & 4 & 1 & 20.000 \\
\hline 1 & & 5 & 1 & 30.000 \\
\hline 1 & & 6 & 1 & 40.000 \\
\hline$\overline{1}$ & 06 & 1 & 0 & 80.000 \\
\hline 1 & & 2 & 0 & 40.000 \\
\hline 1 & & 3 & 0 & 60.000 \\
\hline 1 & & 4 & 1 & 20.000 \\
\hline 1 & & 5 & 1 & 30.000 \\
\hline 1 & & 6 & 1 & 20.000 \\
\hline 1 & 07 & 1 & 0 & 90.000 \\
\hline 1 & & 2 & 0 & 60.000 \\
\hline 1 & & 3 & 0 & 70.000 \\
\hline 1 & & 4 & 1 & 40.000 \\
\hline 1 & & 5 & 1 & 20.000 \\
\hline 1 & & 6 & 1 & 20.000 \\
\hline 1 & 08 & 1 & 0 & 30.000 \\
\hline 1 & & 2 & 0 & 60.000 \\
\hline 1 & & 3 & 0 & 50.000 \\
\hline 1 & & 4 & 1 & 20.000 \\
\hline 1 & & 5 & 1 & 20.000 \\
\hline 1 & & 6 & 1 & 50.000 \\
\hline 1 & 09 & 1 & 0 & 70.000 \\
\hline 1 & & 2 & 0 & 50.000 \\
\hline 1 & & 3 & 0 & 50.000 \\
\hline 1 & & 4 & 1 & 30.000 \\
\hline 1 & & 5 & 1 & 10.000 \\
\hline 1 & & 6 & 1 & 20.000 \\
\hline$\overline{1}$ & 10 & 1 & 0 & 40.000 \\
\hline 1 & & 2 & 0 & 40.000 \\
\hline 1 & & 3 & 0 & 60.000 \\
\hline 1 & & 4 & 1 & 10.000 \\
\hline 1 & & 5 & 1 & $\begin{array}{l}20.000 \\
\text { (continua) }\end{array}$ \\
\hline
\end{tabular}


Tabela 18 - Proliferação de fibroblastos (cont.)

\begin{tabular}{|c|c|c|c|c|}
\hline Grupo & Paciente & Amostra & 0/1 PTF & Total cels \\
\hline 1 & & 6 & 1 & 10.000 \\
\hline 2 & 11 & 1 & 0 & 50.000 \\
\hline 2 & & 2 & 0 & 90.000 \\
\hline 2 & & 3 & 0 & 60.000 \\
\hline 2 & & 4 & 1 & 50.000 \\
\hline 2 & & 5 & 1 & 30.000 \\
\hline 2 & & 6 & 1 & 20.000 \\
\hline 2 & 12 & 1 & 0 & 160.000 \\
\hline 2 & & 2 & 0 & 140.000 \\
\hline 2 & & 3 & 0 & 80.000 \\
\hline 2 & & 4 & 1 & 130.000 \\
\hline 2 & & 5 & 1 & 90.000 \\
\hline 2 & & 6 & 1 & 60.000 \\
\hline 2 & 13 & 1 & 0 & 100.000 \\
\hline 2 & & 2 & 0 & 300.000 \\
\hline 2 & & 3 & 0 & 60.000 \\
\hline 2 & & 4 & 1 & 60.000 \\
\hline 2 & & 5 & 1 & 10.000 \\
\hline 2 & & 6 & 1 & 10.000 \\
\hline 2 & 14 & 1 & 0 & 40.000 \\
\hline 2 & & 2 & 0 & 90.000 \\
\hline 2 & & 3 & 0 & 60.000 \\
\hline 2 & & 4 & 1 & 20.000 \\
\hline 2 & & 5 & 1 & 30.000 \\
\hline 2 & & 6 & 1 & 10.000 \\
\hline 2 & 15 & 1 & 0 & 70.000 \\
\hline 2 & & 2 & 0 & 170.000 \\
\hline 2 & & 3 & 0 & 130.000 \\
\hline 2 & & 4 & 1 & 50.000 \\
\hline 2 & & 5 & 1 & 30.000 \\
\hline 2 & & 6 & 1 & 10.000 \\
\hline 2 & 16 & 1 & 0 & 60.000 \\
\hline 2 & & 2 & 0 & 90.000 \\
\hline 2 & & 3 & 0 & 130.000 \\
\hline 2 & & 4 & 1 & 10.000 \\
\hline 2 & & 5 & 1 & 30.000 \\
\hline 2 & & 6 & 1 & 60.000 \\
\hline 2 & 17 & 1 & 0 & 100.000 \\
\hline 2 & & 2 & 0 & 70.000 \\
\hline 2 & & 3 & 0 & 140.000 \\
\hline 2 & & 4 & 1 & 40.000 \\
\hline 2 & & 5 & 1 & 20.000 \\
\hline 2 & & 6 & 1 & 20.000 \\
\hline 2 & 18 & 1 & 0 & $\begin{array}{l}100.000 \\
\text { (continua) }\end{array}$ \\
\hline
\end{tabular}




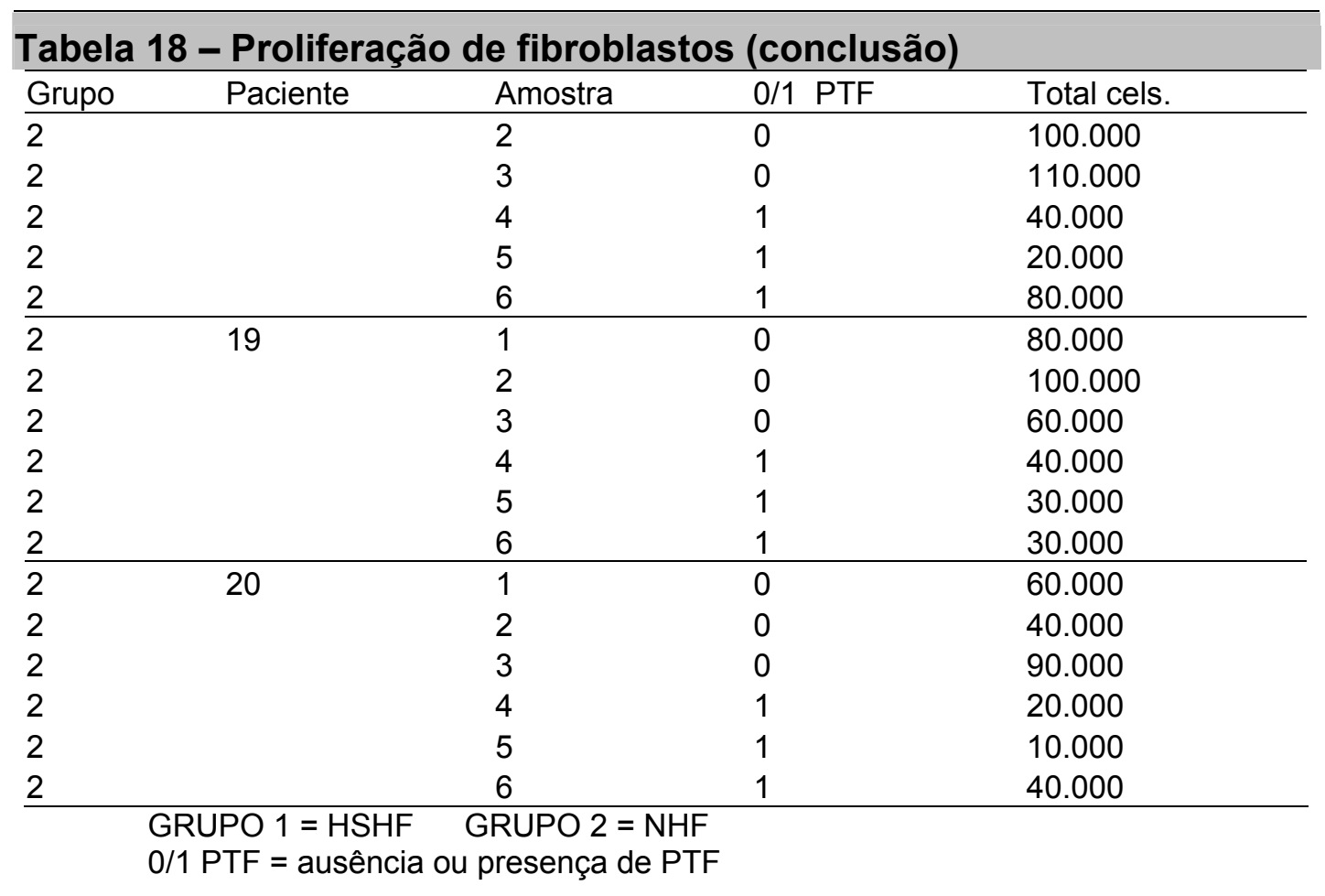

\begin{tabular}{|c|c|c|c|c|c|c|}
\hline \multicolumn{7}{|c|}{ Tabela 19 - Área de contração do gel com fibroblastos $\left(\mathrm{cm}^{2}\right)$} \\
\hline Paciente & Amostra & 0/1 PTF & $\mathrm{Oh}$ & $24 \mathrm{~h}$ & $48 \mathrm{~h}$ & Grupo \\
\hline \multirow[t]{6}{*}{01} & 1 & 0 & 1.96 & 1.44 & 1.10 & 1 \\
\hline & 2 & 0 & 1.96 & 1.44 & 1.37 & 1 \\
\hline & 3 & 0 & 1.96 & 1.35 & 1.30 & 1 \\
\hline & 4 & 1 & 1.96 & 1.52 & 1.44 & 1 \\
\hline & 5 & 1 & 1.96 & 1.60 & 1.48 & 1 \\
\hline & 6 & 1 & 1.96 & 1.48 & 1.24 & 1 \\
\hline \multirow[t]{6}{*}{$\overline{02}$} & 1 & 0 & 1.96 & 0.87 & 0.68 & 1 \\
\hline & 2 & 0 & 1.96 & 0.80 & 0.68 & 1 \\
\hline & 3 & 0 & 1.96 & 0.78 & 0.66 & 1 \\
\hline & 4 & 1 & 1.96 & 1.33 & 1.27 & 1 \\
\hline & 5 & 1 & 1.96 & 1.24 & 1.13 & 1 \\
\hline & 6 & 1 & 1.96 & 1.19 & 1.10 & 1 \\
\hline \multirow[t]{6}{*}{03} & 1 & 0 & 1.96 & 1.37 & 1.34 & 1 \\
\hline & 2 & 0 & 1.96 & 1.39 & 1.37 & 1 \\
\hline & 3 & 0 & 1.96 & 1.44 & 1.41 & 1 \\
\hline & 4 & 1 & 1.96 & 1.60 & 1.54 & 1 \\
\hline & 5 & 1 & 1.96 & 1.62 & 1.49 & 1 \\
\hline & 6 & 1 & 1.96 & 1.59 & 1.56 & 1 \\
\hline \multirow[t]{6}{*}{$\overline{04}$} & 1 & 0 & 1.96 & 1.47 & 1.42 & 1 \\
\hline & 2 & 0 & 1.96 & 1.34 & 1.31 & 1 \\
\hline & 3 & 0 & 1.96 & 1.33 & 1.3 & 1 \\
\hline & 4 & 1 & 1.96 & 1.60 & 1.54 & 1 \\
\hline & 5 & 1 & 1.96 & 1.63 & 1.42 & 1 \\
\hline & 6 & 1 & 1.96 & 1.62 & 1.45 & 1 \\
\hline
\end{tabular}




\begin{tabular}{|c|c|c|c|c|c|c|}
\hline \multicolumn{7}{|c|}{ Tabela 19 - Área de contracão do gel com fibroblastos $\left(\mathrm{cm}^{2}\right)$ (cont.) } \\
\hline Paciente & Amostra & 0/1 PTF & $\mathrm{Oh}$ & $24 \mathrm{~h}$ & $48 \mathrm{~h}$ & Grupo \\
\hline \multirow[t]{6}{*}{05} & 1 & 0 & 1.96 & 1.49 & 1.45 & 1 \\
\hline & 2 & 0 & 1.96 & 1.40 & 1.38 & 1 \\
\hline & 3 & 0 & 1.96 & 1.45 & 1.35 & 1 \\
\hline & 4 & 1 & 1.96 & 1.70 & 1.67 & 1 \\
\hline & 5 & 1 & 1.96 & 1.71 & 1.54 & 1 \\
\hline & 6 & 1 & 1.96 & 1.67 & 1.67 & 1 \\
\hline \multirow[t]{6}{*}{06} & 1 & 0 & 1.96 & 1.47 & 1.48 & 1 \\
\hline & 2 & 0 & 1.96 & 1.45 & 1.43 & 1 \\
\hline & 3 & 0 & 1.96 & 1.47 & 1.45 & 1 \\
\hline & 4 & 1 & 1.96 & 1.50 & 1.53 & 1 \\
\hline & 5 & 1 & 1.96 & 1.48 & 1.47 & 1 \\
\hline & 6 & 1 & 1.96 & 1.50 & 1.54 & 1 \\
\hline \multirow[t]{6}{*}{$\overline{07}$} & 1 & 0 & 1.96 & 1.40 & 1.19 & 1 \\
\hline & 2 & 0 & 1.96 & 1.17 & 0.90 & 1 \\
\hline & 3 & 0 & 1.96 & 1.10 & 0.90 & 1 \\
\hline & 4 & 1 & 1.96 & 1.59 & 1.40 & 1 \\
\hline & 5 & 1 & 1.96 & 1.47 & 1.37 & 1 \\
\hline & 6 & 1 & 1.96 & 1.47 & 1.33 & 1 \\
\hline \multirow[t]{6}{*}{08} & 1 & 0 & 1.96 & 1.09 & 0.94 & 1 \\
\hline & 2 & 0 & 1.96 & 1.16 & 1.07 & 1 \\
\hline & 3 & 0 & 1.96 & 1.17 & 1.08 & 1 \\
\hline & 4 & 1 & 1.96 & 1.37 & 1.40 & 1 \\
\hline & 5 & 1 & 1.96 & 1.33 & 1.33 & 1 \\
\hline & 6 & 1 & 1.96 & 1.35 & 1.27 & 1 \\
\hline \multirow[t]{6}{*}{$\overline{09}$} & 1 & 0 & 1.96 & 1.54 & 1.51 & 1 \\
\hline & 2 & 0 & 1.96 & 1.38 & 1.35 & 1 \\
\hline & 3 & 0 & 1.96 & 1.44 & 1.34 & 1 \\
\hline & 4 & 1 & 1.96 & 1.63 & 1.47 & 1 \\
\hline & 5 & 1 & 1.96 & 1.56 & 1.54 & 1 \\
\hline & 6 & 1 & 1.96 & 1.67 & 1.52 & 1 \\
\hline \multirow[t]{6}{*}{$\overline{10}$} & 1 & 0 & 1.96 & 1.33 & 1.29 & 1 \\
\hline & 2 & 0 & 1.96 & 1.41 & 1.31 & 1 \\
\hline & 3 & 0 & 1.96 & 1.45 & 1.29 & 1 \\
\hline & 4 & 1 & 1.96 & 1.63 & 1.56 & 1 \\
\hline & 5 & 1 & 1.96 & 1.51 & 1.51 & 1 \\
\hline & 6 & 1 & 1.96 & 1.51 & 1.50 & 1 \\
\hline \multirow[t]{6}{*}{$\overline{11}$} & 1 & 0 & 1.96 & 1,62 & 1,40 & 2 \\
\hline & 2 & 0 & 1.96 & 1,59 & 1,47 & 2 \\
\hline & 3 & 0 & 1.96 & 1,55 & 1,49 & 2 \\
\hline & 4 & 1 & 1.96 & 1,66 & 1,57 & 2 \\
\hline & 5 & 1 & 1.96 & 1,61 & 1,60 & 2 \\
\hline & 6 & 1 & 1.96 & 1,66 & 1,62 & 2 \\
\hline \multirow[t]{5}{*}{12} & 1 & 0 & 1.96 & 1,55 & 1,44 & 2 \\
\hline & 2 & 0 & 1.96 & 1,53 & 1,48 & 2 \\
\hline & 3 & 0 & 1.96 & 1,62 & 1,48 & 2 \\
\hline & 4 & 1 & 1.96 & 1,55 & 1,60 & 2 \\
\hline & 5 & 1 & 1.96 & 1,63 & 1,60 & $\begin{array}{l}2 \\
\text { (continua) }\end{array}$ \\
\hline
\end{tabular}


Tabela 19 - Área de contração do gel com fibroblastos $\left(\mathrm{cm}^{2}\right)$ (conclusão)

\begin{tabular}{|c|c|c|c|c|c|c|}
\hline Paciente & Amostra & 0/1 PTF & $\mathrm{Oh}$ & $24 \mathrm{~h}$ & $48 \mathrm{~h}$ & Grupo \\
\hline & 6 & 1 & 1.96 & 1,72 & 1,64 & 2 \\
\hline \multirow[t]{6}{*}{$\overline{13}$} & 1 & 0 & 1.96 & 1,60 & 1,63 & 2 \\
\hline & 2 & 0 & 1.96 & 1,61 & 1,59 & 2 \\
\hline & 3 & 0 & 1.96 & 1,61 & 1,63 & 2 \\
\hline & 4 & 1 & 1.96 & 1,71 & 1,68 & 2 \\
\hline & 5 & 1 & 1.96 & 1,71 & 1,73 & 2 \\
\hline & 6 & 1 & 1.96 & 1,69 & 1,71 & 2 \\
\hline \multirow[t]{6}{*}{$\overline{14}$} & 1 & 0 & 1.96 & 1,48 & 1,30 & 2 \\
\hline & 2 & 0 & 1.96 & 1,54 & 1,38 & 2 \\
\hline & 3 & 0 & 1.96 & 1,51 & 1,37 & 2 \\
\hline & 4 & 1 & 1.96 & 1,56 & 1,44 & 2 \\
\hline & 5 & 1 & 1.96 & 1,52 & 1,50 & 2 \\
\hline & 6 & 1 & 1.96 & 1,54 & 1,54 & 2 \\
\hline \multirow[t]{6}{*}{15} & 1 & 0 & 1.96 & 1,43 & 1,23 & 2 \\
\hline & 2 & 0 & 1.96 & 1,43 & 1,27 & 2 \\
\hline & 3 & 0 & 1.96 & 1,43 & 1,34 & 2 \\
\hline & 4 & 1 & 1.96 & 1,47 & 1,40 & 2 \\
\hline & 5 & 1 & 1.96 & 1,57 & 1,51 & 2 \\
\hline & 6 & 1 & 1.96 & 1,49 & 1,58 & 2 \\
\hline \multirow[t]{6}{*}{$\overline{16}$} & 1 & 0 & 1.96 & 1,31 & 1,33 & 2 \\
\hline & 2 & 0 & 1.96 & 1,46 & 1,38 & 2 \\
\hline & 3 & 0 & 1.96 & 1,49 & 1,38 & 2 \\
\hline & 4 & 1 & 1.96 & 1,54 & 1,49 & 2 \\
\hline & 5 & 1 & 1.96 & 1,59 & 1,41 & 2 \\
\hline & 6 & 1 & 1.96 & 1,65 & 1,53 & 2 \\
\hline \multirow[t]{6}{*}{$\overline{17}$} & 1 & 0 & 1.96 & 1,35 & 1,29 & 2 \\
\hline & 2 & 0 & 1.96 & 1,33 & 1,34 & 2 \\
\hline & 3 & 0 & 1.96 & 1,38 & 1,31 & 2 \\
\hline & 4 & 1 & 1.96 & 1,59 & 1,46 & 2 \\
\hline & 5 & 1 & 1.96 & 1,59 & 1,45 & 2 \\
\hline & 6 & 1 & 1.96 & 1,61 & 1,51 & 2 \\
\hline \multirow[t]{6}{*}{18} & 1 & 0 & 1.96 & 1,49 & 1,24 & 2 \\
\hline & 2 & 0 & 1.96 & 1,42 & 1,25 & 2 \\
\hline & 3 & 0 & 1.96 & 1,44 & 1,26 & 2 \\
\hline & 4 & 1 & 1.96 & 1,42 & 1,45 & 2 \\
\hline & 5 & 1 & 1.96 & 1,49 & 1,47 & 2 \\
\hline & 6 & 1 & 1.96 & 1,49 & 1,44 & 2 \\
\hline \multirow[t]{6}{*}{19} & 1 & 0 & 1.96 & 1,29 & 1,36 & 2 \\
\hline & 2 & 0 & 1.96 & 1,39 & 1,30 & 2 \\
\hline & 3 & 0 & 1.96 & 1,24 & 1,21 & 2 \\
\hline & 4 & 1 & 1.96 & 1,60 & 1,54 & 2 \\
\hline & 5 & 1 & 1.96 & 1,62 & 1,51 & 2 \\
\hline & 6 & 1 & 1.96 & 1,56 & 1,51 & 2 \\
\hline \multirow[t]{6}{*}{20} & 1 & 0 & 1.96 & 1,35 & 1,23 & 2 \\
\hline & 2 & 0 & 1.96 & 1,33 & 1,27 & 2 \\
\hline & 3 & 0 & 1.96 & 1,38 & 1,34 & 2 \\
\hline & 4 & 1 & 1.96 & 1,66 & 1,44 & 2 \\
\hline & 5 & 1 & 1.96 & 1,61 & 1,50 & 2 \\
\hline & 6 & 1 & 1.96 & 1,66 & 1,56 & 2 \\
\hline
\end{tabular}

